HW - 83605

UC-48, Biology and Medicine (TID-4500, 34th Ed.)

PROGRESS IN RADIOLOGICAL PHYSICS

A Summary of Hanford Laboratories Achievements

in These Programs Under General Electric

1947- 1964

By

W. C. Roesch

Physics and Instrument Laboratory

September 1964

$$
\text { (n) }
$$




\section{DISCLAIMER}

This report was prepared as an account of work sponsored by an agency of the United States Government. Neither the United States Government nor any agency Thereof, nor any of their employees, makes any warranty, express or implied, or assumes any legal liability or responsibility for the accuracy, completeness, or usefulness of any information, apparatus, product, or process disclosed, or represents that its use would not infringe privately owned rights. Reference herein to any specific commercial product, process, or service by trade name, trademark, manufacturer, or otherwise does not necessarily constitute or imply its endorsement, recommendation, or favoring by the United States Government or any agency thereof. The views and opinions of authors expressed herein do not necessarily state or reflect those of the United States Government or any agency thereof. 


\section{DISCLAIMER}

Portions of this document may be illegible in electronic image products. Images are produced from the best available original document. 

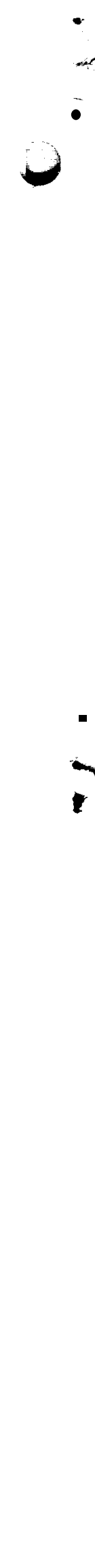

0.

$\gamma$ 


\section{TABLE OF CONTENTS}

\section{LIST OF FIGURES •} INTRODUCTION :

WHOLE BODY COUNTING.

Hanford Whole Body Counter

Shadow Shield Counter.

Hanford Mobile Whole Body Counter

Radioactivity in Alaskan Eskimos

Radioactivity in Uranium Miners.

Medical Studies .

Special Problems . . . . . . . . .

Iodine- 131.

Phosphorus- 32.

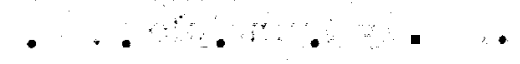

Plutonium .

Wound Counting.

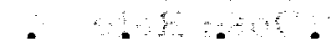

Lung Burdens

Urinalysis for $\mathrm{Cs}^{137}$ in Populations.

Sodium-22.

\section{NEUTRON DOSIMETRY}

Early Work .

Plutonium Problems $\quad$ • $\quad . \quad$. 25

Positive Ion Van de Graaff . $\quad$. . . . . 27

Double-Moderator Neutron Dosemeter . • • • . . 31

Cosmic Ray Neutrons • $\quad$. 32

Neutron Standards. $\quad$ • $\quad$ •

Radioactive Neutron Sources . $\quad$. 33

Precision Long Counter. . $\quad$ • 35

Low Energy Fast Neutrons . . • . 37

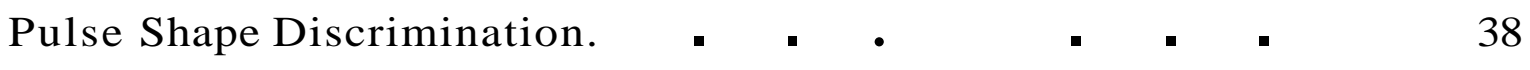

Fast Neutron Medical Research Facility . $\quad$ • 39 
THEORETICAL DOSIMETRY

Age Theory of Charged Particles

Radiation Nonequilibrium . .

NCRP Stopping Power Study Group .

Field Equations in Dosimetry and the ICRU Ad Hoc Committee.

Total-Absorption Gamma-Ray Calorimetry - • $\quad \cdots \quad 47$

Electron Van de Graaff Calorimetry and Instrumentation • • $\quad 49$

Radiation Field Calorimetry $\ldots \ldots \ldots$

GAMMA-RAY DOSIMETRY. . $\quad \ldots \ldots \ldots$

Low Energy X Rays from Plutonium. $\quad \bullet \quad \bullet \quad 52$

Fluorescent X-Ray Source . . . $\quad 5 \cdot 53$

The Bragg-Gray Principle . . . • . . $\quad 54$

Plutonium Surface Dose Rate $\quad$ - $\quad \bullet \cdot \bullet \quad 54$

Gamma Rays . $\quad \ldots 6$

W Measurements . $\quad$ • 59

Film Badges . $\quad$ • $\quad$ • $\quad \cdots, \quad$ e 61

Sensitive Gamma-Ray Instruments • . . . 62

BETA-RAY DOSIMETRY • $\quad 63$

$\begin{array}{lll}\text { Surface Dose Problems } \quad \text {. } & 63\end{array}$

Nonsurface Problems . $\quad 63$

Beta-Ray Dose Calculations . $\quad \cdots \cdot \bullet$

Tritium Standardization . . . $\quad$ • 67

OTHER ACTIVITIES . . . . . . . . 68

Accident Dosimetry . $\quad$. $\quad \ldots \quad \ldots .68$

Radiation Damage in Graphite . $\quad . \quad \ldots \quad \ldots \quad 69$

Gonadal Radiation . $\quad$ - . $\quad$ e 70

Education. $\quad$ - $\quad * \quad \cdot \quad \cdot \quad 71$

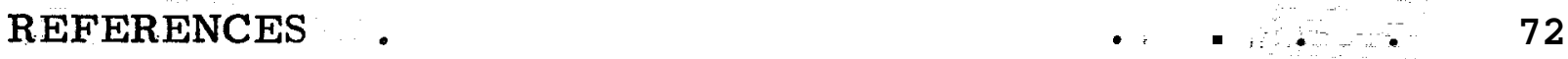

DISTRIBUTION - $\quad \cdots, \ldots$ 


\section{$\underline{\text { LIST OF FIGURES }}$}

Figure

The Hanford Whole Body Counter

$\underline{\text { Page }}$

Distribution of Radioisotopes in Adult Males During 1959

Title

The Shadow Shield Whole Body Counter

Exterior View of the Hanford Mobile Whole Body Counter

Interior View of the Hanford Mobile Whold Body Counter

Variations in $\mathbf{C s}^{137}$ in the Adult Eskimos of Anaktuvuk Pass, Alaska Since July 1962

Differential Scan of Radon Daughters ( $B i^{214}$ ) Following Inhalation of Uranium Mine Dust

Differential Scan with a Collimated Shadow Shield Whole Body Counter of a Tumor Patient with a Liver and Bladder Involvement

Beta-Ray Coincidence Counter Used for Whole Body Counting of $P^{32}$

Pulse Height Spectra Due to Thermal Noise in 6292 and 9514 Photomultiplier Tubes

A Counter for Plutonium in the Lung

Comparison of Urinalysis Results with Whole Body Anaktuvuk Pass, Alaska

Neutron Spectra Measured by the Nuclear Emulsion Technique

The Apparent Sensitivity of a Moderated $\mathrm{BF}_{3}$ Counter at Different Distances from a Source for Various Heights of the Source Above the Floor

Positive Ion Accelerator Laboratory 27

Interior of the Positive Ion Accelerator Laboratory 28

Diagram of the Precision Long Counter 36

Response of an Anthracene Scintillator to Neutrons Using a Pulse Shape Discrimination Circuit

The University of Washington Fast Neutron Medical Research Faciltiy 
21 Hanford Laboratories Two Million Volt Electron Van de Graaff

22a X- and Gamma-Ray Dose Rate from Reactor Plutonium at 0 and 5 Days After Separation

"Hard Gamma" Dose Rate from Reactor Plutonium at 0 and 5 Days After Separation

23 Cavity Ionization Chambers Used for the Study of the Bragg-Gray Principle

24 Values Measured for $\mathrm{W}_{\text {air }}$, the Average Energy Lost by Electrons Per Ion Pair Formed in Air

60

25 Extrapolation Chamber for Measurement of Electron Beams 


\title{
PROGRESS IN RADIOLOGICAL PHYSICS
}

\author{
A Summary of Hanford Laboratories Achievements \\ in These Programs Under General Electric \\ 1947-1964
}

\section{INTRODUCTION}

The Radiological Physics operation was formed in 1947 to conduct a research and development program in radiological and health physics aimed at improving the quality and reducing the expense of radiation protection. It was part of the Radiological Sciences Department until the Hanford Laboratories were formed. Then it became part of the Physics and Instruments Laboratory. This report is a review of the main work done by Radiological Physics since its inception. The review will be limited to a brief narrative of what led to each study, what was done, and what were the essential results. The main sections of the report start with the principal fields of study at the present time and then take up older fields. Within each section the review is roughly chronological.

\section{WHOLE BODY COUNTING}

Whole body counting is the detection, identification, and measurement of radioactive materials in the body with instruments placed outside the body. Radiological Physics became interested in whole body counting in 1954 when they used some rather rudimentary equipment to measure lung burdens of people exposed during the ruthenium emissions from the Redox plant. This experience and the reports of the development of high sensitivity whole body counters at Argonne and at Los Alamos led to a decision to build a counter at Hanford. The counter was to be part of the Hanford radiation protection program.

Hanford Whole Body Counter

Radiological Physics and Radiation Protection Operation prepared a project proposal (Project CA-658) for the counter in 1955. Radiological Physics was responsible for technical planning, overseeing construction, development of equipment and techniques, and initial operation of the 
counter. During the processing of the project proposal, Radiological Physics tested shielding and construction materials to find ones containing little radioactive material. This was necessary to give the comnter a low background. The shield and everything that went inside it were measured for radioactivity as construction progressed. These measurements and preliminary work on counting instruments and techniques were done in a shield made of crushed rock. (1) The background in the rock shield was 1.6 to 2 times that in a good iron or lead shield. It served its purpose, however, and aroused considerable interest as a cheap, temporary shield.

Figure 1 shows the Hanford Whole Body Counter. (2) The counter is in an addition to the Bioassay Building (747-A Building). The counter was modeled after the one at Argonne National Laboratory. It consists of

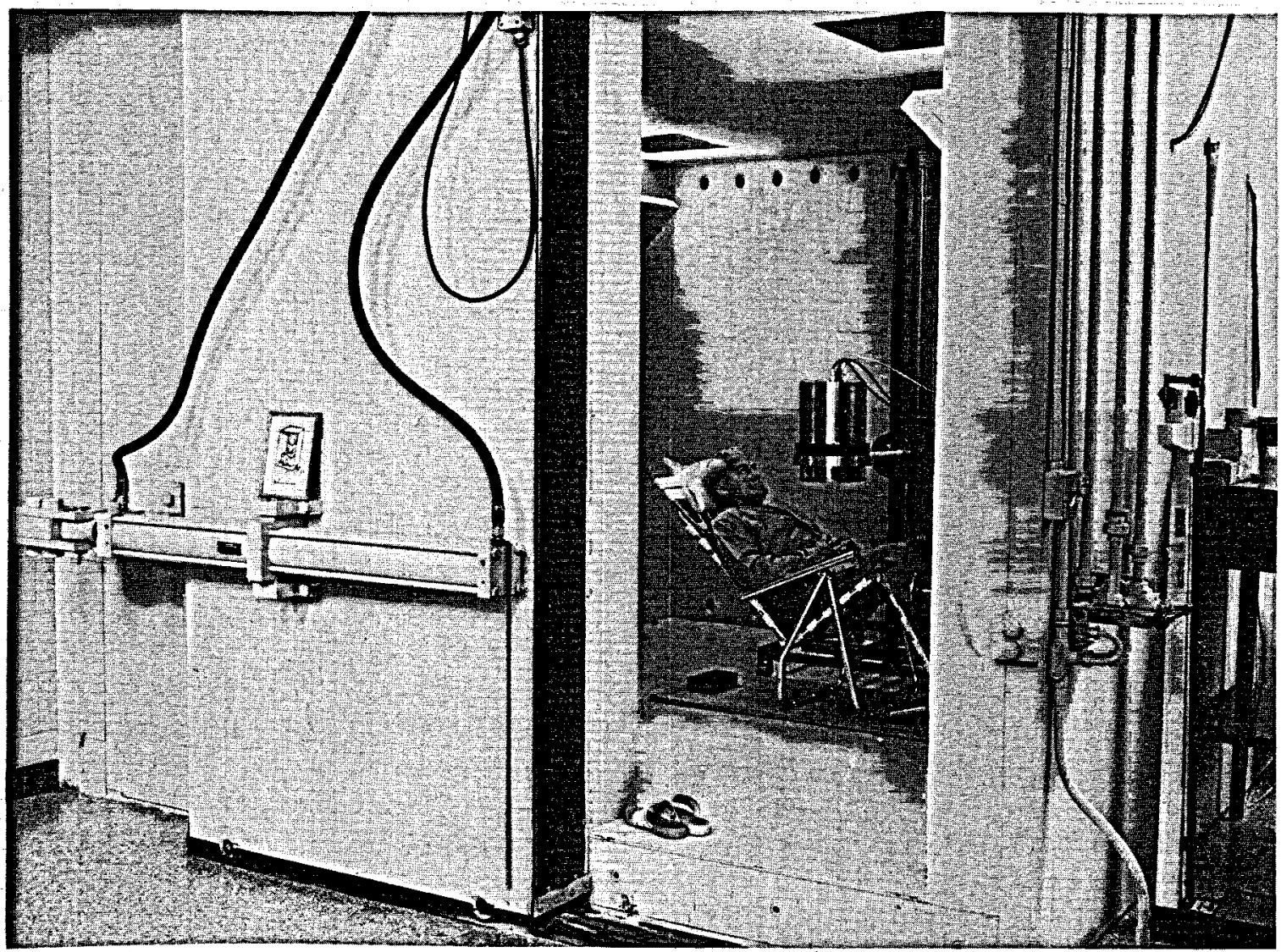

Neg. 17908-8

FIGURE 1

The Hanford Whole Body Counter' 
a 9-3/8 in, diameter by 4 in, thick NaI(T1) scintillation crystal in an iron room with $10 \mathrm{in}$. thick walls. The subject to be counted sits in a chair that is tilted so that his body is in a rough arc below the crystal. A 20 min count is sufficient to measure the normal radioactive materials in the body to about $5 \%$ accuracy. The performance compares favorably with that of others. ${ }^{(3)}$ The sensitivity is quite adequate for radiation protection and for research. The building for the counter contains enough dressing rooms, showers, and toilets to permit counting of large numbers of people and the whole facility w as designed to create a pleasant, clinical atmosphere conducive to routine operations.

Construction of the counter was finished early in 1959. Radiological Physics occupied the facility and developed equipment (particularly mounting of photomultipliers on scintillation crystals), techniques of operation, and calibrations for the counter. They began semiroutine counting of Hanford employees about mid-1959. Figure 2 shows histograms of the distribution of the common radioisotopes in the people counted. Almost at once they found that $\mathrm{Zn}^{65}$ was present in nearly everyone in the vicinity of Hanford as a result of its release into the Columbia River in water used to cool the reactors. This isotope was given considerable study. ${ }^{(2,4)}$ The principal routes of entry into people were drinking water, Columbia River fish, and sea foods, particularly oysters. $\mathrm{Zn}^{65}$ has been the subject of routine radiation protection attention ever since. $\mathrm{Na}^{24}$ was also found frequently in reactor area workers as a result of its presence in their drinking water. ${ }^{(5)}$

In 1960 Radiological Physics turned the operation of the whole body counter over to the Internal Dosimetry subsection of the Radiation Protection Operation. Radiological Physics has continued to help in special cases. For example, we did the counting of the people exposed to neutrons during the Recuplex accident. $(6,7)$ we also continued for a number of years to study cases of people exposed in accidents $(8,9)$ to acquire information useful in setting maximum permissible limits. The present limits are based largely on animal data, Information on uptake, distribution, and retention of radioisotopes by humans is needed for future revisions. 

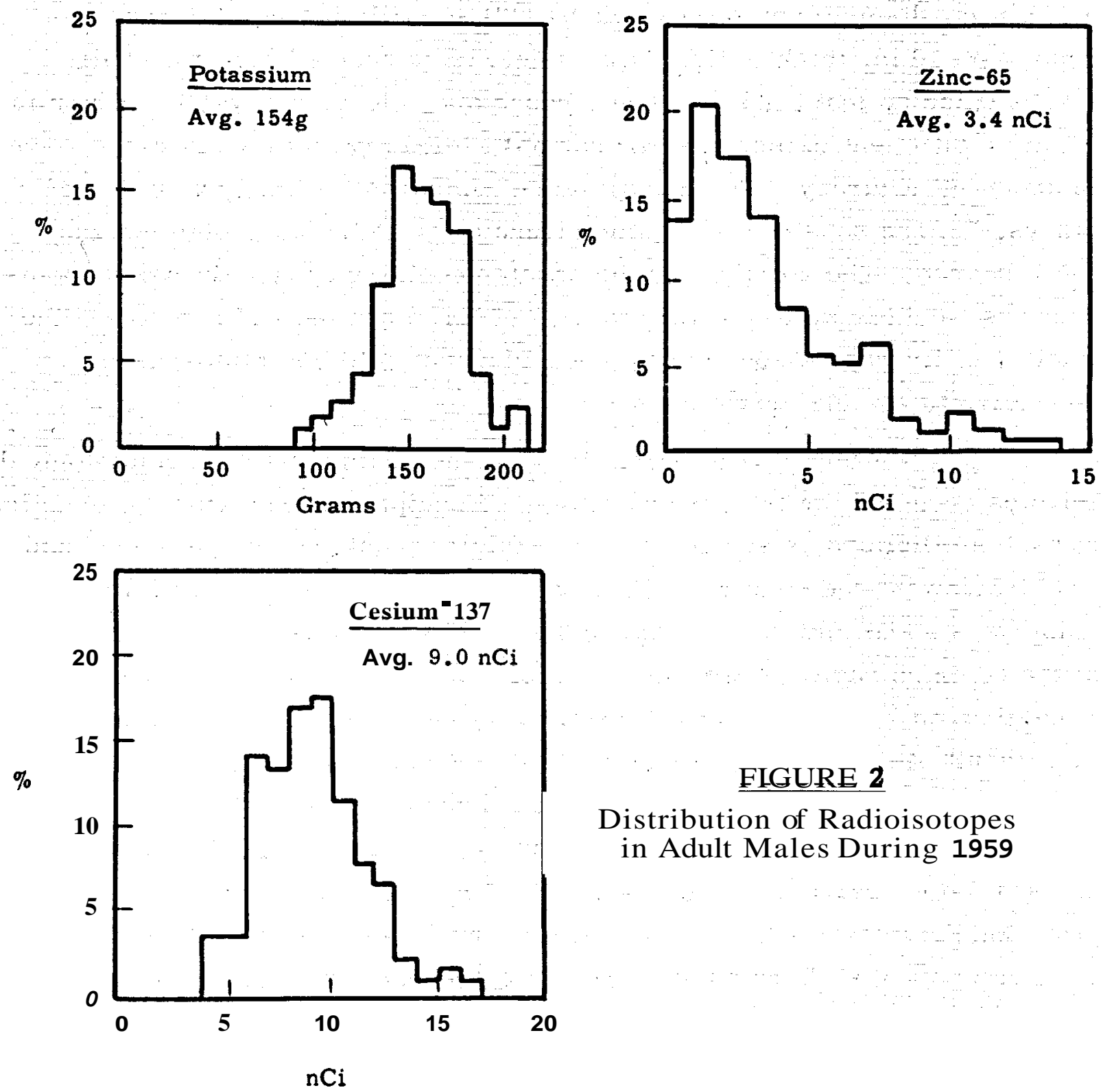

\section{ELGURE 2}

Distribution of Radioisotopes in Adult Males During 1959

RadiologicalPhysics has also continued to help with addition of new instrumentation and with recalibiration of the counter. Worrk on special whole body counting problems is described below

Shadow Shield Counter

The Hanford Whole Bordy Ccunter was a very successful addition to the radiation protection program. It soon became apparent that the ability to count even larger numbers of people might be needed. R aldiological 
Physics ppr ached this problem assuming that, rather than building more iron-room facilities, they should develop a simple, small counter that would indicate quickly if a person contained any unusual radioactive material. If he did, he could be placed in the iron-room counter for a thorough examination. Work on another problem had considerable influence on the development of a counter to meet these requirements. It had been observed that the iron-room counter did not always give the correct result for $\mathrm{Zn}^{65}$ in a person. ${ }^{(2)}$ This was due to the poor "counting geometry" of a person sitting beneath the crystal in the position shown in Figure 1. It was found that moving the crystal along the body of a reclining subject (scanning) gave much better results. ${ }^{(10)}$ This technique was incorporated in the new counter. The new counter is illustrated in Figure 3 (the subject moves under the crystal rather than the crystal over the subject), The crystal is

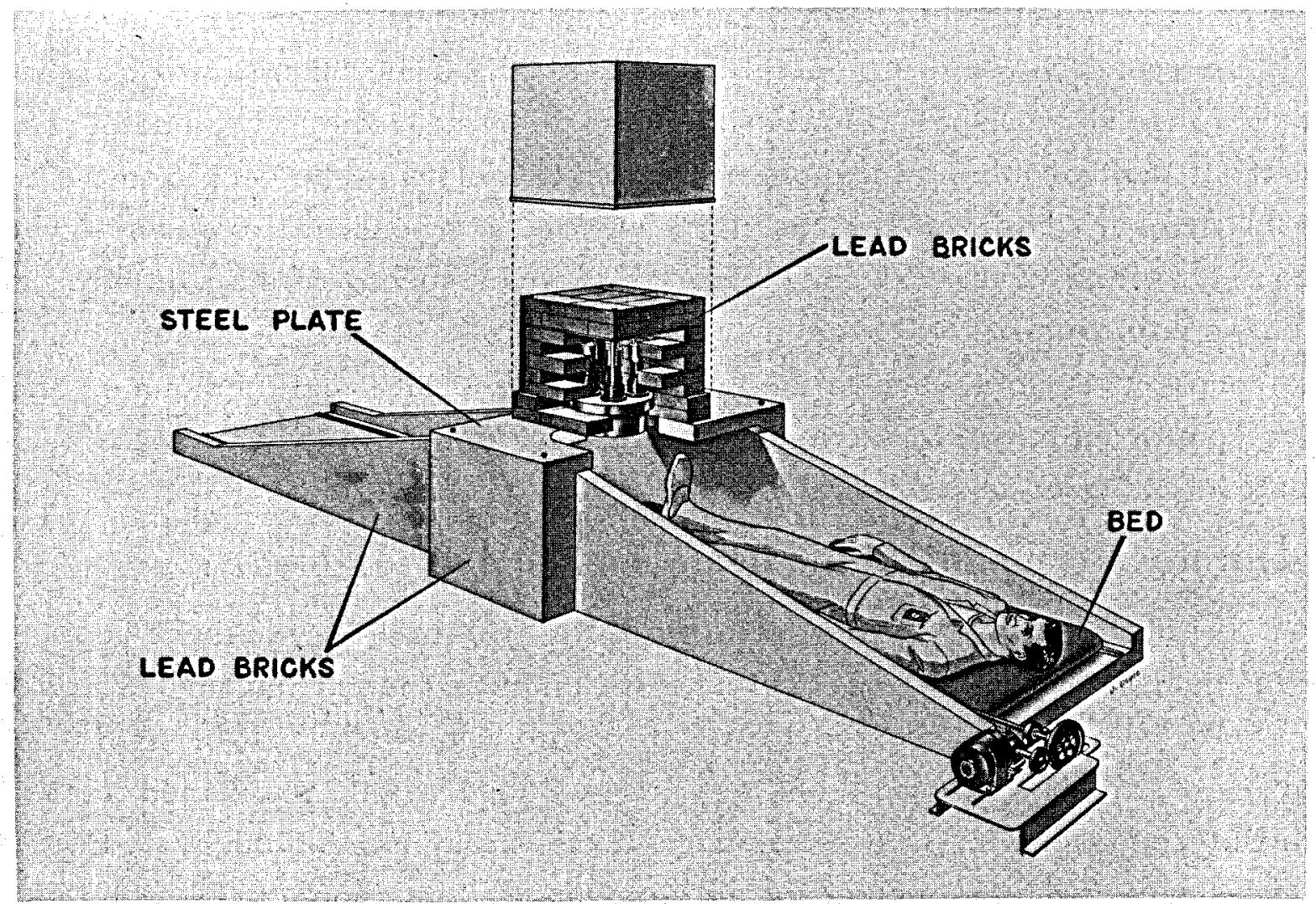

Neg. 0630693

FIGURE 3

The Shadow Shield Whole Body Counter 
shielded on all sides except that facing the subject, but it is in the "shadow" of a shield behind the subject--hence the name "shadow shield". $(11,21,13)$

\section{Hanford Mobile Whole Body Counter}

The properties of the shadow shield counter were much better than had been envisioned in the original goal. In spite of the open construction, the background for high energy gamma rays is as good as that of the iron room. The dependence of counter sensitivity on the size of the person being counted is as good or better than that of the iron-room counter. The sensitivity is about three-fourths that of the iron-room counter; this is not generally a problem since, when necessary, a larger crystal can be used to increase the sensitivity or subjects can be counted for slightly longer times. These facts made it possible for the Radiation Protection Operation to use the counter in a way much different from that first intended.

The counter is housed in a semitrailer and is equipped to operate anywhere that electrical power can be obtained. The counter is taken to work areas or to the scenes of special activities or accidents. This solves one of the most difficult problems in whole body counting, getting the people to the counter. The quality of the results is very good so only in rare cases that require special crystal arrangements is it necessary to refer people to the iron-room counter. Figure 4 shows the exterior of the semitrailer housing the counter; Figure 5 shows the interior of the trailer and the counter and electronic equipment. The mobile counter is now an important tool in the Hanford radiation protection program.

\section{$\underline{\text { Radioactivity in Alaskan Eskimos }}$}

Late in 1961 a former member of Radiological Physics who had been engaged in whole body counting work and was then at the University of Lund, Sweden, on a postdoctoral fellowship wrote us ${ }^{(15)}$ of their discovery of high body burdens of $\mathrm{C} \sim \sim$ im Laplanders. He suggested that similar conditions might exist among Alaskan Eskimos and suggested we count some of them. Such counting was arranged as cooperation with the Radioecology group of the Biology Laboratory as part of their Project Chariot studies. During the summer of 1962 we measured the radioisotopes in over 700 people at four villages above the Arctic Circle in Alaska 


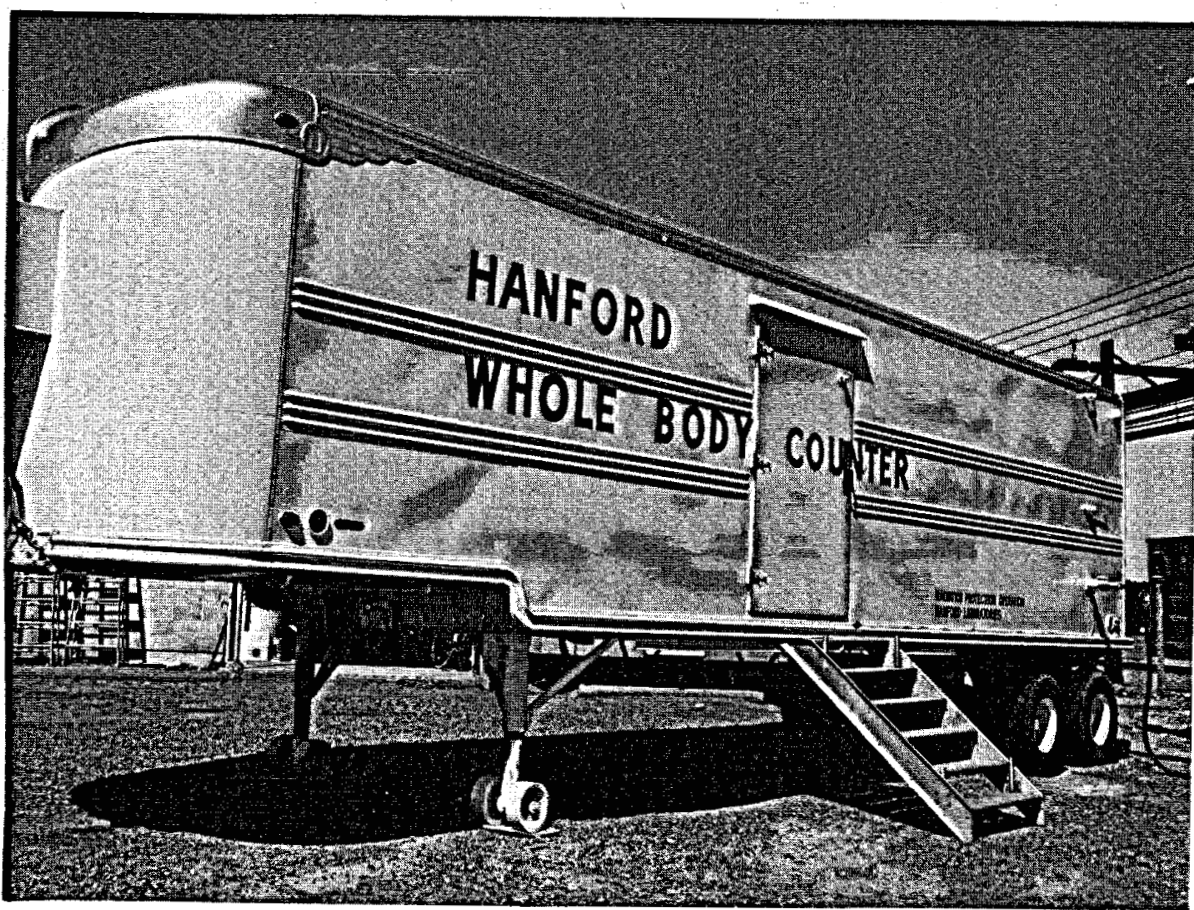

Neg. 32527-3

FIGURE 4

Exterior View of the Hanford Mobile Whole Body Counter

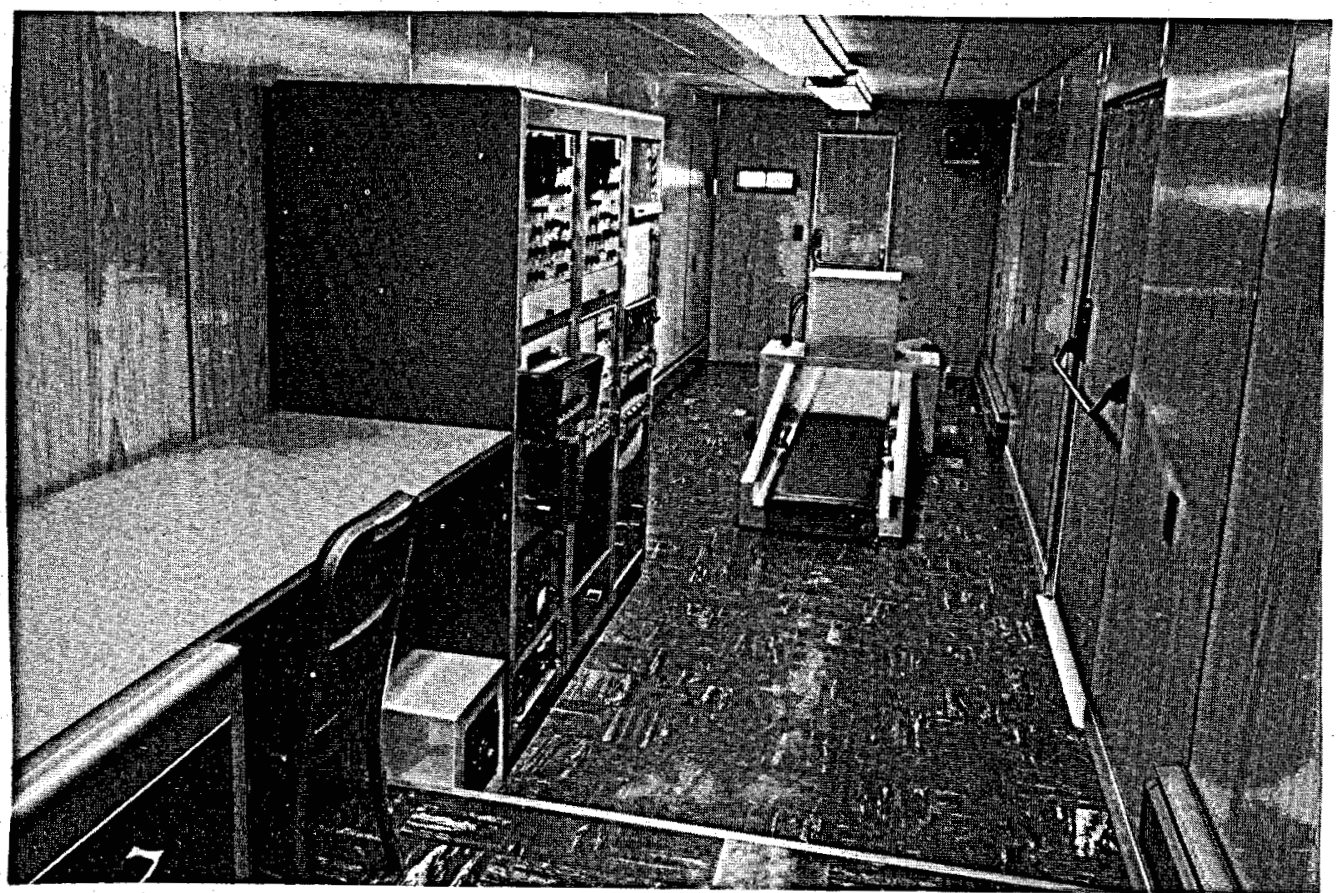

Neg. 32527-3

FIGURE 5

Interior View of the Hanford Mobile Whole Body Counter AtC.eE RICHLAID. WASH. 
with our shadow shield whole body counter. The averages for body burdens of $\mathrm{Cs}^{137}$ were as much as 80 times higher than the average for people in the rest of the United States. The people of the interior village of Anaktuvuk Pass had the highest average burden of $\mathbf{C s}^{137}$, which was $421 \mathrm{nCi}$; the maximum individual burden was $790 \mathrm{nCi} \cdot(7,16-21)$ In the summer of 1963 we went to these same villages again and to one other. Adults of Anaktuvuk Pass had an average body burden of $628 \mathrm{nCi}$, a nearly $50 \%$ increase over the summer before; the maximum body burden was $1.24 \mu \mathrm{Ci} .{ }^{(22,23)}$ During 1964 we are making visits to Anaktuvuk Pass roughly every 3 mo to establish how the body burdens vary throughout the year. The data obtained so far are shown in Figure 6. The average body burden decreased during the winter months and then climbed sharply when the first spring herd of caribou arrived. During the winter the Eskimos ate caribou that had been feeding all summer on green plants that contained very little $\mathrm{Cs}^{137}$. The spring herds had been feeding largely on lichens and were at their peak of activity.

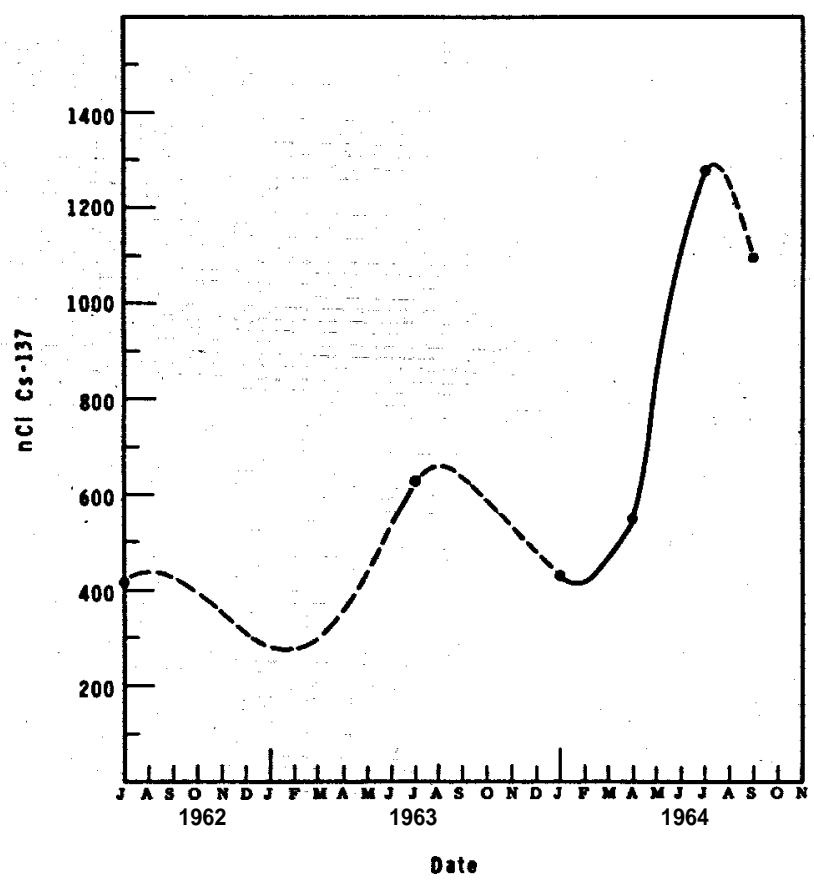

Neg. 0642733 FIGURE 6

Variations in $\mathrm{Cs}^{137}$ in the Adult Eskimos of Anaktuvuk Pass, Alaska Since July, 1962 
The ecolqgical studies carried out by Radioecology established that the high body burdens were due to circumstances similar to those in Lapland. $(17,20)$ Fallout is accumulated on lichens which are very longlived. Caribou, moose, reindeer, etc. graze upon the lichens and acquire large amounts of $\mathbf{C s}^{137}$ which are then transmitted to the Eskimos when they use these animals for food.

The whole body counts of the Eskimos showed the presence of Cs 134 as well as $\mathbf{C s}^{137}$. $\mathrm{Cs}^{134}$ was also found in reindeer and caribou meat. It was also found on air filters collected at Richland. The appearance of $\mathrm{Cs}^{134}$ seems to be worldwide, During 1962 there was generally about $1 \%$ as much $\mathrm{Cs}^{134}$ as $\mathrm{Cs}^{137} \cdot \mathrm{Cs}^{134}$ is not present in fission products to this concentration. The relative concentration has been decreasing ever since at a rate greater than that due to radioactive decay. Apparently whatever led to its presence in fallout is no longer going on and it is being diluted by fresh fallout. $(7,18,22-25)$

A method for estimating body burdens of $\mathrm{Cs}^{137}$ by gamma-ray counting of urine specimens was developed and used in the Alaska studies . and will be described below.

\section{Radioactivity in Uranium Miners}

The inhalation of dust is a major contributor to respiratory . disorders in mine workers. The hazards of these dusts are increased in uranium mines by the presence of high concentrations of the radioactive daughter products of radon which attach themselves to dust nuclei and release their decay energy to the tissue of the respiratory system following inhalation. The interest of Radiological Physics in this matter began in 1961 when an employee of the Colorado State Public Health Service was assigned to them for training in whole body counting so he could study such problems, Later Radiological Physics, Radiological Chemistry, and Inhalation Toxicology became directly involved through the inhalation studies program of the latter group. We first tried counting men at Hanford shortly after a visit to a uranium crushing mill near Spokane, Washington. This did not work because the detectable radon daughters have short half-lives 
and had decayed away before the men returner to Hanford. We then took the Hanford Mobile Whole'Body Counter up to the mill and succeeded in making a brief study. (23) Late $r$ we used the counter at two uranium mines in Colorado. $(26,27)$ The counter had been modified to permit location of the radioactive material in the body as well as determining the amount present. Figure 7 shows the distributions of radioactivity found in one of the people studied. The results showed that almost all of the radondaughter activity inhaled by a person is retained in the body, most of it (about $75 \%$ ) is deposited in the lower respiratory tract, and it is not

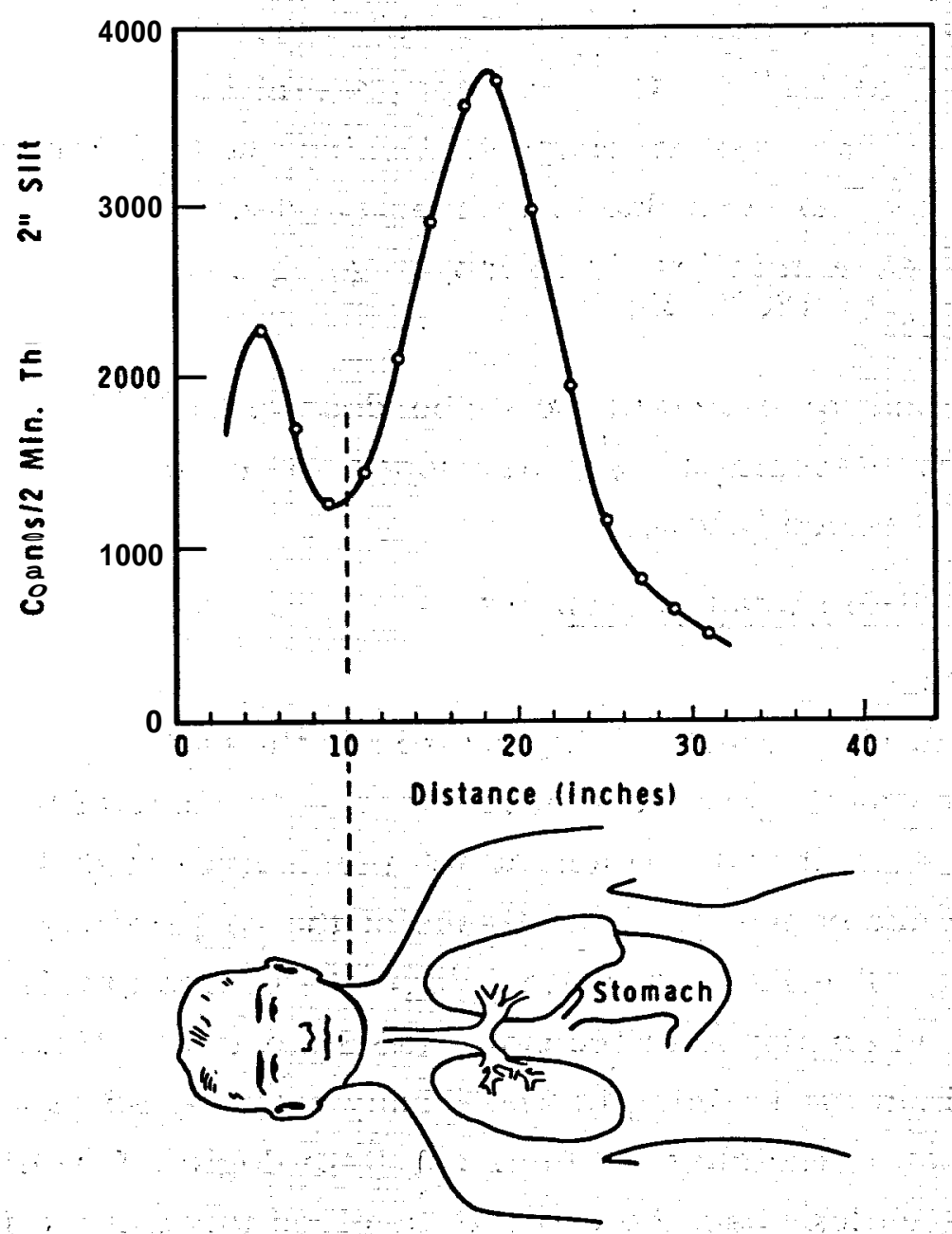

Neg. $0641124-2$

FIGURE 7

Differential Scan of Radon Daughters ( $\mathrm{Bi}^{214}$ )

Following Inhalation of Uranium Mine Dust . 
appreciably translocated before the activity decays away. Most of the activity was attached to dust particles less than $0.1 \mu$ in size, regardless of the particle size distribution in the mine atmosphere. The activity of the radium in the dust was small compared with that of the radon daughters.

\section{Medical Studies}

The medical profession is interested in whole body counting because it provides another way of obtaining information about the body. Radiological Physics has worked with Swedish Hospital, Seattle, several times in obtaining persons with known body burdens of radioisotopes to serve as calibration subjects for whole body counters. In 1962 Radiological Physics took a shadow shield counter to the hospital to try two medical experiments. (7) The first of these was to measure the decrease in the potassium content of a patient who had been treated with an artificial kidney at the Pacific Northwest Research Institute. The decrease was detectable (it was the change in $\mathrm{K}^{40}$ that was measured), but the estimate of the decrease was about twice the decrease measured by chemical means. Our counter is calibrated for potassium in its normal distribution in the body and could not measure this nonnormal change properly. All whole body counters are this way, and this represents a major challenge in the extension of whole body counting techniques to medicine. The second experiment was to locate tumors in patients who had been given an $\mathrm{I}^{131}$ labeled compound. This experiment was successful. The shadow shield counter had sufficient sensitivity to permit tumor location with much less $I^{131}$ than required by conventional methods. Figure 8 shows scans of a normal subject who contained the tagged compound and of a woman who w as found to have liver and bladder involvement in her disease.

\section{Special Problems}

Iodine-131

The maximum permissible body burden of $\mathrm{I}^{131}$ is so low $(0.7 \mu \mathrm{Ci})$ that neither the iron-room counter nor the shadow shield counter, as usually used, can reliably detect such small amounts. Because of the 


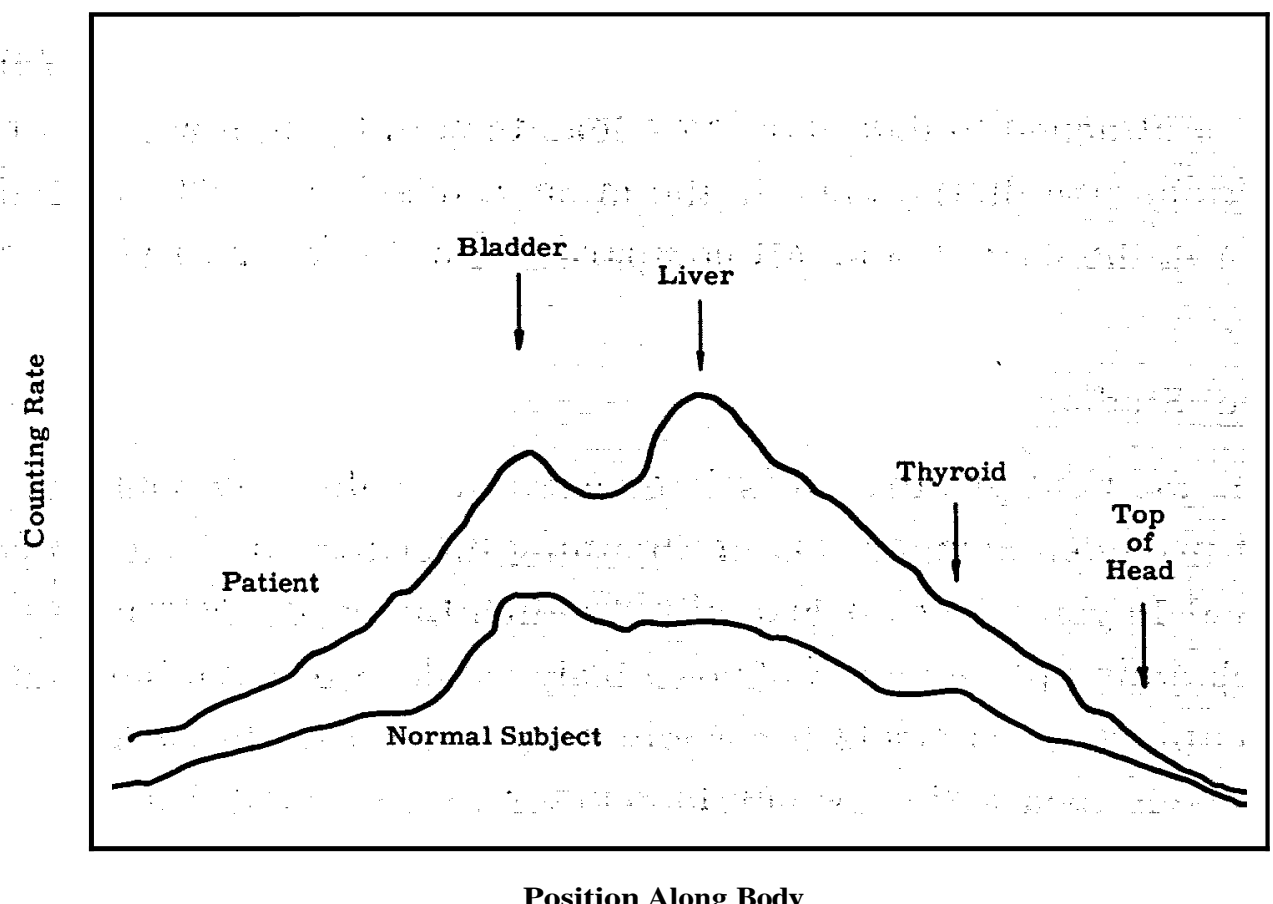

FIGURE 8

Differential Scan with a Collimated Shadow Shield Whole Body Counter of a Tumor Patient with Liver and Bladder Involvement

interest in this radioisotope in atomic energy operations and in fallout studies, we investigated other ways of using the large crystals of these counters. $(9,28)$ It turned out that'it was better to use one or more $3 \times 3$ in. NaI(T1) crystals than to use the large crystal. The smaller crystal can be placed closer to the human thyroid so that the sensitivity to background ratio is actually better than for the large crystal. It can detect as low as $17 \mathrm{pCi}$ of $\mathrm{I}^{131}$ in the thyroid.

A suitable counter was worked out in time to study $\mathrm{I}^{131}$ in people following the U.S.S.R weapon tests in the fall of 1961 . At that time $\mathrm{I}^{131}$ was detected in all subjects who regularly drank fresh milk or who drank reconstituted dry milk. The thyroid burdens ranged from 18 to $150 \mathrm{pCi}$. A few attempts at uptake studies were made by measuring thyroid burdens for the experiment. The results were of interest but were limited in value because the activity of the $\mathrm{I}^{131}$, in the milk could not be controlled. 
Other groups later used the $I^{131}$ counter in a similar study in which people drank the milk from a cow given a constant activity of $\mathrm{I}^{131}$ per day.

\section{Phosphorus-32}

$\mathbf{P}^{32}$ is present in water of the Columbia River after it has been used for cooling the reactors. This isotope is concentrated by marine organisms and by fish. The amounts present in Columbia River fish make it of considerable interest to those concerned with radiation protection at Hanford.

The iron-room and shadow shield counters function by detection of gamma rays emitted by radioisotopes. $P^{32}$ emits no gamma rays; it is a pure beta-ray emitter. The first approach to counting $\mathrm{P}^{32}$ in vivo was to detect the bremsstrahlung ( $X$ rays) emitted during and after the decay.

These $\mathrm{X}$ rays have a distribution in energy with most of them below $0.2 \mathrm{MeV}$. This means that there is nothing about the energy that permits it to be identified as peculiar to $\mathrm{P}^{32}$, but, on the other hand, it makes detection and background reduction easier. We found that a sery thin $(3 \mathrm{~mm}) \mathrm{NaI}(\mathrm{Tl})$ crystal was quite efficient for these rays but had a low efficiency for high energy gamma rays and therefore had a low background. Such a crystal 4-1/4 in. in diameter could detect as little as $250 \mathrm{nCi}$ in a person (as low as $25 \mathrm{nCi}$ if, somehow, a background count were available before acquiring the $\left.\mathrm{P}^{32}\right) .(30,31)$

The body burdens of $\mathbf{Z n}^{65}$ that also result from eating Columbia River fish were found to be a serious interference for bremsstrahlung counting of $\mathrm{P}^{32}$. To combat this interferenre the counter was moved to a position by the head where the relative amount of $\mathrm{Zn}^{65}$ was low but there was still considerable $\mathrm{P}^{32}$. A simultaneous count was made on the other side of the head with the big crystal from the iron-room counter to determine a,correction for the presence of interfering radioisotopes. (7) This technique was an improvement but it was still not sufficient to overcome the interference from relatively high burdens of $\mathrm{Zn} 65$.

$\mathrm{P}^{32}$ beta rays from the head of the subject were detected with the bremsstrahlung counter. We found that a transmission-type proportional counter placed in front of the bremsstrahlung counter and operated in 
coincidence with $j$ (Figure 9) made a very good counter for these beta rays. Determination of $\mathrm{P}^{32}$ by this-method of counting proved better than detecting the bremsstrahlung. The background counting rate varies much less from person to person and can be corrected for by use of a beta-ray absorber placed in front of the counter. The detection limit for the counter is about $50 \mathrm{nCi}$. No prior background count of $€$ he subject is required to detect this amount. $(23,32)$

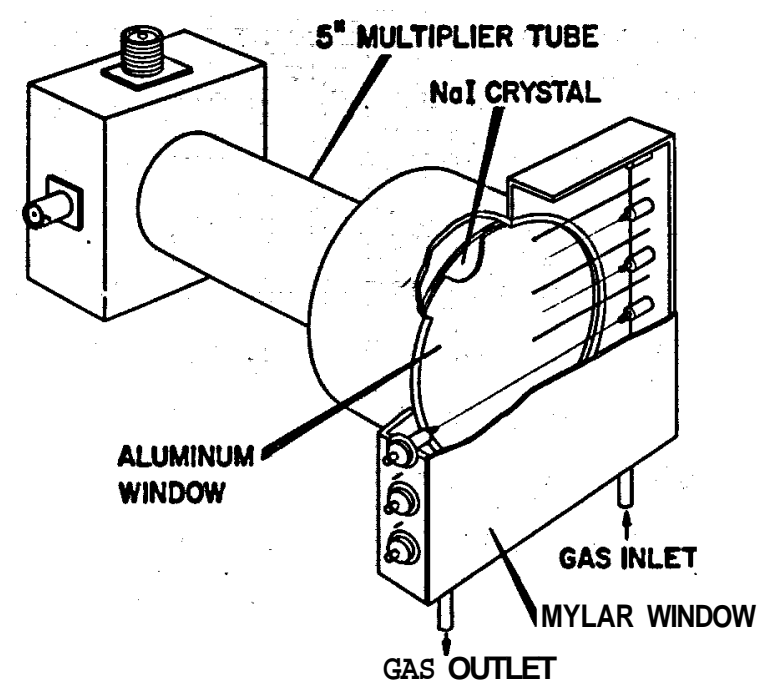

Neg. 0641158

FIGURE 9

Beta-Ray Coincidence Counter

Used for Whole Body Counting of $\mathrm{P}^{32}$

During the work on $\mathrm{P}^{32}$ counting we had the services of subjects containing known amounts of $\mathrm{P}^{32}$ obtained through the kindness of Dr. E. E. Osgood (University of Oregon Medical School) and of the Swedish Hospital, Seattle.

$\underline{\text { Plutonium }}$

Most of the plutonium isotopes are alpha-particle emitters and plutonium is a bone-seeking element; hence, it is a very dangerous material. The maximum permissible body burden of $\mathrm{Pu}^{239}$ is $40 \mathrm{nCi}$, one of the lowest assigned. Plutonium is one of the main radiation hazards at plants and laboratories such as Hanford. 
If plutonium is on a person's skin, it can be detected by the alpha particles it emits. The range of these particles is only about $4 \mathrm{mg} / \mathrm{cm}^{2}$. If the plutonium is present in even a very tiny scratch, it may be missed by an alpha-particle counter. Some of the decays of the plutonium isotopes lead to excited states of their uranium daughters. Unfortunately, very few of these excited states lead to the emission of gamma rays that might make whole body counting possible; most of the excited states decay by internal conversion. Internal conversion leaves the uranium daughter in a state of atomic excitation which sometimes results in X-ray emission. For $\mathrm{Pu}^{239}$ about $4 \%$ of the alpha decays are followed by $X$ rays. These are the $\mathbf{L}$ $\mathrm{X}$ rays of uranium and have energies in the range 13 to $21 \mathrm{keV}$. The $\mathrm{X}$ rays provide a possibility for the detection of plutonium buried in the body. The mass absorption coefficient of the rays in tissue is about $1 \mathrm{~cm}^{2} / \mathrm{g}$. Absorption of $\mathrm{X}$ rays from very deep in the body will be considerable. Bones will be practically opaque to the rays. In practice, however, most wounds of concern have been quite shallow and absorption in the overlying tissues small. After wounds, inhalation is the main route of entry of plutonium into the body. These two cases will now be discussed.

Wound Counting. Radiological Physics first encountered the $\mathrm{X}$ rays from plutonium in the interpretation of the dose rates from massive pieces of the material in 1951 (see below). At that time attempts were made to detect the $X$ rays from microscopic quantities of plutonium with micawindow counters and later with argon-filled proportional counters. Detection was possible but not of small enough activities to be of practical interest in wound counting. In 1954 we were able to obtain some very thin NaI(T1) crystals for scintillation counters. We found that they made excellent $\mathrm{X}$-ray detectors. A layer of NaI $1 \mathrm{~mm}$ thick detects nearly every X ray striking it. It is so thin, however, that the efficiency for higher energy photons is very small so that the background cbunting rate is low. It was another year before these crystals, mounted in holders with thin windows to admit the $X$ rays to the crystal, could be obtained commercially. Then they were put to use in studying plant employees known or suspected of having plutonium in wounds. $(33-35)$ When the Hanford Whole Body Counter 
was completed, wound counting became a regularly employed auxiliary, technique. ${ }^{(2,36)}$ In this application the thin-crystal counters can be broughtvery close to the activity to be measured and the sensitivity is consequently very high. It is normally possible to detect at least a few tenths of a nanocurie of plutonium. F or deep wounds the sensitivity is less and absorption and geometry correctinns are necessary. (9)

A practical complication in the counting of plutonium is that the material is seldom a single isotope. The isotopes 239, 240, and 241 are normally present, and often 238 and 242 as well. The number of $X$ rays per alpha particle is not the same for the different isotopes which complicates interpretation of the data. The $\mathrm{Am}^{241}$ daughter of $\mathrm{Pu}^{241}$ emits X and gamma rays which help with the detection of plutonium but still further complicate the interpretation of results.

Lung Burdens. The absorption of the low energy X rays from Plutonium is so very great that at first it did not appear that it would be possible to detect it when in the lung. We performed an experiment with an anesthetized pig borrowed from the Biology Laboratory to see just how great the absorption was. ${ }^{(37)} \mathrm{We}$ pushed a $1 \mathrm{mCi}$ plutonium source down the hog's throat and'used one of the wound counters to measure how many $\mathrm{X}$ rays penetrated his chest. It appeared that 5 to $10 \%$ of the $\mathrm{X}$ rays escaped. While this is a small fraction of an already small number of X rays, it appeared that detection of quantities in the lung less than the maximum permissible body burden would be possible if the counters were big enough and if their background counting rates could be reduced sufficiently.

This conclusion was confirmed later by experience in counting an individual containing an estimated $400 \mathrm{nCi}$ of plutonium with a large, thincrystal counter. (2)

The expense of making large, thin scintillation counters and the difficulties with photomultiplier tube noise, described below, made it appear that proportional counter would be better for lung counting. Proportional counters might also have sufficient resolution to separate the three main energy groups of the L X rays and thus permit estimation of 
depth in the body from the relative strengths of the three groups; scintillation counters do not have enough resolution even to distinguish the presence of the groups. We prepared a proportional counter that was big enough to cover a man's chest. One side was a thin, Mylar window that would admit $\mathrm{X}$ rays but would also withstand at least 5 atmospheres pressure. Good pulse height resolution was obtained. With 2 atmospheres of argonmethane, a 10 min counting time, and no attempt to decrease background, the minimum detectable amount of plutonium in the lung was $400 \mathrm{nCi}$. It was estimated that the use of krypton to give higher efficiency, of longer counting time, and of feasible reductions in background would lead to minimum detectable activities below the maximum permissible body burden. This work was frustrated by the fact that available krypton is .badly contaminated with $\mathrm{Kr}^{85}(\mathbf{3 8}, 39)$ In the search for a suitable counting gas with high $\mathrm{X}$-ray absorption, we tested several gasses containing bromine, but without success. We manufactured some germane, $\mathrm{GeH}_{2}$, in the belief that it might, like methane, be a good counting gas and be highly absorbing because of the germanium. The gas counts, but we have been unable to make a batch that counts well. Xenon does not seem to be a very good counting gas.

Scintillation counters use photomultiplier tubes to detect the light emitted in the scintillators. These tubes have a background counting rate of their own that is due to thermal emission of electrons from their cathodes. The pulse heights from plutonium $X$ rays in NaI(TI) are so small that the pulses from these thermal events can be of the same height (Figure 10). The thermal pulses were one of the main sources of background in the early wound counters, and they had to be eliminated if lung counting with them was to be successful. The way in which the two types of pulses can be told apart is that the thermal noise pulses last a very much shorter length of time than those from NaI(T1). Several methods were developed for distinguishing between fast and slow pulses that worked on large pulses but not on those of the size obtained from the $\mathrm{X}$ rays. Apparently the statistical fluctuations in the small pulses made parts of them look just like fast pulses to these devices. Finally, a method modeled 


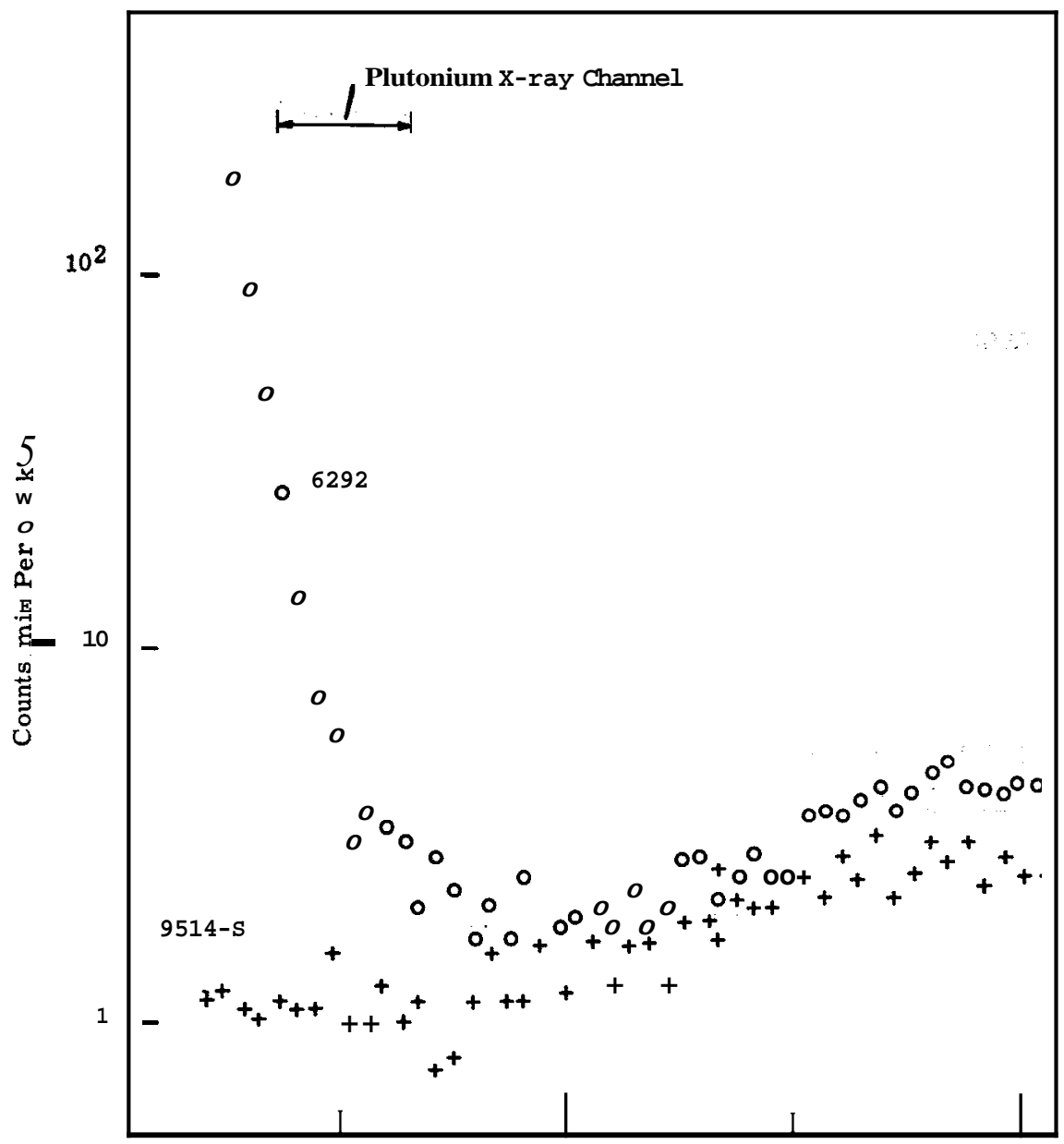

FIGURE 10

Pulse Height Spectra Due to Thermal Noise in 6292 and 9514 Photomultiplier Tubes

after the pulse-shape discrimination circuits used with neutron scintillators was developed that worked satisfactorily. Almost simultaneously a low thermal noise photomultiplier tube was found that made the method unnecessary (see below). Development of the method is being completed, however, for some anticipated uses on large photomultipliers where the noise will still be a problem.

In the fall of 1962 we found that some EMI photomultiplier tubes had much smaller thermal noise backgrounds than the tubes we had been 
using. (7) Figure 10 shows a typical comparison of the noise spectra of an old (6292) tube and a new (9514)tube. The reduction appeared to be enough to make lung counting possible. The unsatisfactory status of the proportional counter development led to the decision to build a counter using the new tubes. At the same time quartz was substituted for glass in the crystal mounts and the counter shield was lined with graded shields to reduce the real radiation background. The counter was assembled by late 1963. (23) It consists of 52 of the photomultiplier tubes, each having a thin $\mathrm{NaI}(\mathrm{T} 1)$ scintillator attached. Figure 11 shows the counter in use.

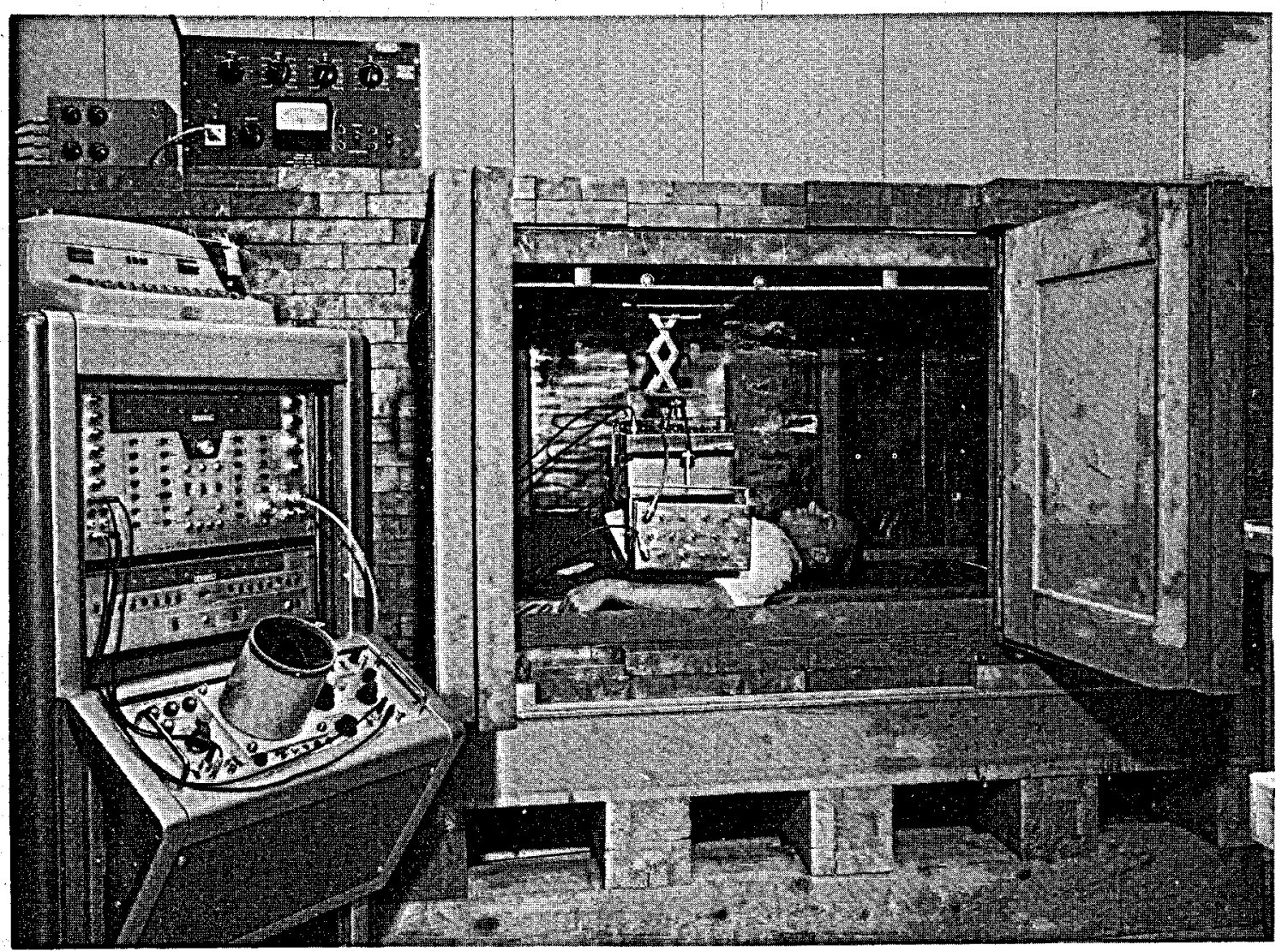

FIGURE 11

A Counter for Plutonium in the Lung

The background of the completed counter was actually less than had been predicted. Counts of people showed their background to vary considerably 
from one to the next. At present we are looking for a method of reducing or predicting this background. Until this is done, it is not possible to estimate just how small an activity of plutonium can be detected; it appears, however, that it will be less than a maximum permissible body burden. At the same time we are resolving instrument problems and working out measurement methods by using the counter on Biology Laboratory dogs that contain Plutonium. In addition to aiding our development work, the counting of these dogs is helping the Biology program by giving them information about the dogs prior to sacrifice. Other people are finding other uses for the counter: measuring animal excreta for plutonium, monitoring the steps in a chemical analysis for plutonium, etc.

\section{$\underline{\text { Urinalysis for } \mathbf{C s}^{137} \text { in Populations }}$}

During the study of radioactivity in Alaskan Eskimos, we took the opportunity to study the relation between the body burden of $\mathrm{Cs}^{137}$ and the amount eliminated in the urine. These data are of basic physiological interest and are also of interest in establishing the usefulness of urinalysis as a method for studying such body burdens. In the summer of $\mathbf{1 9 6 2}$ fifteen Eskimos who had been counted with the shadow shield counter also gave urine samples. There was a correlation between the $\mathrm{Cs}^{137}$ in the body and that in a $24-\mathrm{hr}$ urine sample, but it was not a very good one. We felt that this might have been due to our difficulty in explaining to the Eskimos what we wanted, with the result that we did not get full 24-hr samples. We tried comparing amounts of $\mathrm{Cs}^{137}$ and $\mathrm{K}^{40}$ eliminated in urine and found that there was a good correlation between the ratio of the $\mathrm{Cs}^{137}$ and the $\mathrm{K}^{40}$ in the urine to the $\mathrm{Cs}^{137}$ body burden. $(7,40)$ The correlation is not good enough to permit accurate prediction of the body burden of an individual from a urine measurement, but the average of measurements for several people or measurement of a pooled sample should be quite accurate in predicting the average burden in a population. It is especially convenient that the use of the $\mathrm{Cs}^{137}$ to $\mathrm{K}^{40}$ ratio makes it unnecessary to insist on 24-hr samples.

During the winter of 1962-63 we measured urine samples from three villages in Alaska that had not been visited with the whole body counter the 
preceding summer. The results for Fort Yukon were high enough to lead us to visit there with the counter the following summer. (19, 21-23,41)

Additional confirmation of the original correlation of the $\mathrm{Cs}{ }^{137} / \mathrm{K}^{40}$ ratio in the urine to the $\mathrm{Cs}^{137}$ in the body was obtained by analysis of samples secured in 1963 and 1964. Also, in 1964 the body burdens of Cs 137 in people in Richland became high enough to permit similar measurement\&on them. The value of the ratio was about $20 \%$ less than for the Eskimos of the same body burden.

In 1964 we started making monthly measurements on urine samples from three Alaskan villages and from Kadlec Hospital in Richland. The measurements in the villages were, in part, to provide a more detailed study of how burdens varied there during the year. Also, we are making quarterly whole body counts at one of the villages and we can compare results in Richland with those from the Hanford Whole Body Counter. These can give additional confirmation of the validity of the use of urinalysis to provide average $\mathrm{Cs}^{137}$ burdens for populations and encourage its use by others. The results obtained by the urinalysis and the whole body counting, available to date, are shown in Figure 12. The results obtained using the cesium/potassium ratio are generally too high. We traced this to there being too low quantities of potassium in the urine. Using the amount of $\mathbf{C s}^{137}$ in a $24-\mathrm{hr}$ sample gives good agreement with the body burdens determined by whole body counting.

Sodium-22. Gamma-ray counting of Eskimo urine specimens in early 1964 revealed the presence of $\mathrm{Na}^{22}$, a radioisotope not previously seen in people. The amounts in the Eskimos were probably less than'a nanocurie but were increasing to the point where they may become detectable by whole body counting. Radiological Chemistry also found $\mathrm{Na}^{22}$ in urine of Richlanders but in much lower amounts than for Eskimos. $\mathrm{Na}^{22}$ was also found in meat (caribou, beef) in amounts compatible with those found in people. 


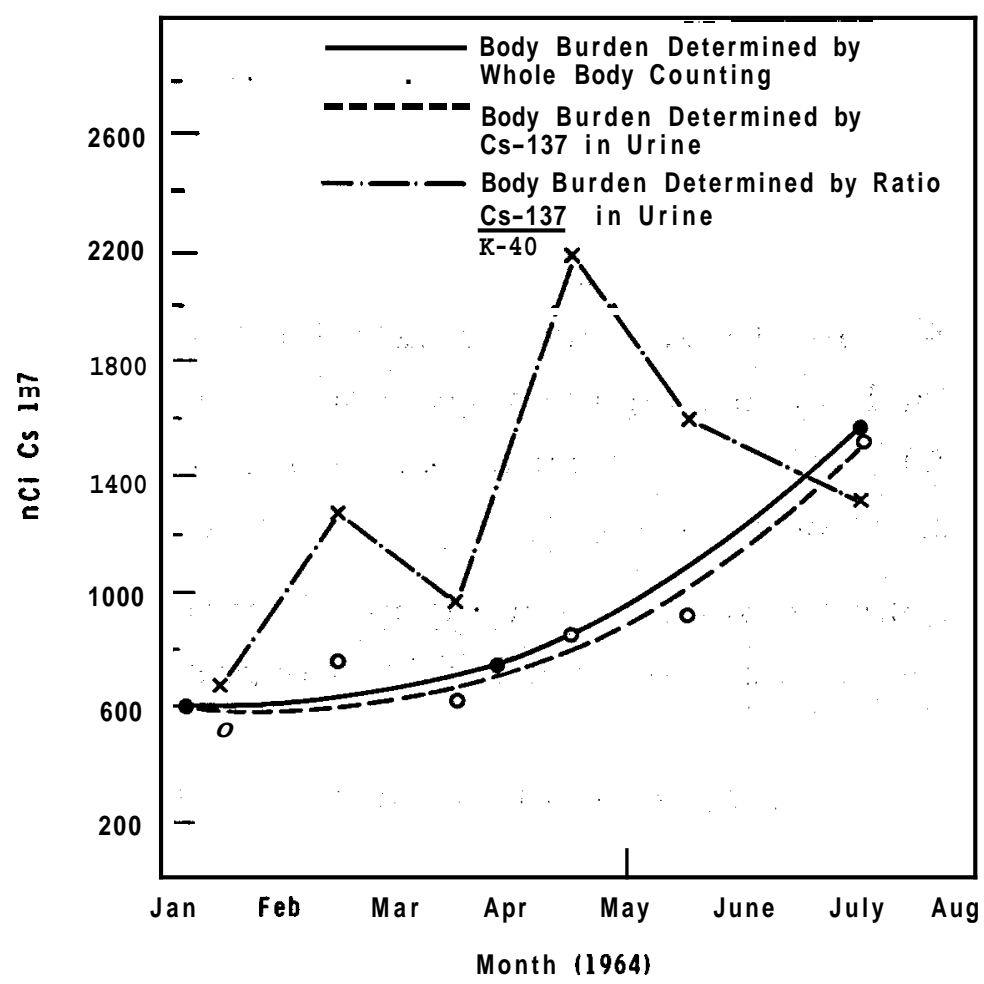

Neg. 0642515-5 FIGURE 12

Comparison of Urinalysis Results with Whole Body Counting Results for Cs 137

in Eskimos at Anaktuvuk Pass, Alaska

\section{NEUTRON DOSIMETRY}

Early Work

When the Radiological Physics group was formed, neutrons had only been known for $15 \mathrm{yr}$. Everywhere the knowledge of how to measure them was only rudimentary. The measurement techniques available at Hanford were the use of moderated $\mathrm{BF}_{3}$ proportional counters, where the relation of counting rate to dose rate was practically unknown, and the use of balanced ion chambers (Chang \& Eng and Neut), which were never really quite balanced and usually required measuring small differences between large numbers. The primary needs were better measurement methods and good standards. 
The first experiment was a study of the radiations emerging from a hole in a Hanford reactor. (42) The aim was to find a radiation source suitable for further experimental work. It was not successful; the radiations emerging from the hole were too complex to be analyzed by the elementary methods available. During this same period a very rough estimate was made of the radiation penetrating the shield of a Hanford reactor.

Shortly after this, Po-B and Po-Be neutron sources became available. Ra-a-Be sources were already on hand, but their high gamma-ray emission limited their usefulness. The low gamma-ray emission from these new sources made many new experiments possible. The first ones were received uncalibrated at Hanford, and we calibrated them against Ra-a-Be sources in a sigma pile. The sensitivity of a number of instruments, including instruments not intended for neutrons, (43) was determined. The neutron spectra provided by our sources were only crudely known sowe measured them by nuclear emulsion techniques. Figure 13 shows the three spectra measured.

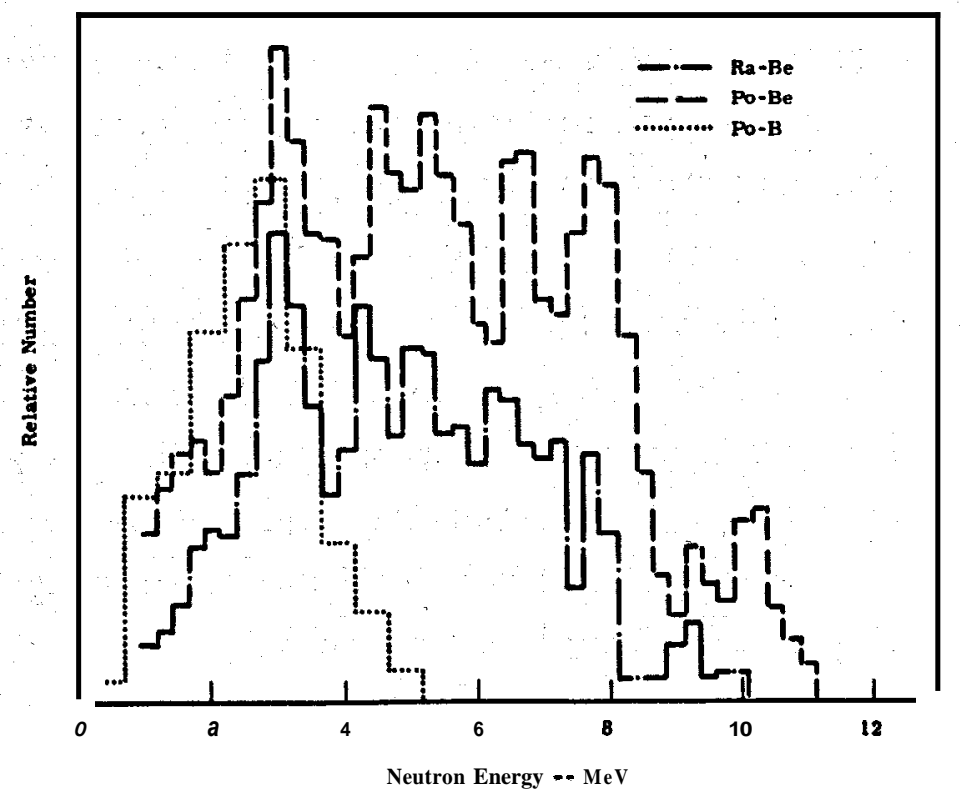

Neg. 0642635-3 FIGURE 13

Neutron Spectra Measured by the Nuclear Emulsion Technique (The histograms are not normalized, so only their shapes have significance.) 
The first attempt at improved instrumentation was a methane-filled proportional counter。(44) It had a very good rejection of gamma rays and a reasonable sensitivity, about 40 counts per minute per $\mathrm{mrad} / \mathrm{hr}$. Like all other work done during this period, there w as no way to determine the response of the device as a function of neutron energy. It was suspected that the counting rate per unit dose rate depended very strongly on the energy of the neutrons, and, therefore, the instrument was not a suitable health physics instrument.

A series of cylindrical tanks, whose heights equaled their diameters, was prepared. We measured the counting rates of a moderated $\mathrm{BF}_{3}$ counter and the proportional counter mentioned above when they were placed outside these tanks and Po-B, Po-Be, or Ra-a-Be sources were placed inside. The tanks were filled first with water and then later with paraffin. These results were published for their value in designing small neutron shields;(45) they have been quoted frequently ever since, because it is one of the few experimental studies available. We also measured the counting rate of a $\mathrm{BF}_{3}$ counter placed in the center of the tanks when the sources were placed outside. The aim was to select the optimum size cylinder for making measurements indicative of the dose rate. Again, since it was not possible to study the response of the system for monoenergetic neutrons, it was not possible to draw any useful conclusions. This study was the forerunner of a successful one that led to the double-moderator dosemeter (see below).

Another neutron detector that we investigated during this period was the "Hornyak button", (46) a mixture of luminescent zinc sulfide in lucite that was a reasonable scintillator for neutrons but a poor one for'gamma rays. Its study ended when we found that its gamma-ray sensitivity was great enough that it was unable to detect neutrons when the gamma-ray exposure rate was above a few roentgens per hour.

\section{Neutron Film Badge Program}

Our experience with emulsions for neutron spectrum measurements and developments at Oak Ridge led us to adopt the use of nuclear emulsions as personnel meters for fast neutrons. (47) A routine system for calibrating, 
developing, and reading them was developed and turned over to the External Dosimetry operation. In spite of some limitations, it remains the best system available and it is still in use. The main limitations are: 1)that the emulsions are not sensitive to neutrons below a little less than $1 \mathrm{MeV}$, 2) that it is not generally possible to detect neutron doses below a little less than 100 mrem nor more than a few rem, and 3) that gamma-ray exposures of a few roentgens prevent use of the emulsions for neutrons. Development of a satisfactory personnel meter for fast neutrons remains a major problem in radiological physics.

\section{$\underline{\text { Plutonium Problems }}$}

A number of problems in neutron and gamma-ray dosimetry originated in the weapons manufacturing facility at Hanford (234-5 Building). Here one encounters metallic plutonium or compounds of plutonium. The radiations that give problems come from the radioactive decay or spontaneous fission of the plutonium or the nuclear reactions induced by the plutonium alpha particles in the material with which the plutonium is associated. Neutrons are produced by spontaneous fission and by $(a, n)$ reactions.

Early studies by Radiological Physics were aimed at identifying those areas of the weapons facility subject to significant neutron radiation. A particularly important source was identified as the $(a, n)$ reaction in fluorine compounded with plutonium. The neutron spectrum from this reaction is similar in shape to that from Po-B (Figure 13) but peaks at an energy which is only about half as great. Such low energies give rise to problems in the use of the neutron film badge. Track fading in the nuclear emulsion is especially important at low energies ${ }^{(48)}$ and the number of tracks per unit dose is different. When the Van de Graaff facility was first obtained.(see below), neutron calibrations were performed there. After our confidence in our ability to intercompare sources of different spectra built up, we calibrated a plutonium fluoride source made from production material against our standard snurces and Calibrations Operation has used it ever since for neutron calibrations. ${ }^{(49)}$ 
Engineering interest in the strength of $(a, n)$ sources led us to do several experiments to estimate the source strength resulting from different reactions. These experiments used the double moderator, long counter, and large moderator described below. These experiments were only moderately successful because the sources being measured were always obscured by neutrons from spontaneous fission, They led to the program of $(\mathrm{a}, \mathrm{n})$ studies described below.

In the course of calibrating moderated $\mathrm{BF}_{3}$ detectors for plutonium work, we discovered how strongly neutron scattering influences the results, particularly with detectors that employ moderation. Figure 14 is one example of scattering measurements. It shows the apparent sensitivity of a moderated $\mathrm{BF}_{\mathbf{3}}$ counter at different distances from a source for various heights of the source above the floor of a large room. Errors of $150 \%$ can occur. Discovery of this scattering phenomenon has had a profound

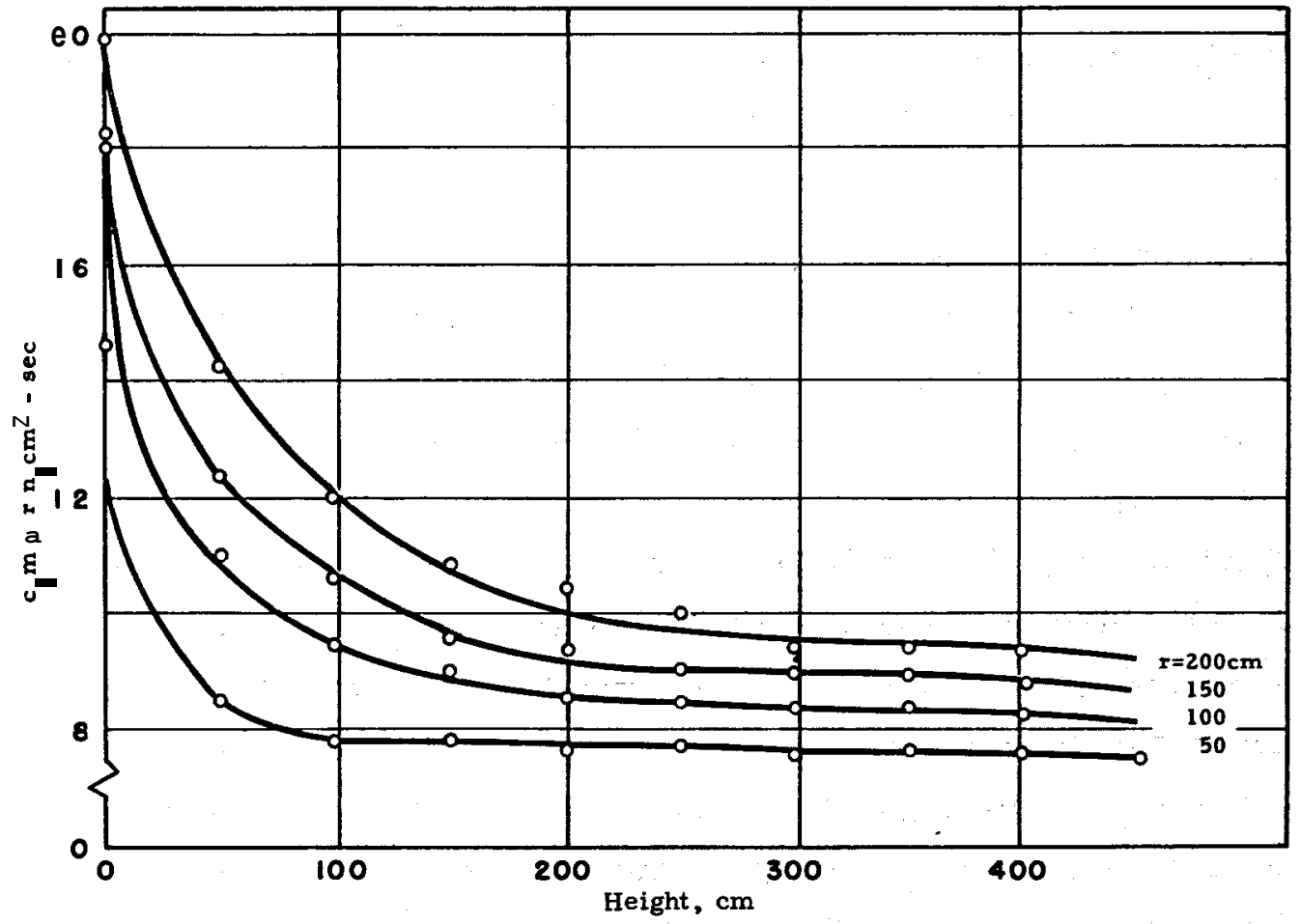

FIGURE 14

The Apparent Sensitivity of a Moderated $\mathrm{BF}_{3}$ Counter at Different Distances (r) $\underset{\text { arces menumb. mass. }}{\text { from }}$ Source for Various Heights of the Source Above the Floor 
influence on the course of all our subsequent work. A very careful study was made ${ }^{(50)}$ to provide information needed in planning the Van de Graaff facility. In general it appears that the effects of scattering can usually not be completely eliminated; they can only be minimized. It then becomes necessary to employ experimental techniques that yield measurements of and corrections for scattering.

$\underline{\text { Positive Ion Van de Graaff }}$

The early work showed that fruitful development in neutron dosimetry would require sources of monoenergetic neutrons. Positive ion Van de Graaff accelerators became commercially available at about this time so a project proposal (CG-489) was prepared for such a machine and a building for it. The facility was completed in the spring of 1954 .

Figure 15 illustrates the accelerator and how it is housed. The accelerator is in the room at the right. This room has $1 \mathrm{ft}$ thick concrete

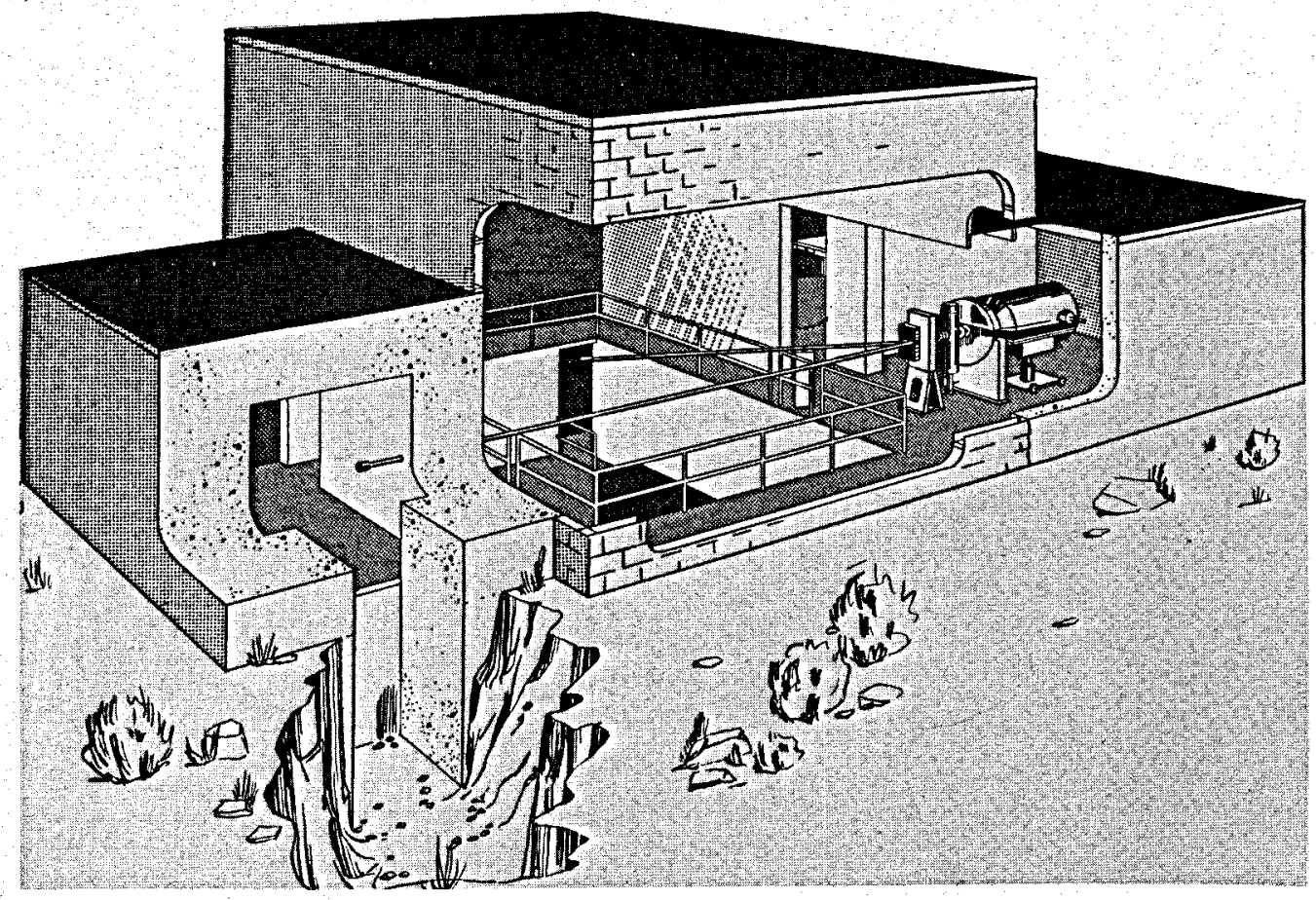

FIGURE 15

Positive Ion Accelerator Laboratory 
walls to attenuate $X$ rays that are produced inside the Van de Graaff tank during operation. The positive ions accelerated by the machine emerge at the left and pass through a magnet. Usually this magnet bends the beam of ions so that it strikes a neutron-producing target in the center of the very large main room and over a $7 \mathrm{ft}$ deep pit. There are no massive neutron scattering materials within $10 \mathrm{ft}$ of the target. The dimensions of this room were chosen as described above to minimize neutron scattering. Figure 16 is a photograph taken from inside this room. The Van de Graaff is in the far rear, behind a paraffin shield not shown in Figure 15. A light aluminum floor covers the pit. If the magnet is turned off, the ion beam proceeds straight down a long tube to a target inside a room with $4 \mathrm{ft}$ thick concrete walls. These walls are necessary for protection

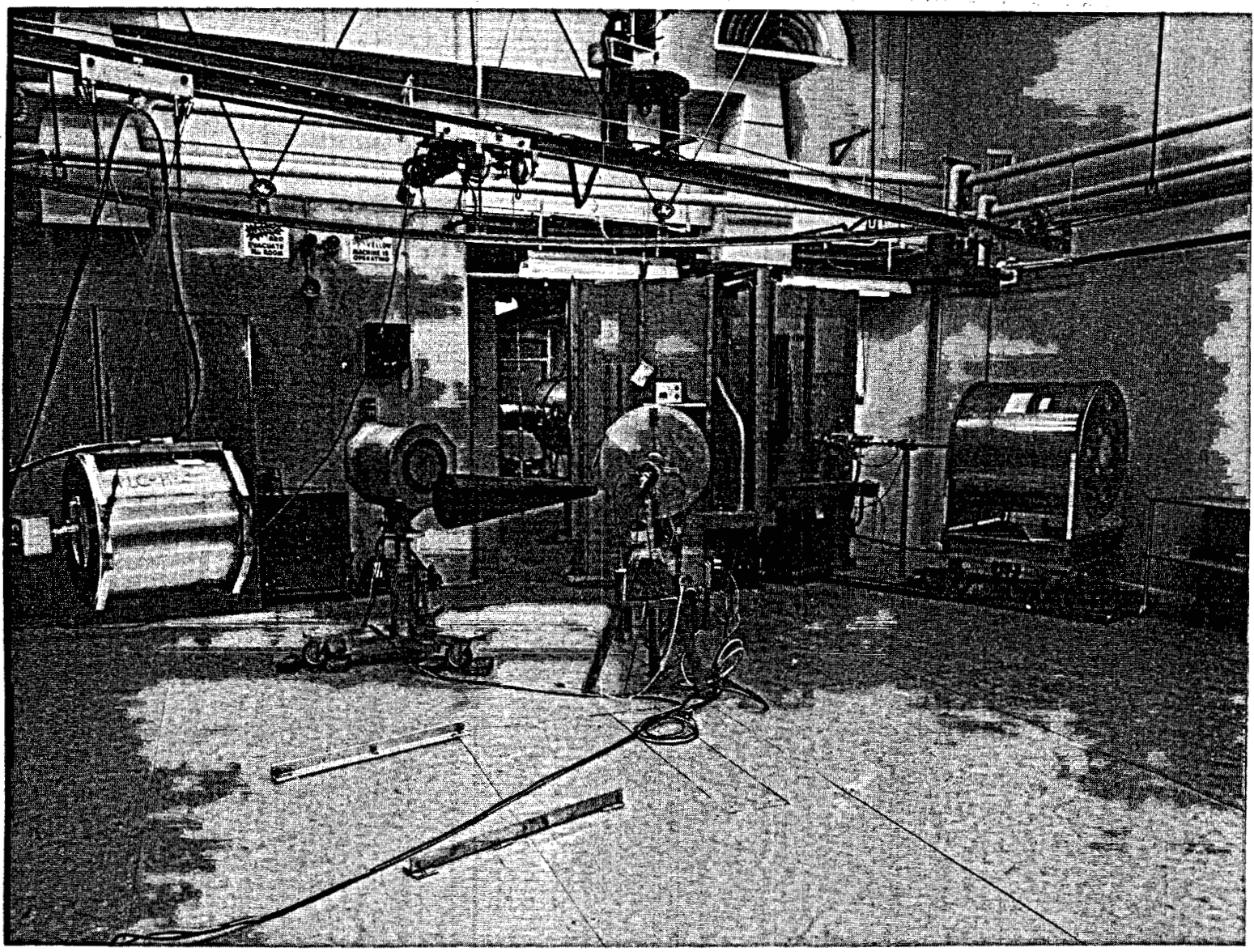

Neg. 062489-1

FIGURE 16

Interior of the Positive Ion Accelerator Laboratory

AEC-AE NJEMLAND. WASH. 
from the intense sources 'of'neutrons that can be developed with the undeflected beam. Neutron scattering in this room is quite severe, It is also possible to bend the ion beam in the opposite from the normal direction to use the beam itself in experiments or to produce and slow down neutrons in a tank of paraffin. Behind the Van de Graaff room in Figure 15 is a small office. Beyond the far side of the Van de Graaff room is a control room and laboratory that houses most of the experimental instruments used in the building. Overhead in Figure 16 is seen a long boom whose ends are supported by a circular track. Instruments and shielding can be hung from this boom and raised and lowered and changed in azimuth and radial distance from the target from which the neutrons emerge. With this apparatus it is possible to perform many experiments without leaving the control room.

The Van de Graaff accelerator was manufactured by the High Voltage Engineering Company. It has a terminal voltage of up to two million volts. It accelerates ions of either hydrogen or deuterium gas. These ions bombard targets of deuterium or tritium (in gas cells or in a zirconium or titanium matrix), lithium, beryllium, carbon, etc. to produce neutrons by nuclear reactions. If the targets are very thin, monoenergetic neutrons are produced. Monoenergetic neutrons can be produced in the range 0.06 to $5.1 \mathrm{MeV}$ and around $14 \mathrm{MeV}$. Generally, dose rates in the range 1 to $10 \mathrm{mrad} / \mathrm{hr}$ are available at 1 meter from the target. With thick targets dose rates two orders of magnitude or more higher can be produced, but the neutrons will have a range of energies or even possess a complicated spectrum. ${ }^{(52-55)}$ Some of the targets are commercially available, but methods had to be developed to produce others in our own laboratory. (56-58) We have found that minimizing gamma-ray and undesired neutron emission from the Van de Graaff targets is a continuing problem. Undesired neutrons usually come from the $D(d, n)$ reaction when bombarding nondeuterium targets with deuterium ions; most of the ions are embedded in the target and gradually accumulate to the point where they constitute a target of appreciable neutron yield. ${ }^{(9)}$ 
The studies described above of the neutron emission from plutonium and its compounds made it desirable to be able to use the Van. de Graaff to accelerate helium nuclei, i.e. produce alpha particles that could be used to study $(\alpha, n)$ reactions. The ions desired are the doubly charged helium ions because these would be accelerated to $4 \mathrm{MeV}$ energy by our $2 \mathrm{MV}$ Van de Graff; actually we hope to simulate plutonium alpha particles, which have energies slightly above $5 \mathrm{MeV}$, even better by also increasing the Van de Graaff voltage. A helium ion source was developed, but it was found to produce far more $\mathrm{He}^{+}$than $\mathrm{He}^{++}$ions, When the Van de Graaff was operating at capacity, the current of $\mathrm{He}^{++}$was insufficient for experimental work. We proceeded then to develop a charge separator that would separate most of the $\mathrm{He}^{++}$from the $\mathrm{He}^{+}$ions and have the Van de Graaff accelerate only the former. This device was successfully completed during the summer of 1964.

A major problem in neutron physics laboratories is measuring neutron energies. For this purpose we modified our Van de Graaff system to permit time-of-flight measurements. In this technique the ion beam is converted into short (a few nanoseconds) bursts of ions by oscillating the beam past a slit through which the ions must pass to proceed to the target. The neutrons are produced only in the time interval that these bursts strike the target. Electronic measurements of the time intervals between the bursts striking the target and the detection of the neutrons in a detector some distance from the target give the times of flight for that distance; from these can be calculated the velocity and the energy of the neutrons. We completed a system for doing this that employed a relatively crude electronic timing system. (59) Members of Experimental Nuclear Physics invented a device for time measurement, called the vernier chronotron, that permitted more accurate time measurement and much more rapid accumulation and analysis of the data. (60) Experimental Nuclear Physics has conducted an extensive program of measurements of fast neutron cross sections with the Van de Graaff and the time-of-flight system.

Another facility available in the Van de Graaff laboratory is a large paraffin and polyethylene neutron moderator. It is the large cylinder to the 
right in Figure 16. It is used to produce thermal neutrons from the fast neutrons generated by the Van de Graaff, to measure neutron yields of the Van de Graaff targets or of radioactive sources, and as a shield for intense neutron sources. (9) It proved very valuable in the dosimetry study of the Recuplex criticality accident. (61)

\section{Double-Moderator Neutron Dosemeter}

The first study undertaken when the positive ion accelerator became available was a continuation of the one described above in which the counting rate of $\mathrm{a} \mathrm{BF}_{3}$ proportional counter exposed to neutrons was determined as a function of the thickness of paraffin (or plastic) moderator surrounding it. This time, of course, the study was performed with monoenergetic neutrons. Almost at once it was found that at a paraffin thickness of 4.5 in. the counting rate per unit dose rate (that would be produced in tissue placed at the same point) was independent of the neutron energy in the energy range 0.1 to $5 \mathrm{MeV}$, the range of most interest in radiation protection problems at nuclear energy plants such as Hanford. This meant that the counting rate could be used as a measure of the dose rate. Later it was found that at a thickness of $2.4 \mathrm{in}$. the counting rate per unit flux density was independent of energy so that with this moderator thickness the counting rate was a measure of the flux density. The ratio of the counting rates at the two thicknesses is proportional to the neutron energy for monoenergetic neutrons below 1.5 MeV. Hence, the ratio gives the average energy of a spectrum all of whose energies are below this level. When employed with suitable care, the ratio gives useful information about spectra containing still higher energies. $(62-66)$ For properties of polyethylene moderators see Reference 7 . These discoveries led to the design of an instrument consisting'of $\mathrm{a} \mathrm{BF}_{3}$ counter surrounded by a cylinder of moderating material of the thickness for measuring flux density and this surrounded by a removable cylindrical sleeve of moderator that brings the total moderator thickness to that necessary to measure dose rate. This instrument has played an important part in much of our subsequent work in neutron dosimetry. It was also adopted for use in the radiation protection program at Hanford. Its sensitivity and relatively troublefree operation have made it very popular. It was the basis for the design 
of a relatively inexpensive criticality monitor now widely used at Hanford." For this purpose the $\mathrm{BF}_{3}$ counter is replaced by foils that become radioactive on exposure to neutrons.

\section{Cosmic Ray Neutrons}

When a good $\mathrm{BF}_{3}$ counter is used, the double-moderator dosemeter is so sensitive that the background due to neutrons produced by cosmic ray effects can be detected. A measurement of this background was made. $(7,68)$ Long counting times were required to obtain statistical accuracy. A Simpson Pile was built to monitor changes in cosmic ray intensity during the measurements. Measurements were made at various altitudes from 400 to $8400 \mathrm{ft}$. It turned out that almost all of the background counting rate at sea level was due to cosmic ray produced neutrons. At sea level the dose rate was $\mathbf{0 . 5 8}$ mrad per year, the flux density was 0.084 neutrons $/\left(\mathrm{cm}^{2}\right)(\mathrm{sec})$, and the average energy of the neutrons was $0.9 \mathrm{MeV}$.

$\underline{\text { Neutron Standards }}$

The development of good neutron standards is both a goal of the neutron dosimetry program at Hanford and a step necessary in that program. The work just described on the double-moderator was done with a preliminary method of making standard measurements. The basis for all these measurements was the known emission rate of a $\mathrm{Ra}-\mathrm{a}-\mathrm{Be}$ source. This rate had been determined at the Argonne National Laboratory and by the National Bureau of Standards before our program started. Comparisons of the emissions of other sources to this one were effected by means of a "long counter". The long counter is a particular type of paraffin-moderated $\mathrm{BF}_{3}$ counter that was introduced during the war in the expectation that its counting rate per unit flux density would be nearly independent of energy. Some measurements were available that indicated that this was true, although there were discrepancies between estimates of just how much the sensitivity did vary with energy. After comparison of emission rates by means of the long counter, dose rates were determined from calculated relations between dose rate and flux density 
made by the National Committee on Radiation Protection. These required knowing the neutron energy or energy spectrum.

After the period of intense development work on the double-moderator, we made a study to determine what action we should take to provide ourselves with better standards. The known methods of absolute flux density or source emission measurement were difficult and would require considerable effort on any one of them; furthermore, no one of them alone would be adequate for the range of problems we faced. It appeared wisest to avoid becoming involved with these absolute methods if we could. The idea was then conceived of working on the long counter to make it a generally acceptable device for the intercomparison of neutron fluxes. If this could be done, the instrument could be calibrated in absolutely known fluxes of other laboratories and thus provide us with the benefit of the absolute measurements without our having to make them. Also, and not just incidentally, it would make the intercomparisons of these known fluxes available to these other laboratories; this would be a significant contribution to the scientific community. The work on the long counter is described below in the section on the Precision Long Counter.

$\underline{\text { Radioactive Neutron Sources }}$

The development of a precision long counter does not reduce our dependency on the use of radioactive neutron sources for standards:

- The Ra-a-Be source remains the standard source of known emission.

- $\mathrm{Pu}-\mathrm{Be}$ sources are calibrated against it to serve as operating standards; their low gamma-ray emission makes them more desirable for general use. $\mathrm{Pu}-\mathrm{Be}$ sources were incorporated in the precision long counter for normalization of counting rates.

- Source measurement techniques were necessary for the study of neutron emission from plutonium and its compounds.

- A plutonium fluoride source was calibrated and introduced into the Hanford neutron calibration program, etc. 
There are some problems in using radioactive neutron sources. First, one must be sure that the contents of the source, and hence the neutron emission rate, is stable; this is determined through repeated emission measurements in a sigma pile or other stable device. The neutron emission is seldom isotropic but will have the same degree of symmetry as the physical construction of the source. This assymetry must be measured, e. g. with the double-moderator, and allowed for in converting total emission rates into flux densities, The neutron spectrum must be known. We measured some spectra (Figure 13). The ratio technique with the doublemoderator gave us a useful method of studying neutron spectra and a very sensitive technique for detecting small differences in spectra. $(8,69)$ This technique showed the presence of a group of neutrons in the $\mathrm{Pu}-\mathrm{Be}$ spectrum at a lower energy than any spectrometric method has yet been able to reach. Also, the spectrum changes with the size of the source. This is due to the scattering in the material of the source and led us to secure some very low mass sources employing $\mathrm{Pu}^{238}$ as the active isotope. It also showed that the asymmetry of emission just mentioned is accompanied by an asymmetry in the neutron spectrum. ") Finally, there are secular variations in neutron emission from most sources due to the presence of nonequilibrium amounts of daughter products. We have compared sources for differences in rate of change of neutron emission. ${ }^{\prime}$ ) Another reason for the procurement of the $\mathrm{Pu}^{238}$ - Be sources was that they might show a smaller rate of change due to this effect than other sources. We have worked closely with Mound Laboratory on studying secular changes. They have made calorimetric measurements of source activity changes; these should be closely related to changes of neutron emission.

The use of $\mathrm{Sb}-\mathrm{Be}$ sources proved desirable in some of our work because their average energy of about $25 \mathrm{keV}$ cannot easily be reached by producing neutrons with the Van de Graaff. $\mathrm{Sb}^{124}$ has a half-life of about 60 days which must be accurately known for the neutron work. We measured the half-life to much better accuracy than it was previously known by a calorimetric method to be described below. $(7,9,23,70)$ The result was $60.20 \pm 0.01$ days. 


\section{$\underline{\text { Precision Long Counter }}$}

The purpose of improving the long counter was described above. The immediate goal was to develop a counter design such that each counter made from it would be as much like every other counter as possible. The reason for this was that we wanted the 'final reference to absolute calibrations to be applicable to every such counter that we or others might make. Problems encountered during the development included eliminating distortion of plastic moderator parts, fabricating suitable absorbers of scattered neutrons, and avoiding material of high neutron absorption near the $\mathrm{BF}_{3}$ tube. The third model made was judged successful. $(7-9,71,72)$ (Machine drawings of the counter and the $\mathrm{BF}_{3}$ tube are available from Cooper-Trent Blueprint and Microfilm Corporation, 2701 Wilson Blvd., Arlington 1, Virginia))

Two precision long counters are shown in Figure 16; one is hanging from the instrument boom and the other is on a test stand to its right. Figure 17 shows an illustration of the counter. $\mathrm{A} \mathrm{BF}_{3}$ proportional counter, long relative to its diameter, is the sensitive element at the center of the counter. It is moderated by polyethylene that is firmly supported by heavy aluminum casing. In use, neutrons are incident from the right in Figure 17. Around the outside is a polyethylene shield intended to attenuate neutrons scattered toward the counter from the sides; between this shield and the inner moderator is a layer of boron in a polyethylene matrix that absorbs the neutrons moderated by the outer shield.

Very high quality $\mathrm{BF}_{3}$ tubes were required for the precision long counter. The pulse height spectrum had to possess a minimum at which the discrimination level could be set to minimize sensitivity to variations in that level. The, necessarytubes were obtained through the efforts of manufacturers in meeting our specifications. Although other parts of the precision long counter can be made almost identical from one counter to the next, even with the best of care this cannot be done for the $\mathrm{BF}_{3}$ tubes. Hence, a small $\mathrm{Pu}-\mathrm{Be}$ source is an integral, but removable, part of the precision long counter. $\mathrm{BF}_{3}$ tubes and $\mathrm{Pu}-\mathrm{Be}$ sources can be intereompared to very high accuracy in any one precision long counter. The use of 


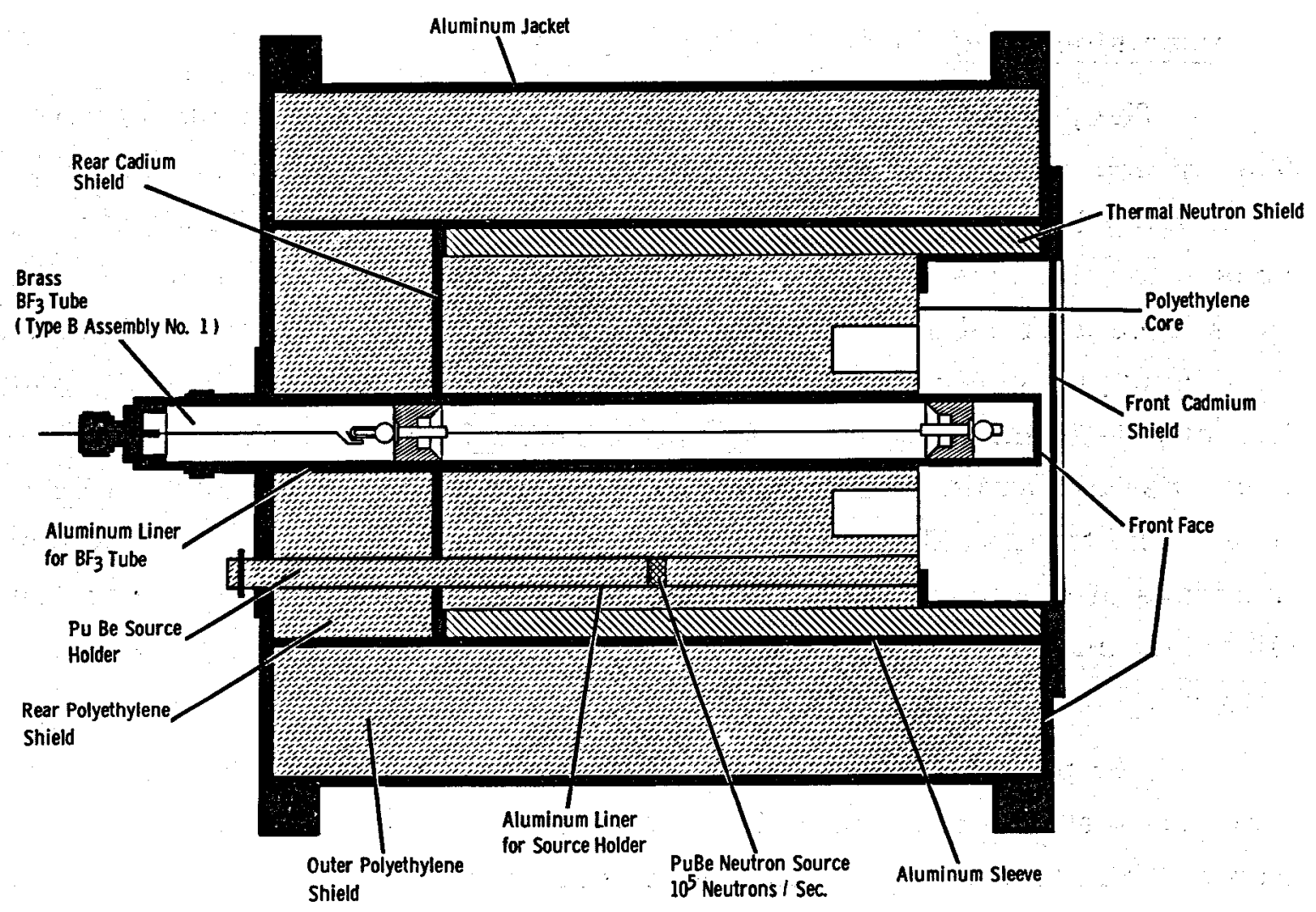

Neg. 061547-1

FIGURE 19

Diagram of the Precision Long Counter

$\mathrm{Pu}-\mathrm{Be}$ sources is one of the reasons for our strong interest in the secular variation of such sources described above. In measurements with sources such as $\mathrm{Ra}-\mathrm{Be}$ or $\mathrm{Sb}-\mathrm{Be}$ that have strong gamma-ray emission, we found that most $\mathrm{BF}_{3}$ tubes were unstable. ") We found tubes made from oxygenfree copper to have acceptably small reaction to gamma rays.

In spite of the shield for scattered neutrons, the precision long counter has enough sensitivity for them that scattering determinations must be part of every precision experiment. We worked out a method of making measurements as a function of distance from the source that permitted eliminating the effects of scattering. $(7,8)$ Its use by others indicates that the nature of the scattering problem is different in each different type of laboratory building. 
Even before the completion of our work on the precision long counter it has been adopted by at least six laboratories in this country, one in Canada', and one in France. We have just completed a program of intercomparisons of some of these'counters. (23) counters can make measurements that are at least within $0.5 \%$ of each other and more often with $0.3 \%$ or less. During the shipment of one of our counters between laboratories a change of a few tenths of a percent took place in its sensitivity that we have not been able to explain. The calibration of the precision long counter with absolutely known fluxes remains to be performed.

\section{$\underline{\text { Low Energy Fast Neutrons }}$}

Most neutrons in nuclear energy plants are emitted with energies greater than $1 \mathrm{MeV}$. They lose energy, however, as they interact with their surroundings. Since the absorption cross sections for them are generally small until they have reached nearly thermal energy, almost any lower neutron energy may be encountered. Theoretical studies indicate significant fractions of the dose delivered by neutrons in such situations may be due to neutrons with energies in the range of 0.1 to $1 \mathrm{MeV}$ (which we call low energy fast neutrons). Ratio measurements with the double-moderator usually indicate average neutron energies in this range under field conditions, Also, frequent discrepancies between the doublemoderator, dosemeter (which is sensitive to neutrons in this energy range) and neutron film badges (which are not) are probably due to neutrons of such energies. We felt that more should be known about the dose-spectrum of the neutrons in plants such as Hanford to make sure that they were being measured correctly and as a guide for future instrument and biological research.

Neutron measurements, particularly spectrum determinations, in the 0.1 to $1 \mathrm{MeV}$ range are generally difficult. No neutron spectrometer suitable for field use is known for this energy range. We first tried a device developed at Argonne National Laboratory and known as the Perlow spectrometer to see if we could make use of it. It proved unsuitable for 
field work because of the interference by high energy fast neutrons with the measurement of low energy fast neutrons.

$(8,73)$ We studied a lithiumsandwich, solid-state coincidence counter spectrometer but concluded that it was too insensitive for our problem. ${ }^{(7)}$ our study of a method used by other laboratories and employing different size spherical moderators around a thermal neutron detector showed it was based on inaccurate calibration curves and would, in any case, not yield the definitive data we feel are needed. ${ }^{(23)}$ We are at present engaged in completing development of a $\mathrm{He}^{\mathbf{3}}$ proportional counter spectrometer that we hope will permit us to make the needed spectrum measurements.

$\underline{\text { Pulse Shape Discrimination }}$

Scintillation counters employing organic scintillators would be useful in fast neutron dosimetry if the scintillations due to recoil protons could be distinguished from those due to secondary electrons from gamma rays. Such scintillators would have high efficiency and the absorbed dose in the scintillator would be very nearly the same as that in tissue because their compositions are fairly similar to that of tissue. Simple pulse height discrimination cannot distinguish between scintillations from recoil protons and those from secondary electrons. Indeed, scintillations due to protons are smaller than those due to electrons of the same energy. Brooks ${ }^{(74)}$ found, however, that while scintillations from the two have a similar sequence of events (each has a fast decay with a decay time of a few nanoseconds followed by a slow component with a decay time of a few hundred nanoseconds) the scintillations from the recoil protons have a relatively greater part of their energy given off in the slow component. This fact can be used to distinguish scintillations from the two types of particles and is called pulse shape discrimination.

We tried several pulse shape discrimination circuits and settled on one based on space charge effects for our purpose. We measured the pulse height spectra for $1 \mathrm{mrad}$ of monoenergetic neutrons for various energies between 0.5 and $5 \mathrm{MeV}$ using the discriminator circuit to select the pulses to be analyzed. In the ideal case of perfect linearity between the energy of the recoil protons and the resulting light and perfect discrimination 
between proton, and eleictrons without rejecti $\mathrm{n}$ of any protons, the rate of light emission would be proportional to the neutron dose rate. The light emission is proportional to the sum of the counts in each channel multiplied by the channel number. This sum is plotted versus the neutron energy in Figure 18. Above $2 \mathrm{MeV}$ the sum is independent of neutron

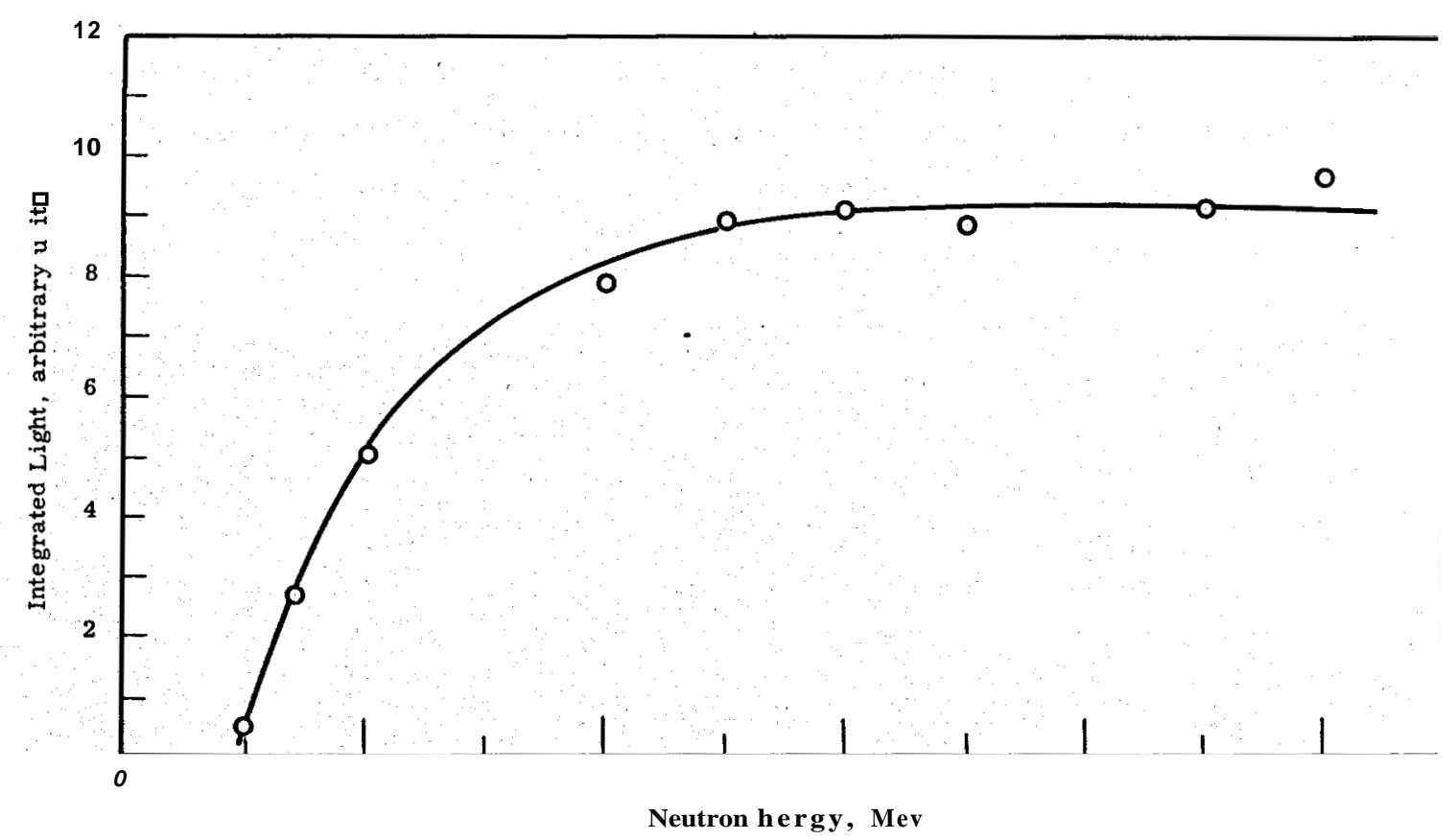

FIGURE 18

Response of an Anthracene Scintillator to Neutrons Using a Pulse Shape Discrimination Circuit

energy and would be a suitable measurement for indication of the neutron dose. The cutoff in sensitivity at $0.5 \mathrm{MeV}$ is due to the inability of the pulse shape discriminator to distinguish between protons and electrons below that energy so it must be set to reject all lower energy pulses. Because of the importance of low energy fast neutrons, the pulse shape discrimination technique is of limited value unless suitably supplemented by some other measurement technique. $(7,23)$

Fast Neutron Medical Research Facility

A member of the faculty of the University of Washington medical school is engaged in research using fast neutrons. It was arranged that AEC-GE MICHLAMD. WASH. 
Radiological Physics would design, secure the components for, and assemble an exposure facility for his work. The neutron source was to be a $T(d, n)$ generator of $14 \mathrm{MeV}$ neutrons such as used in neutron activation analysis. The generator obtained was a Texas Nuclear 9700. A University of Washington graduate student working with us to obtain material for an MS thesis measured the transmission of wood, concrete, and paraffin for $14 \mathrm{MeV}$ neutrons and then designed a shield based on this information. Figure 19 shows the shielding and the generator as it was set up in our laboratory. This work is continuing. We will set up the facility in the University laboratory and then do the dosimetry for it. (23)

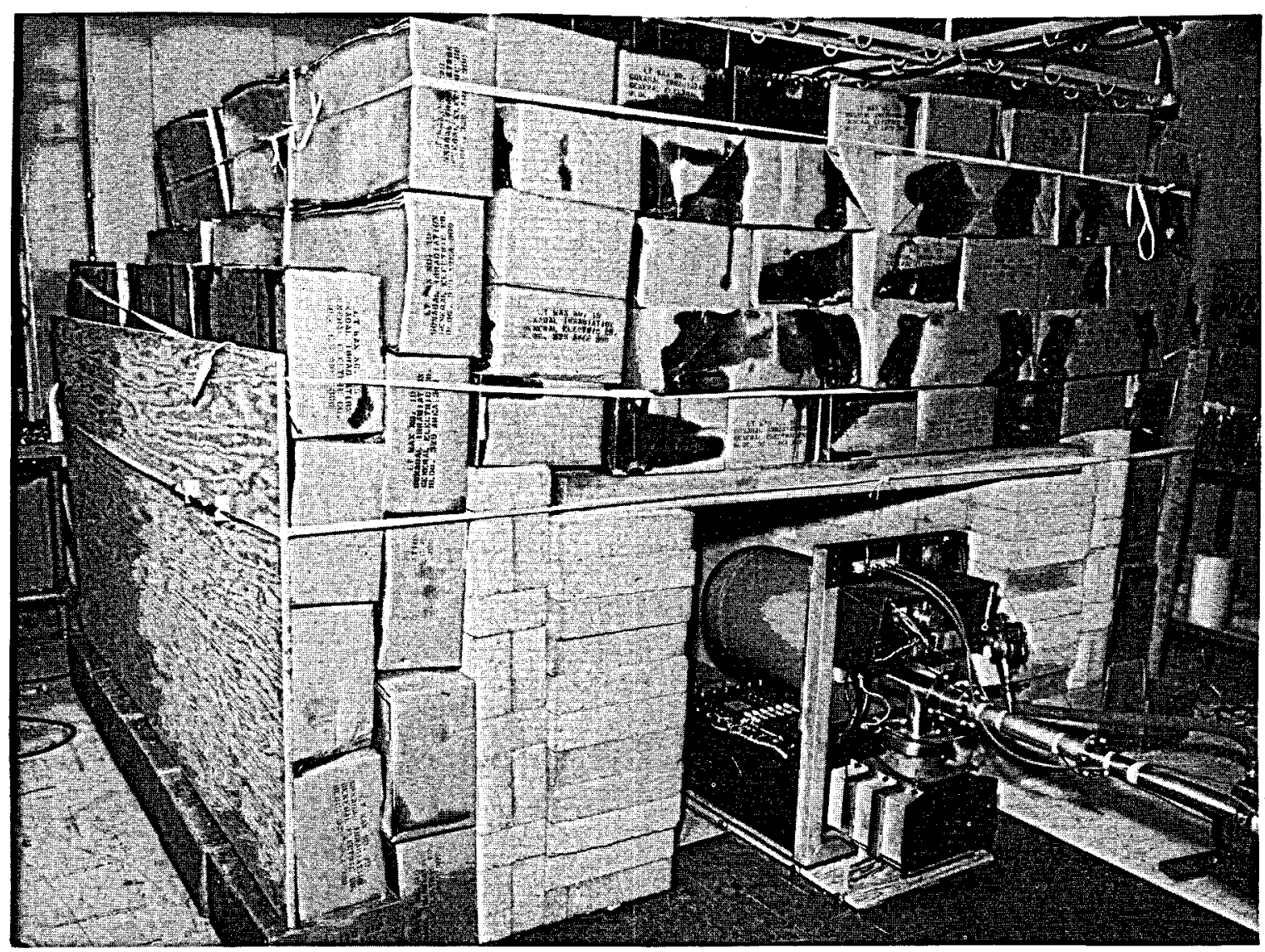

Neg. 0640652-4 FIGURE 19

The University of Washington Fast Neutron Medical Research Facility 


\section{THEORETICAL DÓSIMETRY}

One of the main problems of theoretical dosimetry is: given the nature of the sources of radiation in a given problem, calculate the resulting radiation fields and absorbed dose distributions. Another problem, closely related to the first, is to calculate the response of a radiation detector placed in the field, In general, detailed and complex calculations are needed for each component of the radiation field, i.e. photons and neutrons, their charged secondary radiations, beta rays, charged particle beams, etc. Several laboratories have devoted attention to the problems of photon and neutron fields so Radiological Physics has concentrated on the problems of charged particle fields.

Age Theory of Charged Particles

The penetration and slowing down of charged particles in matter present problems quite similar to those for neutrons. In practical neutron problems an approximation to the rigorous transport equation known as the age equation has been used. The age equation for the flux density averaged over all directions, $\varphi_{0}$, is

$$
\frac{\partial \varphi_{0}}{\partial t}=\nabla^{2} \varphi_{0}+3 K_{1} N
$$

where $\mathbf{N}$ is the source strength density of charged particles,

$\mathrm{K}_{1}$ is their macroscopic transport cross section, and

$t$ is a quantity called the "age" that is calculated from $\mathrm{K}_{1}$. The basic assumption in age theory is that the differential flux density in different directions does not differ too much from the average value $\varphi_{0}$.

Several authors had applied the age equation to problems of penetration of electrons with reasonable success. We first applied it to problems involving sources of beta rays. It was necessary to carry out numerous numerical averages of the theoretical results over various beta-ray spectra. When applied to familiar beta-ray problems, there was good agreement with experimental data except in a few particular instances. These were ones in which the fundamental assumption of age theory probably did not apply. The beta-ray results and those for neutrons both indicate that the 
age equation leads to erroneous results within one "relaxation length" of a localized source. The age theory predicts the ranges and absorption coefficients of beta rays quite accurately and without the use of any adjustable constants. When applied to the surface dose problem, a thick emitter in contact with a thick backscatterer, it predicts the correct dose rate at the boundary of the two media and the change with distance into the backscatterer, and also predicts correctly the effect of different atomic numbers for the two media on these quantities. It predicts correctly the variation with thickness of the dose rate from a large thin source. In the limiting case of a very thin source, the result is in error for distances within one relaxation length from the source but is correct beyond that point. The same is true for a point source. $(75,76)$

One of the most useful results of the age theory study of beta-ray problems has been the result for the surface dose problem. In the idealized problem, two half-infinite media meet at a plane boundary. One of the media contains a uniformly distributed beta-ray emitter. A typical practical situation is presented by a piece of uranium, a beta-ray emitter, held in a man's hand. It is easy to calculate the dose rate at distances greater than the range of the beta particles within the emitting medium, $D_{e}$, because it will be the same as that in an infinite medium, i.e. the product of the source strength density and the average energy of the beta rays. Near the boundary, however, the dose rate depends strongly upon the scattering and ranges in the two materials. Age theory predicts that right at the boundary, but in the nonemitting material, the dose rate will be

$$
D=\frac{s \text { De }}{1+\sqrt{\frac{Z_{e}}{Z}}}
$$

where $Z_{e}$ is the atomic number of the emitting medium,

$\mathrm{Z}$ that of the nonemitting medium, and

$\mathrm{s}$ is the average ratio of the stopping power of the beta rays in the nonemitting medium to that in the emitting medium.

This equation gives dose rates in excellent agreement with our experimental results (to be described below) for beta rays from uranium in contact with 
tissue. It also correctly predicts the results of others for the result of , replacing the tissue by other materials. The theory completes our understanding of this basic and practically important problem. It was applied later to prediction of the surface dose rate from thorium ${ }^{(77)}$ and from plutonium. $(78-81)$

The age theory was later applied to, problems involving the secondary electrons from $x$ or gamma rays. ${ }^{(82)}$ It proved useful in clarifying the relationships between kerma and absorbed dose in studying the response of ion chambers and X-ray film to photons. This was a particularly important study because it gradually led to the investigations of radiation nonequilibrium, cavity chamber theory, and the field equations described below.

$\underline{\text { Radiation, Nonequilibrium }}$

The age theory study of the relations between absorbed dose and kerma led to a more rigorous study. ${ }^{(83)}$ The interesting problems are those where radiation equilibrium does not exist, i.e. 'where the absorbed dose does not equal the kerma. No assumption was made about the nature of the solution of the transport equation for the secondary electrons other than that a solution existed and that the absorbed dose distribution could be represented with a Green's function. The results of the study were theoretically exact but were not numerical; approximations would normally 'appear in the numerical evaluation. The basic relation between absorbed dose, $\mathbf{D}$, and kerma, $\mathbf{K}$, at a point in a photon beam was shown to be

$$
D=K(1+\mu \bar{x}+\ldots) \text {. }
$$

where $\mu$ is the absorption coefficient of the photons and

$\overline{\mathbf{x}}$ is the first moment of-the Green!s function solution in the direction of the beam.

This relation confirmed a supposition that had already frequently been made in the literature and has been used frequently since. The acronym KERM was introduced in this study for the kinetic energy of the secondary electrons released per unit mass. Later, the ICRU Ad'Hoc Committee ( see below) added an a, to prevent confusion with the German word "kern", to give the "kerma" we now use. 
NCRP Stopping Power Study Group

The age theory work above and the interest in cavity theory led to the appointment of a member of 'Radiological Physic's to the chairmanship of the Stopping Power Study Group of the National Committee on Radiation Protection and Measurements (NCRP). The assignment of'this group was to prepare a survey article about cavity ionization chambers that was to include their recommendations on what were the best stopping power ratios to use with such chambers. Following normal NCRP practice, this article appeared as a National Bureau of Standards .handbook. $(84,85)$

Participation in this study group led to an attempt- to establish a rigorous theory of cavity chambers. $(86,87)$ The basic equation governing such chambers was formulated. No attempt was ever made to apply it because it contains quantities about which little or nothing is known at the present time. This study was a direct forerunner of the one on field equations (below). .

The same member of Radiological. Physics was also appointed to a subcommittee 'of the International Commission on Radiological Units and Measurements (ICRU) to prepare stopping power data for their report on the fundamentals of radiation measurement. ${ }^{(71)}$

Field Equations in Dosimetry and the ICRU Ad Hoc Committee

Throughout the short history of our knowledge of radiation and of its measurement, dosimetry, there has been much discussion of the fundamental concepts and quantities used in this field. This is partly due to the continually increasing number of new scientists using these concepts in the expanding field of nuclear science and technology, partly because of the need for extending the concepts so they would be of use for new types of radiation, but chiefly because the piecemeal growth of the quantities had left some of them poorly defined and with the relations among them obscure. The work of Radiological Physics in theoretical dosimetry frequently made these shortcomings obvious. On the other hand, the need for precision of mathematical treatment began to suggest how the foundations of the subject might be revised and improved. Rough drafts of attempts at revision came to the attention of H. H. Rossi, Professor of Radiology (Physics) of Columbia 
University, who was working on the same problem along similar lines. They also came to the attention of officials of the ICRU,who were:acutely aware of the problem and happened to be engaged in trying to do something about it. In 1958 the ICRU set up an Ad Hoc Committee on Quantities and Units to "review the fundamental concepts, quantities, and units which are required in radiation dosimetry and to recommend a system of concepts and a set of definitions which would be, as far as possible, internally consistent and of sufficient generality to cover present requirements and such future requirements as can be foreseen. " Dr. Rossi and a member of Radiological Physics were appointed to this committee. Because of their mutual interest and at the urging of the Ad Hoc Committee these two men collaborated in the preparation of a physical-mathematical study of the foundations of radiation dosimetry. ${ }^{(88)}$ This study resulted in the formulation of certain fundamental equations, called field equations, connecting the usual quantities used to describe radiation fields and the quantities such as absorbed dose used in dosimetry. To carry out the study the authors had to supply precise definitions of some quantities that had been obscure before. Concurrently with this study the Ad Hoc Committee began preparation of its own report which drew heavily on the field equation results. Their completed report was submitted to the ICRU, subjected to criticism within the scientific community, and finally adopted. It is now the international standard in writings and discussions on dosimetry.

To illustrate the nature of these new treatments of dosimetry, consider the quantity called absorbed dose. It used to be defined as "the energy imparted to matter by ionizing particles per unit mass of irradiated material. "The obscurity in this definition was connected with the term "energy imparted." The context of the definition of dose explained that the energy imparted was meant to include the energy associated with ionization, excitation, or changes of chemical bond energy, etc. but to exclude that due to changes in rest mass. This is a sort of catalog of what should be included; the result was that every new radiation effect had to be considered anew to see if it should be included. The new ICRU definition of absorbed dose is similar to the old one (it is worded more carefully to denote the 
the physical limiting process that must be carried out to obtain the dose). The definition of energy imparted, however, is changed completely to "the difference between the sum of the energies of all the directly and indirectly ionizing particles which have entered the volume and the sum of the energies of all those which have left it, minus the energy equivalent of any increase in rest mass that took place in nuclear or elementary particle reactions.. ." This means exactly the same as the earlier definition, but it specifies the energy to be included without requiring a lengthy, and possibly incomplete, catalog of the different types of energy transfer. The equivalence follows from conservation of energy which requires that the difference in energy flowing in and flowing out of a volume equal that which is absorbed therein. This definition also defines energy imparted, and hence absorbed dose, using quantities ordinarily used to describe radiation fields, i.e. particle energies and flux densities. This is the result of the field equation study. The field equations rest upon the fact that absorbed dose can be related to the ordinary field quantities this way. The basic field equation is that the absorbed dose is given by

$$
D=E-Q-(1 / \rho) \nabla \cdot \vec{G} \text {. }
$$

$E$ and $Q$ are allowances for energy emitted by radiation sources and for changes in rest mass, respectively. $\vec{G}$ is a vector constructed from the energies and differential flux densities which gives the energy flow much like the current density vector gives the flow of electrical charge in electrical studies.

\section{$\underline{\text { RADIATION CALORIMETRY }}$}

When radiation is absorbed in matter, its energy is dissipated by secondary particles and finally most of it appears as heat. Calorimetric measurements of this heat have been used since the discovery of ionizing radiations as a means of measurement of the radiation. The work in theoretical dosimetry just described shows that there is usually a close relation between the heat produced and the absorbed dose. Early calorimetric techniques were already capable of good accuracy, but they soon gave way to the simpler, more sensitive ionization methods of measurement. 
Recently attention has returned to calorimetry as a way to measure strong sources or radiation fields and because modern control instrumentation promised to simplify the methods.

\section{Total-Absorption Gamma-Ray Calorimetry}

The first venture into calorimetry by Radiological Physics was the total-absorption method of determining gamma-ray source strengths. In this method the calorimeter consists of a block of metal large enough to absorb (nearly) completely all the gamma rays emitted by a source placed at its center. The temperature rise of this block compared with the temperature rise produced by a known electrical power in a heating element gives the power emitted by the source. This suffices for some purposes, e. g. the intercomparison of source strengths for the same radioisotope. If one knows the energy released per decay by the radioisotope, he can convert the power emitted into the activity of the source. This type of radiation calorimetry was tried first because the relatively large amount of power resulting from total absorption made measurement relatively easy and because there were some problems on hand to which it could be applied immediately.

Because of the large amount of absorbing material needed for total absorption, the system time constant is usually long; typically, it is of the order of a day. If one uses adiabatic calorimetry in order to make his measurements quickly, the temperature changes that he must measure are very small; if he uses isothermal calorimetry, the system parameters must be very stable because many days may be required for a measurement. Our first contribution to this subject was a theoretical analysis that showed that, if one made his measurements at a time which was intermediate between those for adiabatic and isothermal calorimetry, the error in his result was minimized. $(90,91)$ Our calorimeter is illustrated in Figure 20. The calorimeter is an $80 \mathrm{lb}$ cylinder of tungsten alloy. It is mounted in a submarine jacket inside a water bath. The temperature of the bath is controlled to give a stable reference against which to measure the temperature rise of the calorimeter. 
the temperature measurements are made with thermistors. Thermistors are nonlinear devices; a method for linearizing data taken with them was developed. $(93,94)$

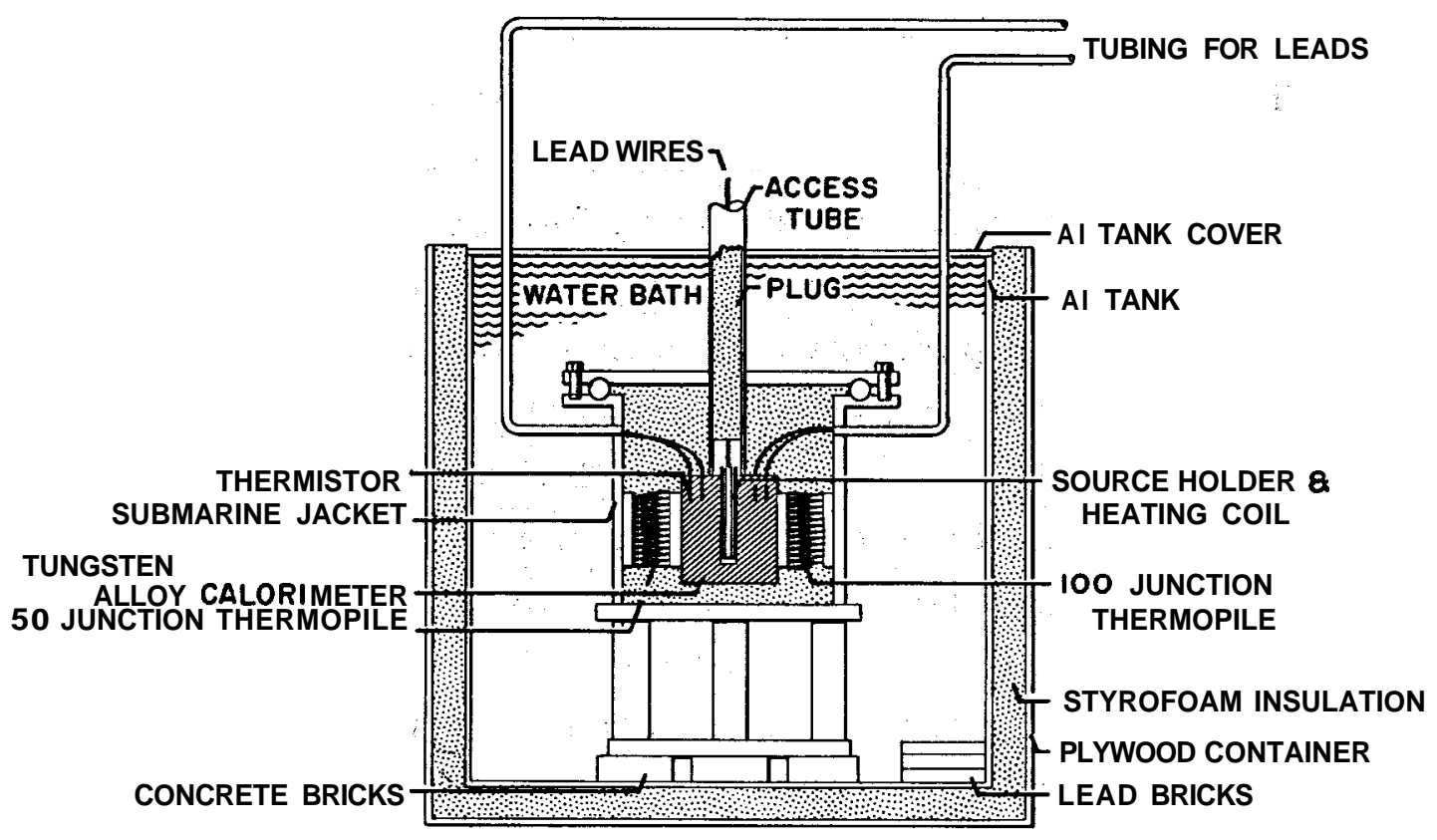

FIGURE 20

Total-Absorption Gamma-Ray Calorimeter

The first use of the calorimeter was to measure the activity of a Co ${ }^{60}$ source obtained for use in the Calibrations Operation. The uncertainty in the result was only $0.77 "$. Exposure dose rates at moderate distances from the source were also determined.

Next a Co ${ }^{60}$ source borrowed from the National Bureau of Standards was measured. The result was $1.7 \%$ less than the value obtained at the Bureau by a coincidence technique. ${ }^{(95)}$ Careful free air chamber measurements had also been made of the source by the Bureau. It was, therefore, possible to collaborate with them in obtaining a precise value for $\mathrm{W}_{\text {air }}$ (the average energy lost by electrons per ion pair formed in air) from a combination of the measurements. The result, $33.8 \mathrm{eV}$, is in good agreement with other modern determinations. (96) 
The radium content of two radium gamma ray sources of the Calibrations Operation were determined and compared.

The availability of a $50 \mathrm{~g}$ piece of plutonium provided an opportunity to test the accuracy of the calorimeter. The heat output of the plutonium was measured with the calorimeter and was compared with a value calculated from an isotopic composition based on mass spectrometer measurements and from known decay schemes of the isotopes; the two results differed by $1 \%$. The sample was also measured with a calorimeter at Mound Laboratory; the two measurements agreed to within $0.2 \%$. ${ }^{(7)}$

The half-life of $\mathrm{Sb}^{124}$, a radioisotope used in neutron sources (see above), was determined to be $60.20=0.01$ days.

Recently relatively large quantities of $\mathrm{Pm}^{147}$ became available by separation from Hanford wastes. This isotope is of interest because of its potential use in power sources. With the collaboration of the Chemistry Laboratory we determined its half-life to be $2.620 \pm 0.005 \mathrm{yr}$ and the specific power of two samples to be $0.3332 \pm 0.0005$ and $0.3325 \pm 0.0007$ watts per gram. Measurements made at Mound Laboratory were within $0.1 \%$ of these results. $(23,98)$

Attempts to improve the calorimeter led to the invention of the "heat amplifier." This device was to use the negative temperature coefficient of a thermistor to achieve an increase in the heat entering the calorimeter over that due just to the source. Heat gain was actually observed, but obtaining useful amplification required operating the thermistors on a part of their characteristic curve where they are not stable. $(9,23,99,100)$

Electron Van de Graaff Calorimetry and Instrumentation

Hanford Laboratories has a two million volt electron Van de Graaff in addition to the positive ion accelerator described above. Radiological Physics has used this accelerator for work in gamma-ray and beta-ray dosimetry and for a study of radiation damage in graphite (see below). The high accuracy of calorimetry methods led us to adapt them for use with the electron accelerator. Figure 21 shows the electron Van de Graaff 
laboratory. The large tank in the center of the picture is the Van de Graaff. The electrons emerge through the tube at the right and either strike a target to produce $X$ rays or emerge through a thin aluminum window as an electron beam. Our Van de Graaff calorimeter was made to be placed immediately in front of this window; it is possible to connect it to the Van de Graaff and share its vacuum system. The calorimeter is thick enough to entirely absorb the electron beam and also functions as a Faraday cup for beam current measurements. A water bath surrounds the calorimeter. There is also a large solenoid around the calorimeter to focus electrons into the calorimeter after they have passed through scattering material. (101)

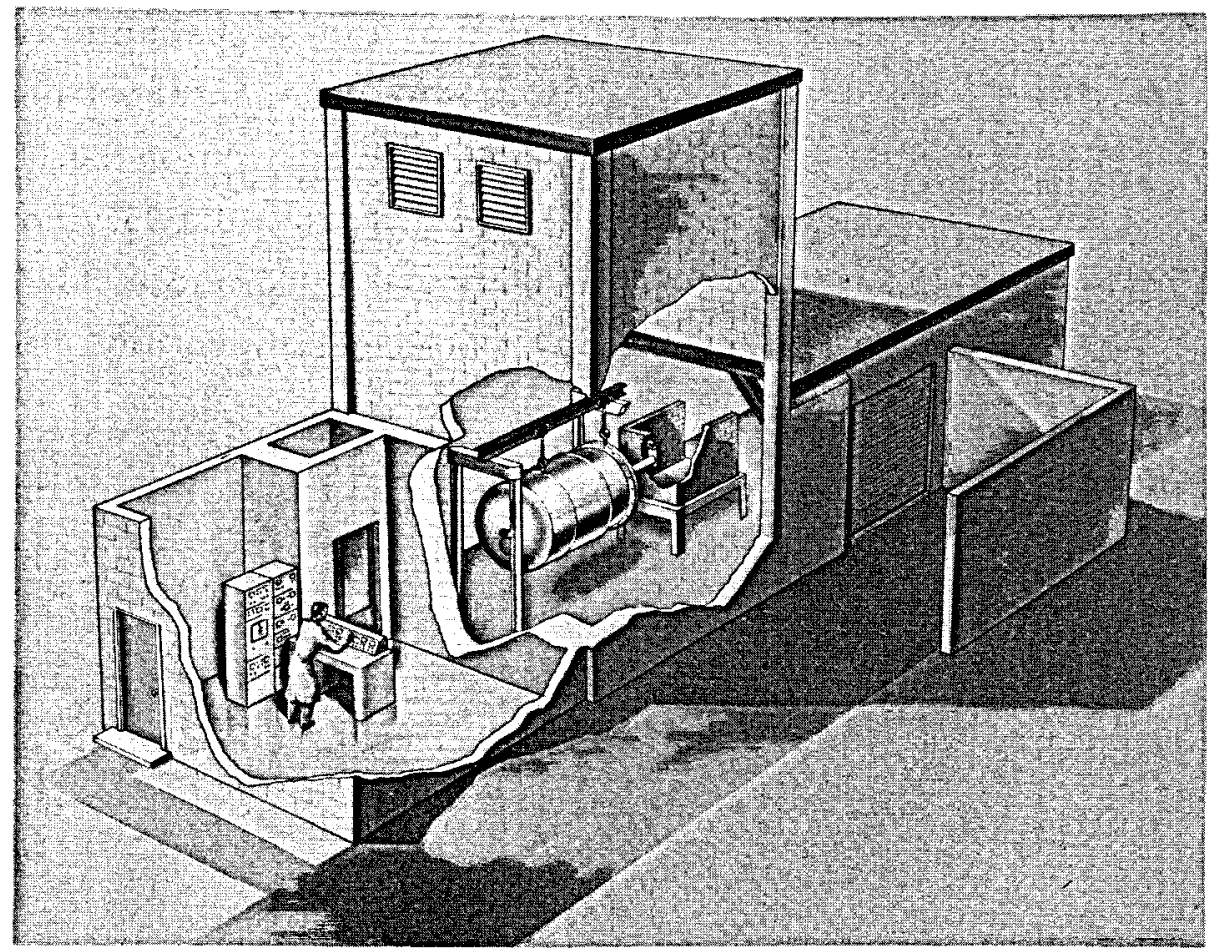

Neg. 0601166-9

FIGURE 21

Hanford Laboratories Two Million Volt Electron Van de Graaff

The accuracy of the calorimeter is about $\pm 0.05 \%$. This was so much better than any of the other apparatus used with the Van de Graaff that new instruments had to be developed to permit full use of the 
calorimeter. A simple but highly accurate method of determining the terminal voltage of a Van de Graaff was developed. This system can determine terminal voltages to an accuracy of about $=0.05 \% .(102,103)$ Also, a precise beam current integrator was developed that can determine the total charge delivered in an experiment to about $\pm 0.05 \%$ accuracy. ${ }^{(104)}$ The system formed by these devices and other apparatus developed for our Van de Graaff was such an improvement over typical systems that it was described separately. (105) New techniques had to be worked out for using standard instruments such as digital voltmeters to obtain the accuracies quoted above.

Most stopping power measurements, including the evaluation of the mean excitation potential, have been accomplished with heavy charged particles. This and the possibility of studying polarization effects with high speed electrons led us to build another calorimeter for use with the Van de Graaff to permit electron stopping power measurements. The calorimeter itself is a very thin foil through which the electron beam passes and loses a very small fraction of its energy. Stopping power measurements made on aluminum were in excellent agreement with those determined theoretically using mean excitation potentials from heavy particle experiments. $(8,106)$

$\underline{\text { Radiation Field Calorimetry }}$

We are at present engaged in developing a calorimeter that can be used for measuring absorbed dose in radiation fields, particularly neutron fields.

\section{GAMMA-RAY DOSIMETRY}

In contrast to the situation in neutron dosimetry (see above), the techniques for measuring $X$ and gamma rays had been under development for $50 \mathrm{yr}$ when the Radiological Physics group was formed. Nevertheless there were some basic problems for the group to study, problems outside the normal experience in gamma-ray dosimetry. These involved the very low energy $\mathrm{X}$ rays discovered emanating from plutonium and the very high energy gamma rays, particularly those from $\mathrm{N}^{16}$, found at some points 
around reactors. There were also problems in improving the effectiveness of film badge personnel dosimeters and in developing.very sensitive measurement methods for environmental monitoring and for biological research. Low Energy X Rays from Plutonium

Shortly after the weapons manufacturing facility was opened at Hanford a number of film badges worn by employees working there were found to show what at first were thought to be beta-ray exposures. There was nothing to indicate significant accompanying gamma radiation. Radiological Physics was asked to identify the beta-ray emitter involved. We soon established that the radiation was not beta rays. Absorption measurements were made with thin absorbers wrapped around small Geiger-Mueller counter tubes. The radiation was absorbed very differently by absorbers of different atomic number; if it had been beta radiation, they would have absorbed nearly equally. The absorption results were consistent with the interpretation that the radiation was low energy $X$ rays. The main component was about $17 \mathrm{keV}$ with weaker components of about $60 \mathrm{keV}$ and about a few tenths MeV. This led to the identification of the low energy radiation as the $\mathrm{X}$ rays following internal conversion during the decay of plutonium. The other components were gamma rays emitted during the decay.

In $\mathrm{Pu}^{239}$, for example, $11 \%$ of the disintegrations lead to an excited state of $\mathrm{U}^{235}$ at $52 \mathrm{keV}$. Only about $0.01 \%$ of the atoms reaching this state decay by gamma-ray emission. The rest decay by internal conversion followed in some cases by $\mathrm{X}$-ray emission from the $\mathrm{U}^{235}$ atom. $\mathrm{L} X$ rays of the $\mathrm{U}^{235}$ are excited. There are about $4 \%$ as many $\mathrm{L} X$ rays as alpha particles. There are several different $X$-ray energies in the $L$ group. The resolution of absorption measurements is not good enough to distinguish between them. Good proportional counters can resolve three peaks at 13.6, 17.4, and $20.5 \mathrm{keV}$ with relative intensities of 1:1.2:0.25. M $\mathbf{X}$ rays are also present and can be detected under circumstances where there is very little absorbing material between the plutonium and the sensitive volume of the detector. The higher energy photons result from alpha decays to higher energy states in the $U^{235}$ that are followed by gamma-ray 
emission.. The other alpha-emitting isotopes of plutonium have similar Xray and gamma-ray emissions. Daughter products, particularly Am ${ }^{241}$, behave similarly.

The discovery that low energy $X$ rays were an important source of radiation exposure in plutonium facilities made it necessary to make special studies for instrument calibration purposes. The ordinary instrument used for radiation protection work had been designed for measuring gamma rays in the energy range from a few tenths to a few MeV. The strong absorption of the low energy $\mathrm{X}$ rays makes it difficult to measure them properly. The first thing done was to determine what correction factors were needed with ordinary instruments when used to measure the $\mathrm{X}$ rays. To do this, the transformer of an $\mathrm{X}$-ray machine was altered to give lower voltages until the $X$ rays emerging from the machine gave the same sort of absorption curve as the plutonium $X$ rays. Then instruments were compared in this $\mathrm{X}$-ray beam with the readings of a free air ionization chamber. Later work led to a modified film badge for use around plutonium. A thin gold absorber was included in the badge to help distinguish between $X$ rays and beta rays. Once the film darkening due to the two had been distinguished, the proper calibration factor could be applied to that due to $\mathrm{X}$ rays. ${ }^{(107)}$

\section{Fluorescent X-ray Source}

The need for study of detectors of low energy $X$ rays made it necessary to have monoenergetic sources of the rays. The calibration study just described'followed a common practice of using heavily filtered X rays to provide roughly monoenergetic photons. Despite the heavy filtration, there remains a considerable spread in energy of these rays: consequently their use in an energy range in which detector sensitivity varies rapidly with energy may be misleading. The "effective energy" of such filtered beams is determined by absorption measurements. In this way an average is obtained that may represent a different weighting of the energy spectrum than that made by the detector'. We developed a device to be placed in front of an ordinary $X$-ray tube in which $\mathrm{K} \mathrm{X}$ rays of different atomic number materials are produced by fluorescence. K X rays have a quite small spread 
in energy and are ideal for instrument studies. Our device produces X ray beams from 8.9 to $100 \mathrm{keV}$, uniform to a few percent over a 6 in. diameter circle, and with dose rates from 0.05 to over $1 \mathrm{R} / \mathrm{hr}$ that are relatively free of scattered photons of undesired energies. It has been widely used by $u$ s and others and in the Calibrations Operation. $(108,109)$ For photons above $100 \mathrm{keV}$, heavily filtered $\mathrm{X}$ rays must still be used.

The Bragg-Gray Principle

The primary standard for low-energy $\mathrm{X}$-ray dosimetry measurements is the free air ionization chamber. For some measurements, such as that of surface dose, the free air ionization chamber is difficult or impossible to use. For these measurements the Bragg-Gray chamber is a valuable instrument. Bragg-Gray chambers are accepted for high energy measurements, but for the low energy measurements it was felt that a comparison of free air ionization chamber measurements with Bragg-Gray chamber data was needed to verify the applicability of the principle at these energies and to establish design limitations on chambers for such use. We made such a fundamental study using a pressure extrapolation chamber and our fluorescent X-ray source. We found that with sufficient care the Bragg-Gray principle could be used in the energy range of the plutonium $X$ rays. $(111,112)$ Later the chambers used in the surface dose measurement described below were calibrated with the same apparatus.

\section{Plutonium Surface Dose Rate}

A primary problem for any extended radiation emitter is the surface dose problem. The standard problem is to determine the dose distribution for a half-infinite medium of the emitting material in contact at a plane with a half-infinite medium of nonemitting material. If the problem is theoretically tractable, this will usually be its simplest form. In practice, the common example is to determine the dose to a man's hand when he is holding some of the material. For both theoretical and practical reasons we undertook to measure the surface dose rate from plutonium in contact with tissue. We used extrapolation chambers to which the Bragg-Gray principle was applied. The measurements were made on production material in the 
manufacturing facility. It was not possible to remove the plutonium from the process hoods because of the danger of contamination. We made a series of chambers of slightly different sizes (to provide the extrapolation) that were made in the shape of the production material and were sealed into openings in plastic bags that were mounted in glove ports in the process hoods. The plutonium was thus inside the hood while our measuring equipment was outside. Absorbing material could also be placed on our side of the bag. The results depended on the type and amount of absorbing material but were roughly a few rad/hr for the L X-ray component and a few tenths $\mathrm{rad} / \mathrm{hr}$ for the higher energy component.

The effect of absorbing material on these dose rates is so great that a method was needed for determining approximate surface dose rates under routine field conditions. The sensitive volumes of ordinary instruments are so large that they cannot be brought close enough to the surface to be measured. We developed a method of using ordinary instruments for surface dose measurements which has come to be called the "D-r-square" $\left(\mathrm{Dr}^{2}\right)$ method. The method is based on an assumption that is usually true for thick or moderately thick sources that the dose rate at any point is proportional to the solid angle subtended by the visible surface of the emitting object. At sufficient distance from the surface the solid angle is proportional to $\mathbf{r}^{-2}$, where $r$ is the distance between the effective centers of the surface and the instrument. This makes the product of dose rate and $\mathbf{r}^{2}$ a constant. In practice it is necessary to find this region where the product is constant and not influenced by scattering. It is possible to do this without having to know exactly where the effective centers of the surface and instrument are, The method was tried on material similar to that on which we had made our surface dose rate measurements and good agreement was found. It was subsequently used semiroutinely in radiation protection at the facility. It was particularly valuable in giving the only available surface dose measurements of the dose due to neutrons from spontaneous fission and from alpha particle induced nuclear reactions. $(113,114)$ 
The plutonium surface dose rate problem came up again much later. Planners became interested in the dose rates to be expected from plutonium from high reactor exposure uranium and from recycled plutonium. In either case the isotopic composition of the plutonium would be considerably different from that we were accustomed to in the Hanford plant. We made a theoretical study of the problem which became the basis for subsequent engineering studies. The problem was different from the surface dose rate of uranium or thorium studied earlier because in plutonium the dose is due to $X$ rays rather than beta rays. Nevertheless the effects of the secondary electrons were accounted for by the age theory methods developed earlier. The contributions of each isotope and the important daughter products were calculated in such a way that the dose rate from any given isotopic composition of material could be computed easily. The only experimental check on these calculations was our own earlier surface dose measurements, but here the agreement was quite good. Figure 22a shows the calculated total photon surface dose rates for plutonium made from uranium of different reactor exposures at two different times after purification; Figure 22b shows the same after absorption of the L X-ray component. These figures illustrate that the dose rates are high, that there is an advantage to processing the material quickly to avoid the increase in dose rate due to the growth of daughter products, and that the latter is relatively much more important in the more penetrating component of the radiation. The calculations also showed that neutron dose rates would increase quite. considerably with reactor exposure and were quite important (78-81) Gamma Rays

There were two principal problems studied for gamma rays. One was the determination of the dose rate from sources such as radium and $\mathrm{Co}^{60}$. At the time there was still some uncertainty about the dose rate from radium sources. The National Bureau of Standards calibrated sources for their content in milligrams of radium: An average value for the dose rate per milligram taken from the literature was used by Calibrations Operation as the basis for all Hanford instrument calibrations. We measured this parameter independently. Several years later the National 


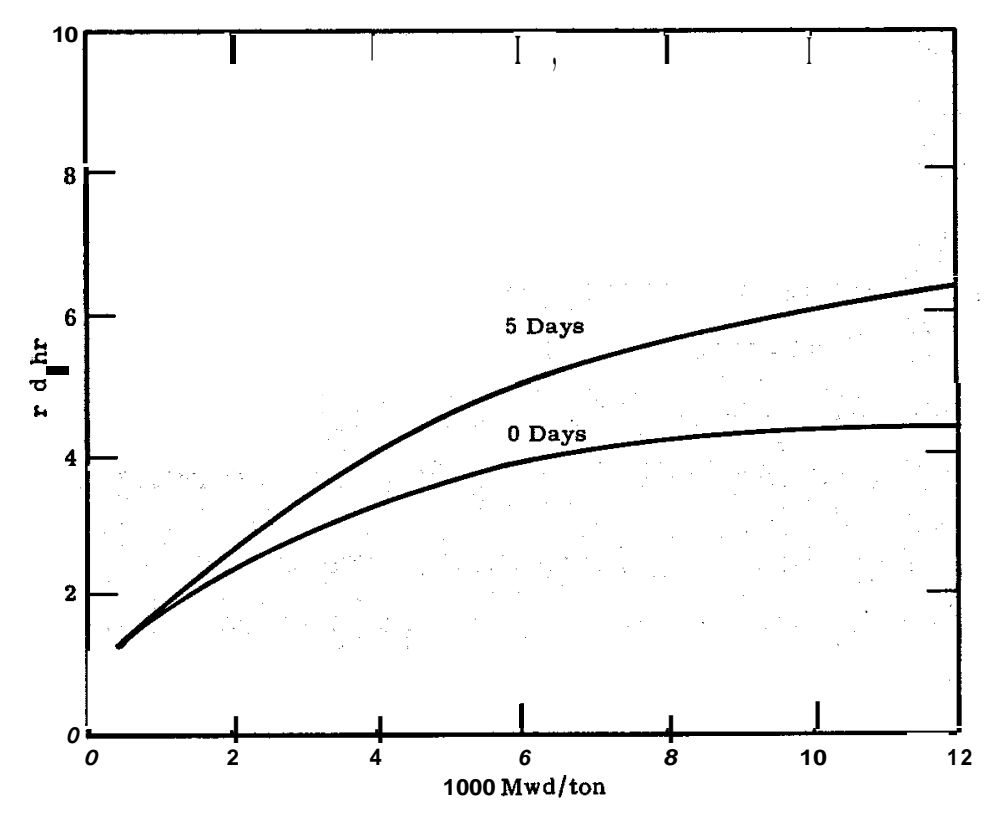

FIGURE 22a

X- and Gamma-Ray Dose Rate from Reactor Plutonium at 0 and 5 Days After Separation

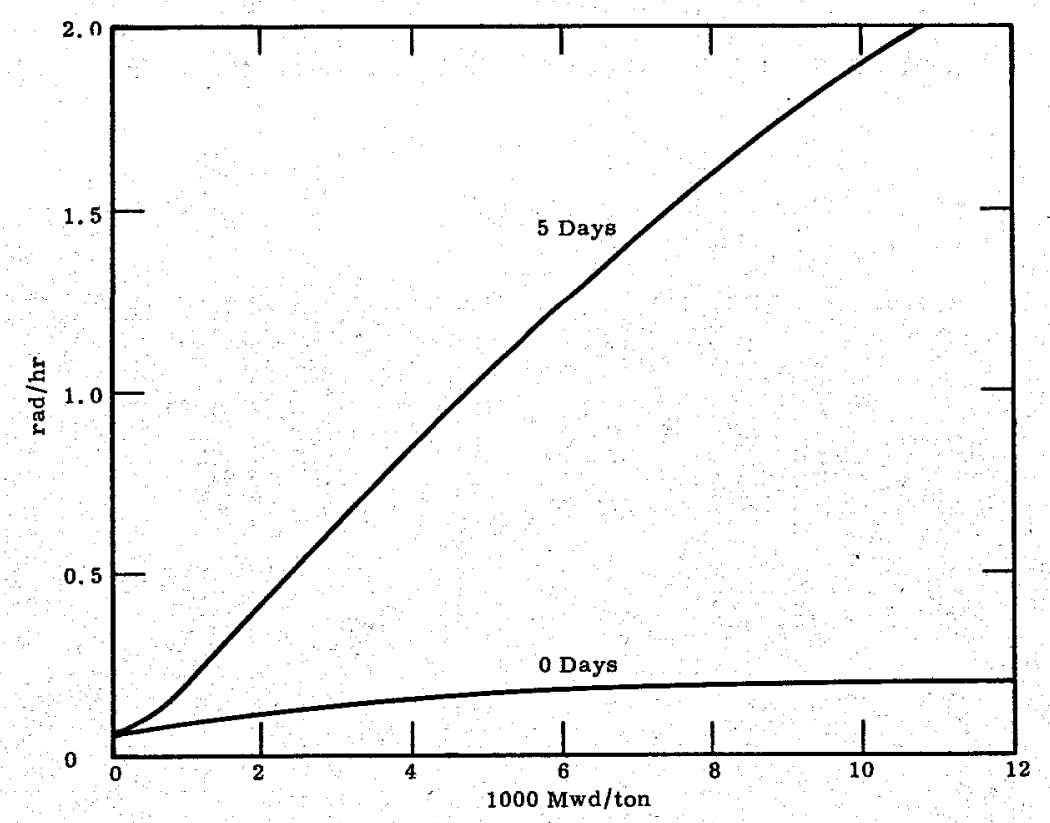

FIGURE 22b

"Hard Gamma" Dose Rate from Reactor Plutonium at 0 and 5 Days After Separation 
Bureau of Standards and the National Research Council of Canada determined and adopted a value very similar to ours. We also determined the dose rate from Co ${ }^{60}$ and other sources for which the National Bureau of Standards calibrations were not available. The other main problem was the calibration of instruments for the measurement of high energy gamma rays from isotopes such as $\mathbf{N}^{16}$ (6 MeV gamma rays) or from neutron capture. At the time the definition of exposure dose contained a stipulation that it could be used up to $3 \mathrm{MeV}$; nothing was said about higher energies.

Both of these gamma-ray problems were solved by use of measurements with cavity ionization chambers obeying the Bragg-Gray principle. It first had to be established that the chambers used actually did obey the Bragg-Gray principle. Some work was done using slightly modified Victoreen chambers. Soon, however, we built a set of chambers of our own that could be read on the Victoreen equipment. These chambers were of different sizes and were made of graphite, aluminum, copper, silver, and lead. They are shown in Figure 23. With a complete set of measurements in which both size and wall material were varied we could assure ourselves that the results were as expected from the Bragg-Gray principle. (115)

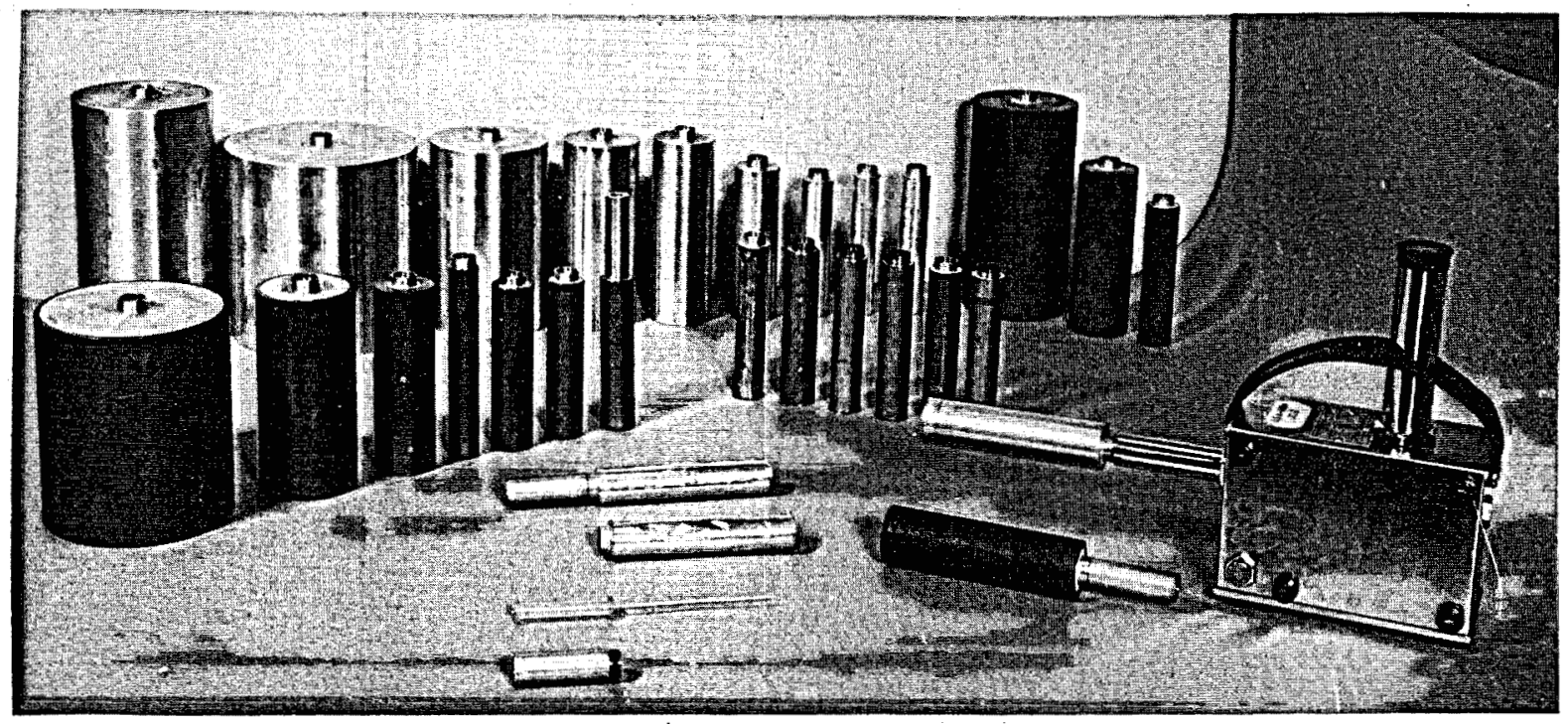

Neg. 052142-7

FIGURE 23

Cavity Ionization Chambers Used for the Study of the Bragg-Gray Principle 
The $\mathbf{N}^{16}$ calibration was carried out near an effluent water line of a reactor. $\mathrm{N}^{16}$ is a very short lived (7 sec half-life) isotope formed in reactor cooling water by an $(n, p)$ reaction in oxygen. A study as just described was carried out to make sure that the chambers were behaving as expected from the Bragg-Gray principle. Then the instruments ordinarily used in radiation protection work were calibrated against them. (116)

$\underline{\text { W Measurements }}$

A parameter in the equation for the Bragg-Gray principle is $\mathrm{W}$, the average energy lost by charged particles per ion pair formed in a given gas. With such a prominent position in dosimetry theory it would be expected that it would be a very carefully determined number. In fact, however, the difficulties of determining it accurately have kept it from being known as well as desired. The values of $\mathrm{W}_{\text {air }}$ for electrons determined between 1924 and 1960 are shown in Figure 24. The values obtained in the last decade of this period were approaching a common value but still had a $12 \%$ spread. Since doses could be determined no more accurately than this number was known, its precise determination was a matter of concern to all working in radiation dosimetry.

Radiological Physics contributed several determinations of $\mathrm{W}_{\text {air }}$ for electrons. The first method compared the readings of a Bragg-Gray chamber with the intensity of a beam of $\mathrm{Co}^{60}$ gamma rays that had been measured calorimetrically. The result was $32.5=0.8 \mathrm{eV}$. (117) So many different measured quantities contributed to this result that the accumulation of errors was considerable. A second measurement was made with the electron Van de Graaff calorimeter equipment. The electron beam intensity was measured calorimetrically both with and without air in a gas ceII -before the calorimeter. The difference in intensity could be compared with the ionization collected in the cell to give $\mathrm{W}=33.6 \pm 1.0 \mathrm{eV} .^{(118)}$ The last and best determination has already been described above in connection with the calorimetric measurement of the National Bureau of Standards Co ${ }^{60}$ source. The result was 33.8 $\pm 0.3 \mathrm{eV} .{ }^{(96)}$ The mean of the best recent determinations is $33.7 \mathrm{eV}$. 


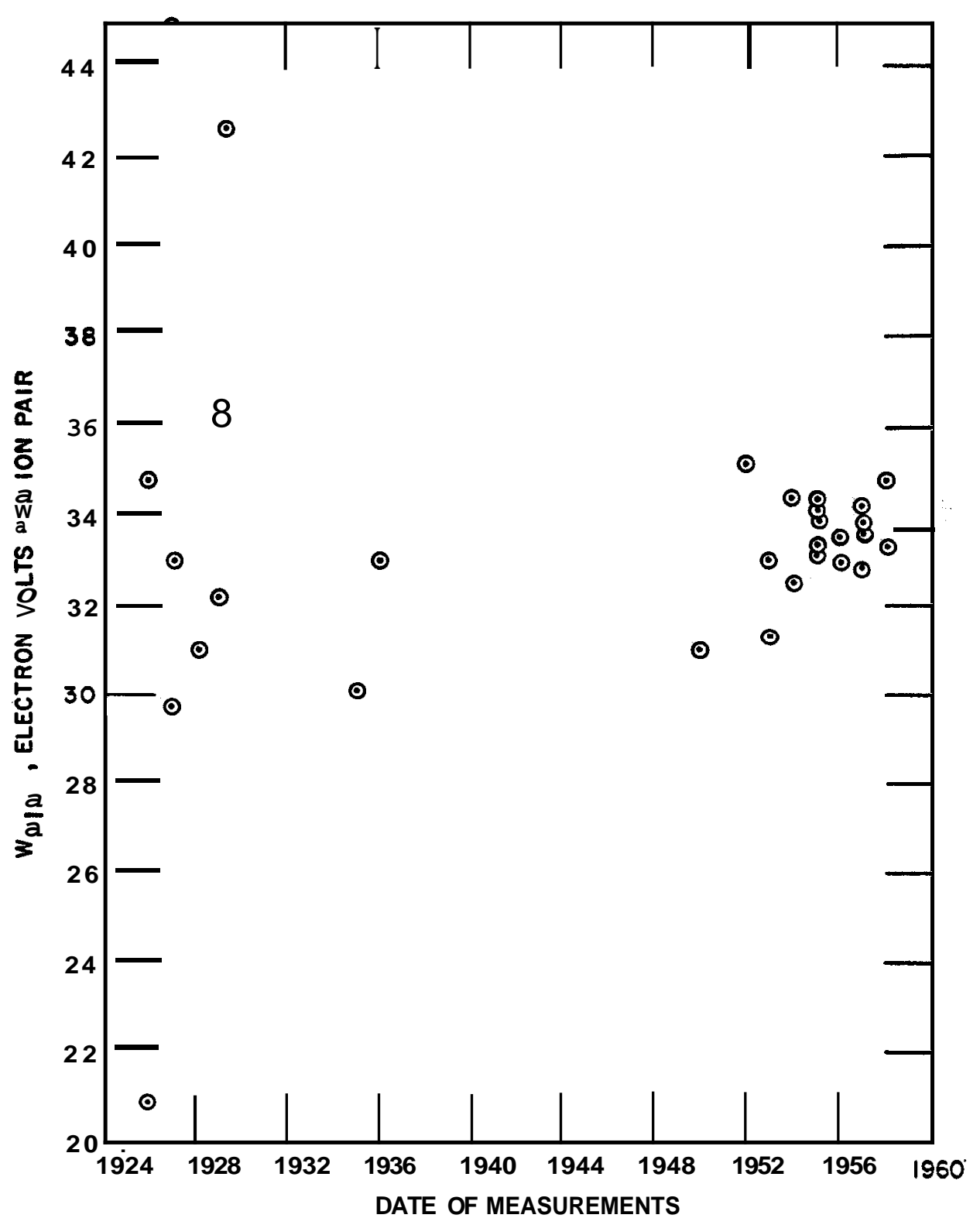

FIGURE 24

Values Measured for W air

the Average Energy Lost by Electrons Per Ion Pair Formed in Air

The value of $\mathrm{W}$ for very low energy electrons. is found to be slightly higher than for electrons in the energy range of those of gamma-ray secondaries. We measured $W_{\text {air }}$ for tritium beta rays, average energy 5.66 $\mathrm{keV}$, using the equipment of the tritium calibration study to be described below. The result was $34.2 \pm 1.5 \mathrm{eV}$ (117) 
The Bragg-Gray principle is also basic to the measurement of neutrons with cavity ionization chambers. The charged particles in this case are mostly recoil protons. Also, one is more apt to use an organic gas or a tissue-equivalent mixture of gases than air. We used our positive ion Van de Graaff and a unique ionization chamber that permitted counting and measuring the ionization of the protons at the same time to measure $\mathrm{W}$ for argon, nitrogen, carbon dioxide, air, and tissue-equivalent gas. For air $\mathrm{W}$ was $35.2 \pm 0.4 \mathrm{eV}$; it is generally observed to be higher for protons than, for high energy electrons. For the tissue-equivalent gas it was $30.0 \pm$ $0.3 \mathrm{eV}$. $(119,120)$

Film Badges

The film badge personnel dosimeter in use at Hanford during and immediately after the war was a dental X-ray packet in a silver box. The silver was $\mathbf{1} \mathrm{mm}$ thick.and contained an opening known as the "open window". Not much was known about the response of this badge to low energy photons or to beta rays. One of the earliest problems concerned the open window. The film behind this window became about $40 \%$ darker than the rest when the film was calibrated with radium gamma rays. It had become the practice to attribute anything in excess of $40 \%$ higher darkening to beta rays. In practice a few films worn by employees were found where the open window portion was lighter than the rest. We demonstrated that this was due to radiation nonequilibrium in the material covering the film emulsion in the open window region. Electrons of more than about $200 \mathrm{keV}$ could penetrate, the material over the open window. Secondary electrons (or beta rays) formed in the source, the air, and nearby structures by the photons of higher than this energy will penetrate to the film and result in a darkening which is dependent on the conditions of exposure.

Energy sensitivity curves for the film badges were obtained using the fluorescent $X$-ray source, heavily filtered $X$ rays, and monoenergetic gamma rays. Study of these data revealed methods for overcoming the nonlinear characteristics of the film and for estimating the energy of the photons producing the exposure. ${ }^{(121)}$ The latter was done by taking ratios of the darkening under the open window to that on the rest of the film. 
Similar techniques had already been proposed for distinguishing beta-ray exposures and plutonium X-rays. (107) The newly formed Radiological Development Operation undertook the engineering development of a new film badge based on these principles.

$\underline{\text { Sensitive Gamma-Ray Instruments }}$

Study of the radiation levels on the Columbia River is an important and continuing radiation protection problem at Hanford. Also, it was desired to study the diffusion and mixing of reactor effluent streams with the main body of the river. We found that these objectives could be met with a large plastic scintillation counter. The scintillator was a $100 \mathrm{lb}$ block of plastic viewed by a single $14 \mathrm{in}$. photomultiplier tube. When carried in a small boat, it was possible to make very detailed scans of the river activity in only a days time. The separate reactor effluent streams could be distinguished and traced as they mixed with the others, The device was also used in a small airplane for quick surveys of the river and of accidental depositions of radioactivity . ${ }^{(\mathbf{1 2 2})}$ It can be used in an automobile for quick surveys of land areas.

An invention by Radiological Physics proved very useful for measuring low radiation levels. In the usual application of ion chambers, they are operated like condensers. They are charged to a given voltage, exposed to radiation, and the resulting lower voltage measured with an electrometer. For very small doses it becomes difficult to'measure the small difference between these two very large voltages. Also, the process does not lend itself to automation. A new method introduced for reading chambers was to recharge them through a resistor and observe the voltage pulse on the resistor. The pulse is proportional to the decrease in voltage caused by the radiation so measurement of differences is not required (avery stable voltage supply is necessary, however). This pulse can be amplified and can be measured with any convenient pulse height analyzing system; automation and recording of data can be done with many standard techniques. In collaboration with Radiological Development Operation we prepared an instrument using this principle. When used, e.g., with pocket ion chambers which are usually used with an electrometer permitting 0-200 $\mathrm{mR}$ readings, 
it is easy to measure $1 \mathrm{mR}$ doses with $\pm 20 \%$ accuracy. $(123,124)$ This instrument has been sidely used in the environmental monitoring program. Pencil chambers can be left outside for days or weeks to measure radiation doses at background levels. The sensitivity of much smaller chambers can be increased in this way and used to measure doses inside animals that have been fed radioactive material.

Another sensitive condenser chamber reader was developed for use in the neutron dosimetry program. The reader uses a vibrating reed electrometer. With pencil chambers, accuracies of at least $\pm 5 \%$ are normally obtainable at $1 \mathrm{mR}$; selected chambers give $\pm 1.5 \%$. This reader also has the property that it measures the charge collected by the chamber independently of its capacitance. $(125,126)$

\section{BETA-RAY DOSIMETRY}

$\underline{\text { Surface Dose Problems }}$

The first encounter with the surface dose problem described in the section on theoretical dosimetry was as a radiation protection problem in the handling of uranium. We desired to know the dose rate to a man's hand when he was holding a piece of uranium. . A special extrapolation chamber was built for this purpose and the dose measured as a function of depth of tissue-like absorbing material, At the standard depth of $7 \mathrm{mg} / \mathrm{cm}^{2}$ used in radiation protection work the dose rate was $0.220 \mathrm{rad} / \mathrm{hr}$. This number became the basis for beta-ray calibrations using uranium and for setting time limits in uranium fuel handling. (127) Later, measurements were made on thorium with this same equipment. ${ }^{(77)}$ The result compared well with predictions from the age theory but was not a characteristic of the material since it changes with time due to growth of daughter products. The equipment was also used to measure $\mathrm{P}^{32}$ and $\mathrm{Sr}^{90}$ beta-ray exposure disks used by the Biology Laboratory in skin experiments.

Nonsurface Problems

The measurement of beta radiation at points not on the surface of the emitting material posed two problems for Radiological Physics. The first was to measure these dose rates in some absolute way in order to 
calibrat ordin ry beta-ray instruments. The second was to provide better instruments for ordinary use in radiation protection.

Some early work was done with a small $\mathrm{Sr}^{90}$ source to provide the beta rays and a small extrapolation chamber having a thin front window and a thick back wall to make the measurements. Soon, however, the electron Van de Graaff became available and it was used for the electron source. There were several problems in doing this, however. The dose rate directly in the ordinary beam emerging from the Van de Graaff was far too high so the beam current had to be decreased several orders'of magnitude; this required altering the Van de Graaff control circuitry to retain control. The electron beam emerges into a lead shield that is there to reduce the need for shielding in the walls of the building when using the machine to produce $X$ rays (Figure 21). The emerging electrons would scatter and strike the lead and produce a strong but diffuse $\mathrm{X}$-ray source that interfered with the electron measurements. These $X$ rays were avoided by installing graphite "pipes" through which the beam would pass until well past the lead shield. Finally, it was neeessary to expose instruments at some distance from the exit port to obtain a wide and uniform electron beam. The average energy of the electrons changes due to absorption in the air and had to be measured. Several extrapolation chambers were tried for making absolute measurements in this beam. ${ }^{(128)}$ The final one is shown in Figure 25a. and $25 \mathrm{~b}$.

C. C. Gamertsfelder of the Biophysics Section invented an instrument intended to have improved response to beta rays. An ordinary CP (Cutie Pie, a beta-gamma survey instrument), for example, has a long cylindrical chamber with thick walls for gamma-ray measurements; for beta rays one end is replaced by a thin window. Beta rays coming at much of an angle to the axis of the instrument cannot get into it through the thick side walls. The proposal for the new chamber was to keep about the same volume but to change to a short, broad cylinder for the chamber. Then . there would be very little side wall to block the entrance of beta rays. The first model was made from a soupbowl; this beta-gamma device 

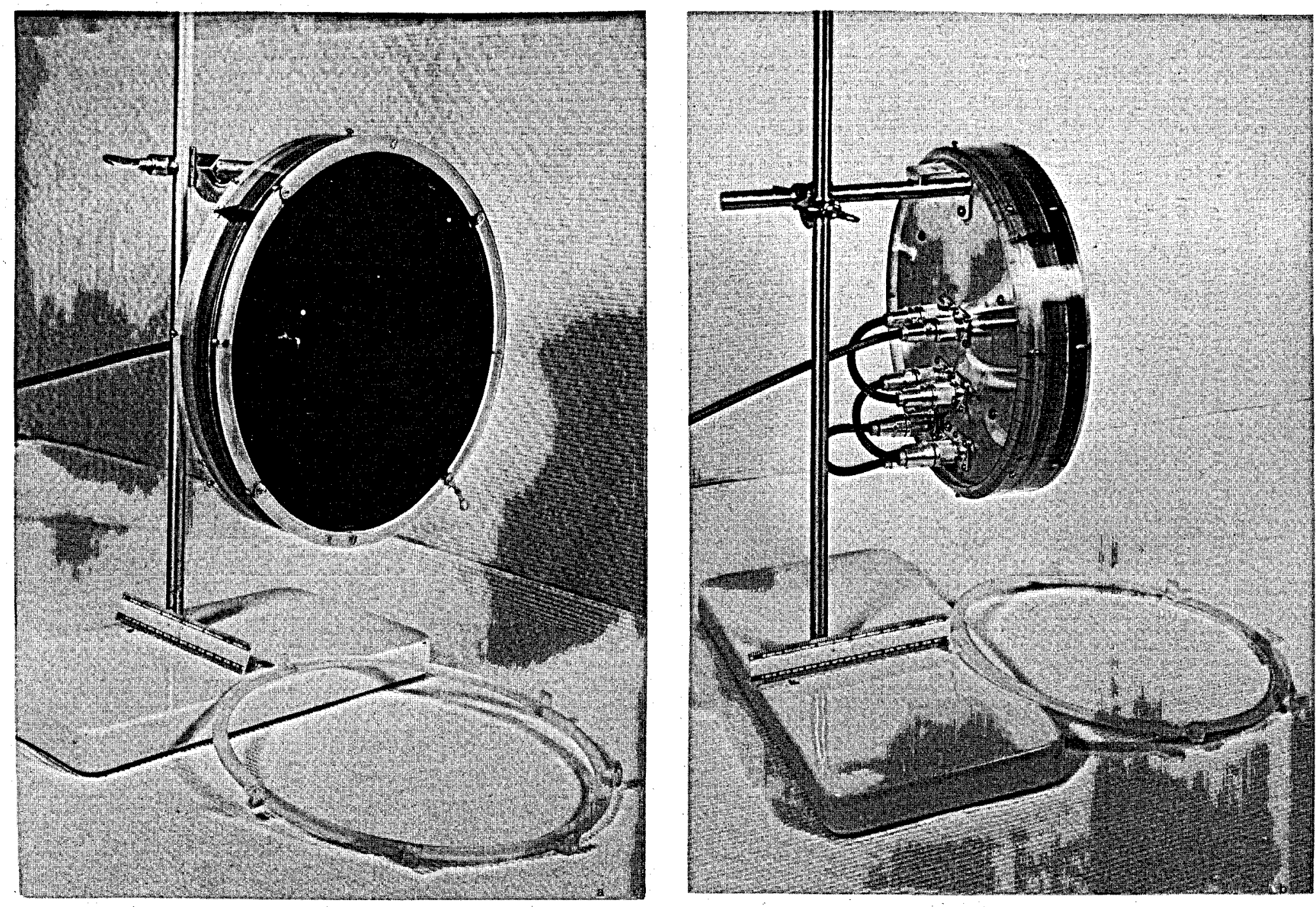

Neg. 054154-11
FIGURE 25

Extrapolation Chamber for Measurement of Electron Beams
今

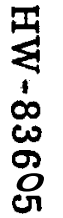


came to be known as the "Soupbowl CP". We studied the properties of this instrument by comparing it with an extrapolation chamber in the Van de Graaff beam. The ratio of the Soupbowl CP reading to that of the extrapolation chamber decreased slowly as the energy decreased but was quite acceptable at energies of interest. Calibration of the device turned out to be quite easy; it is only necessary to cover the thin window with a thick one and then calibrate it with gamma rays. It is then properly calibrated for electrons. $(128,129)$ The Soupbowl C P was widely used in radiation protection work at Hanford.

The difficulties in making a large flat ion chamber with a thin but strong front window could be avoided if the detecting medium were a solid which could support the window. This suggested to us the use of a scintillation detector. The scintillation material chosen for study was anthracene because it is approximately tissue-equivalent in composition and because it is the most efficient light emitter of the known organic scintillators. Because beta particles are rapidly absorbed in matter, the scintillator must be thin, e.g., for $1 \mathrm{MeV}$ beta rays it should be much less than $60 \mathrm{mg} / \mathrm{cm}^{2}$. Thin crystals could have been cut from larger ones but they would have been quite fragile. It was found that machinable and reasonably strong scintillators could be made by grinding anthracene flakes to a fine powder, slurrying the benzene, and molding under heat and pressure. The resulting tablets were mounted on glass and faced on a lathe to the thickness desired. It was found that a scintillator about $25 \mathrm{mg} / \mathrm{cm}^{2}$ thick had an angular response similar to that of an extrapolation chamber and that it had an energy response rather similar to the Soupbowl CP. $(128,130)$ $\underline{\text { Beta-Ray Dose Calculations }}$

Most problems involving internally deposited beta-ray emitters are solved by measuring the activity distribution and then calculating the dose rate. The age theory calculations described above can be used for this purpose. The age theory is particularly valuable when more than one material is present; it is the only simple method at present for solving problems with more than one medium or a medium with boundaries on a vacuum. 
When there is only one uniform medium present, a set of empirical equations developed by Loevinger ${ }^{(131)}$ are convenient for solving problems, These equations give the dose rate near point sources. A number of problems possess sources which can be considered as infinite in one dimension. These are most easily solved by first finding the dose rate near an infiniteline source. This was done and the numerical results found to fit a simple mathematical expression which can be integrated fairly easily in problems of cylindrical geometry. Calculations with this formula were used in computing dose to gut walls and to the thyroids of sheep fed I ${ }^{131}$. (132) Tritium Standardization

The first tritium obtained by Hanford Laboratories arrived with either no activity calibration or only rough calibration. The tritium was obtained as water, Standardization presented considerable difficulty because of the low beta-ray energy, the tendency of HTO to adsorb on surfaces, and the possibility of isotopic effects when changing the chemical form of the tritium. Three independent absolute methods were used to arrive at the final result. The Biology Laboratory determined the specific activity of a solution by preparing it by oxidation and dilution of gaseous tritium whose composition was known from mass spectrometry. Radiological Chemistry measured this solution by absolute counting of tritium gas evolved from it. Radiological Physics measured it by determining the ionization in chambers containing saturated water vapor in equilibrium with the solution. For the latter it was necessary to use three chambers of different size, and therefore different wall area, in order to obtain information from which to correct for the ionization due to tritium adsorbed on chamber walls and on the central electrode of the chambers. The three methods gave results within their limits of uncertainty of each other. $(133,134)$ Also, an intercomparison of the measurements with those of Argonne National Laboratory gave results within the experimental uncertainties. 


\section{OTHER ACTIVITIES}

It is not intended that this report cover all the activities of Radiological Physics. There are, however, a few activities that merit mention that do not fit into the sections above.

\section{$\underline{\text { Accident Dosimetry }}$}

The normal function of a radiation protection organization is to deal with radiation doses comparable to the permissible limits. In the event of an accident, however, it should be ready to assess large radiation doses to help medical treatment of the exposed people. In the case of serious exposure it might be difficult to determine the gamma-ray dose from film badges because they would be too dark to read on a densitometer. Radiological Physics adapted for use here a technique for measuring the dose to such films by activating the silver in the developed emulsion with slow neutrons and comparing the activity with that of films that had received known exposures. (135) For neutron exposures, equipment was kept calibrated and readily available in the positive ion Van de Graaff laboratory for a number of years for the measurement of $\mathrm{Na}^{24}$ in people. $\mathrm{Na}^{24}$ produced during neutron exposures has been found to be a good indication of the average neutron dose received.

In late 1953 and early 1954 large quantities of ruthenium isotopes were emitted from the Hanford Redox plant. Most of the ruthenium was in particulate form; most of the particles were less than $5 \mu$ in diameter. A number of groups in the Laboratory were involved in the special investigations that were needed. Very early in this period Radiological Physics made calculations relating the counting rates of the Geiger-Mueller tube survey meter in use at the time to the activity of a particle. Then we related the dose rate at a standard distance from a particle to the reading it produced on a CP. The reading had to be divided by four; the reason the meter reading was not correct was twofold; the meter was calibrated for surface dose measurements and the effective center of the CP was not at the standard distance from the particle. Later, detailed studies were made of the dose distribution around typical particles. This was done with 
extrapolation chambers; a special chamber was built that permitted dose measurements within about $1 \mathrm{~mm}$ of a particle. The dose distribution was found to be in good agreement with that given by Loevinger's formulae. The Redox emission occurred when we were making our first rudimentary attempts to do whole body counting. A small counter was assembled to measure activity in a man's chest. A large number of people were examined with this counter and several were found with mearurable lung burdens. One case, in particular, permitted a determination of the rate of elimination of the activity from the lung. In the course of these measurements we learned a lot about the shielding of whole body counters; the (concrete) shielded counting room had the highest background of any place we tried to use the counter.

In 1962 a criticality accident occurred in a plutonium waste chemical recovery facility (Recuplex) at Hanford. Four men were hospitalized but were released after medical observation and after estimates of the radiation doses they received were available. Radiological Physics helped in several phases of the investigation of this accident. Shortly after the accident the four men most exposed and 18 others who were nearby were sent 'tothe whole body counter for determinations of $\mathrm{Na}^{24}$ in their bodies, from which the neutron dose they received could be estimated. Radiological Physics carried out this counting and the estimates of the neutron doses. (7) We also studied the film badges worn by the people by the neutron activation technique to estimate the gamma-ray and thermal neutron exposure during the accident ${ }^{(7)}$ and helped Radiological Chemistry use the large moderator to reactivate objects the people were carrying at the time of the accident to help estimate their neutron exposures. Finally, a member of Radiological Physics was chosen to chair the committee that prepared the final report of the dosimetry of the accident. (6)

$\underline{\text { Radiation Damage in Graphite }}$

Considerable research has been done on radiation damage in graphite. This has been done principally with radiation where neutrons produced most of the damage in the sample. Since the energy required to displace an atom from its position in the graphite lattice is only about 
25 to $30 \mathrm{eV}$, and the average energy transferred to an atom in graphite by a fast neutron may be tens of thousands of times this much, the mechanism of damage for neutron irradiation may be mora complicated than simple lattice displacement. We felt that irradiation by electrons gave a promising way to investigate the simplest mechanism of damage, lattice displacement, because the energy given to a lattice atom by an electron is only a few times that required for displacing the lattice, thus minimizing unwanted effects. An opportunity to make such an investigation came up during the period of intensive investigation of candidate graphites for the $\mathrm{N}$-Reactor. Measurements of radiation damage were made in two graphites (NPR and $\mathrm{KC}$ ) using the electron Van de Graaff as a radiation source and some of the instrumentation that we had developed for it for measurements. The measurements included those of length changes, lattice spacing changes, and resistivity changes. $(136,137)$

During this investigation ozone was observed to be produced in large quantities during part of the experiment. Because of the general importance of this very serious safety hazard, a complete investigation of it was made. (138)

Gonadal: Radiation

Concern over radiation to the gonads is universal. The major peace time sources of gonad exposures to a population are natural radiation and diagnostic and therapeutic application of radiation. The Health and Safety Operation at Hanford was requested to make a special study to determine the average gonad dose to the population due to diagnostic procedures used at Kadlec Methodist Hospital, Richland, Washington. The pertinent data were more readily available at Kadlec than in most communities because for many years practically all the roentgenograms taken in the community were made there and all the necessary vital statistics were also kept there. Radiological Physics was asked to do the dosimetry in this study. We measured the typical doses delivered during the common roentgenological examinations. These were then weighted by the frequency of the examination and by the probability of the dose being followed by the conception of 
a child. These weighted doses were $1.3 \mathrm{R}$ for men and $1.2 \mathrm{R}$ for women as compared to 2.6 and $2.9 \mathrm{R}$ from natural radiation. ${ }^{(139)}$

\section{$\underline{\text { Education }}$}

Radiation dosimetry is basic to any use of radiation. Consequently, there is a continual need for the education of people entering this field. Radiological Physics has been called on many times to teach courses in the subject. In particular, a course, Radiology 485, was established at the University of Washington in 1954 as part of the A.E. C. Radiological Physics Fellowship Program. The course was begun under the direction of H. M. Parker and is still being taught by Radiological Physics. It is a graduate level course in radiation physics and dosimetry. A similar course was designed and given for nonspecialists, in particular for physicians sent to Hanford as part of the Armed Forces Special Weapons Project. (113) In addition to this education of others, members of Radiological Physics have used their work at the Laboratory for theses to obtain five MS and one Ph. D. degrees. 


\section{REFERENCES}

1. R. C. McCall. "Low Background Shields," pp. 304-306. 1960.

2. W. C. Roesch, R. C. McCall, and H, E. Palmer. Hanford Whole Body Counter--1959 Activities, HW-67045. December 1960.

3. J. Mehl. "Whole Body Counters Around the World, "Health Physics, vol. 21, pp.50-51. 1963.

4. R. W. Perkins, J. M. Nielson, W. C. Roesch, and R. C. McCall. "Zinc-65 and Chromium-51 in Foods and People," Science, vol. 132, pp. 1895-1897. 1960.

5. F. Swanberg, Jr. Hanford Whole Body Counter Results for 1960, HW-67245 REV. June 1, 1961.

6. H. V. Larson, J. M. Nielson, W. C. Roesch, and E. C. Watson. "Dosimetry Investigation of the Recuplex Criticality Accident ," Health Physics, vol. 9, p. 757.1963.

7. Research and Development Activities in the Radiological Sciences, HW-77609. January 1963.

8. Research and Development Activities in the Radiological Sciences, HW-70050. January 16, 1961.

9. Research and Development Activities in the Radiological Sciences, HW-73337. January 15, 1962.

10. H. E. Palmer and.W. C. Roesch. "Problems and Methods of Determining Zn-85 in Humans, " Health Physics Society, Las Vegas. June 1961.

11. H. E. Palmer and W. C. Roesch. "A Shadow Shield Whole Body Counter," submitted to Health Physics.

12. W.C. Roesch and H. E. Palmer. "New Techniques in Whole Body Counting," Radiation Research Society, Washington. May 1961.

13. W. C. Roesch and H. E. Palmer. "A Shadow Shield for Whole Body Counting, " Health Physics Society, Las Vegas. June 1961.

14. F. Swanberg, Jr: Hanford Mobile Whole Body Counter, HW-80216. December 31, 1963.

15. R. C. McCall. Unpublished Data. (Personal Communication to W. C. Roesch)

16. H. E. Palmer, W. C. Hanson, B. I. Griffin, and W. C. Roesch. ${ }^{11}$ Cesium-137 in Alaskan Eskimos, "Science, ivol. 142, p. 64. 1963.

17. W. C. Hanson, H. E. Palmer, and B. I. Griffin. "Radioactivity in Northern Alaskan Eskimos and Their Foods, Summer 1962," Health Physics, vol. 10, pp. 421-429. 1964. 
18. H. E. Palmer, W. C. Hanson, B. I. Griffin, and W. C. Roesch. "Radioactivity in Alaskan Eskimos," Second Symposium on Radioactivity in Man, Chicago. September 1962.

19. H. E. Palmer, W. C. Hanson, B. I. Griffin, and W. C. Roesch. "Measurement of Radioactivity in Alaskan Eskimos," Symposium on Radioactivity in Scandinavia, Lund, Sweden. May 20-21, 1963.

20. W. C. Hanson, H. E. Palmer, and B. I. Griffin. "Dietary Sources of Cs-I37 in Northern Alaskan Eskimos, "ibid.

21. H. E. Palmer,.W. C. Hanson, and B. I. Griffin, "Cs-137 in the Alaskan Eskimos, " Health Physics Society, New York, June 11-13, 1963.

22. H. E. Palmer, W. C. Hanson, B. I. Griffin, and D. M. Fleming. "Radioactivity Measurements in Alaskan Eskimos in 1963," Science, vol, 144, pp. 859-860. 1964.

23. Hanford Radiological Sciences Research and Development Annual Report for 1963, HW-81746. January 1964.

24. H. E. Palmer and R. W. Perkins. "Cesium-134 in Alaskan Eskimos and in Fallout, " Science, vol. 142, pp. 66. 1963.

25. H. E. Palmer and R. W. Perkins. "Cs-134 in Alaskan Eskimos," Second Symposium on Radioactivity in Scandinavia, Lund, Sweden. May 20-21, 1963.

26. H. E. Palmer, R. W. Perkins, and B. O. Stuart. "The Distribution and Deposition of Radon Daughters Attached to Dust Particles in the Respiratory System of Human Exposed to Uranium Mine Dusts, " Health Physics (in press, December 1964 issue).

27. H. E. Palmer, R. W. Perkins, and B. O. Stuart. "The Distribution and Deposition of Radon Daughters Attached to Dust Particles in the Respiratory System of Humans Exposed to Uranium Mine Atmo:spheres," Hanford Symposium on Inhaled Radioactive Particles and Gases, Richland,. Washington. May 4, 1964.

28. H. E. Palmer and F. Swanberg, Jr. "Determination of Low Level I- 131 in Human Thyroids Resulting from Nuclear Test Fallout," Health Physics Society, Chicago, June 1962.

29. E. C. Watson, I. C. Nelson, D. H.. Wood, R. O. McClellan; and L. K. Bustad. "Effect of Varying Stable Iodine in Diet of Cows Fed I 131 on Uptake of I 131 in Man Drinking the Milk, "Health. Physics, vol. 9, p. 1419.1963.

30. H. E. Palmer. "Detection of P-32 in Vivo, " Radiology, vol. 78, p. 115. 1962.

31. H. E. Palmer, "Detection of P-32 in Vivo," Radiological Society of North America, Chicago. November 1961.

32. H. E. Palmer. "In Vivo Determination of P-32 and Other Pure Beta Emitters," Health Physics Society, Cincinnati. June 15-18, 1964. 
33. W. C. Roesch and J. W. Baum. "Detection of Plutonium in Wounds." Proceedings of the Second United Nations International Conference on the Peaceful Uses of Atomic Energy, vol. 23, pp. 142-143. United Nations, Geneva, 1958.

34. W. C. Roesch and J. W. Baum. "Detection of Plutonium in Wounds," Progress in Nuclear Energy, XII, Health Physics, Pergamon Press, New York, 1959, pp. 322-325.

35. W. C. Roesch and J.W. Baum. "Detection of Plutonium in Wounds," Progress in Nuclear Energy, VII-2, Medical Sciences, Pergamon Press, New York, 1959, pp. 83-86.

36. R. C. McCall. "Measurement of Plutonium in Wounds, "Conference on the Acute Radiation Syndrome, U.S. Naval Medical School, Bethesda. May 1959.

37. W. C. Roesch and J. W. Baum. Feasibility of In .Vivo Plutonium Plutonium Measurements, HW-43370. May 14, 1956.

38. W. C. Roesch and H. E. Palmer. "Detection of Plutonium In Vivo by Whole Body Counting, " Health Physics, vol. 8, pp. 773-776. 1962.

39. W. C. Roesch and H. E. Palmer. "Detection of Plutonium In Vivo by Whole Body Counting," Symposium on Biology of the Transuranic Elements, Richland, Washington. May 1962.

40. H. E. Palmer, W. C. Hanson, and B. I. Griffin. "Cs-137 Excretion and Body Burdens of Alaskan Eskimos," Eighth Annual Bioassay and Analytical Chemistry Conference, Augusta. October 1962.

41. H. E. Palmer. "Determination of the Average Cs-137 Body Burden in a Population by Urinalysis, " Ninth Bioassay and Analytical

Chemistry Conference, San Diego, California. October 10-11, 1963.

42. G.H. Whipple. Radiation Intensities from an Experimental Hole in a Hanford Pile, HW-13459. June 15, 1949. (Confidential)

43" G. H. Whipple, E. E. Baker, and F. R. Gydeson. Fast Neutron Sensitivity of the CP Meter, HW-13658. June 10, $1 \overline{949 .}$

44. G. H. Whipple and J. S. Reddie. Fast Neutron Counter for Health Physics Measurements, HW-17561. March 31, 1950.

45. F. R. Jones. Shields for Neutron Sources, HW-21169. May 1, 1951.

46. W. F. Hornyak. "A Fast Neutron Detector," Rev. Sci. Inst., vo1. 23, p. 264. 1952.

47. E. C. Watson. Fast Neutron Monitoring of Personnel, HW-21552. August 1, 1951.

48. W. C. Roesch. Radiation Studies 234-5 Bldg. (III) Nuclear Track Film, HW-22020. August 21, 1951.

49. J. De Pangher. Calibrated Neutron Sources for the 234-5 Building, HW-55540. March 21, 1958. (Secret) 
50. D. W. Glasgow. Neutron Scattering from the Walls and Air of a Laboratory, Hw-32086. June 9, 1954.

51. E. E. Donaldson. "Precision Positioner for Large Insturments," Nucleonics, vol. 17, p. 94.1959.

52. W. C. Roesch. Neutron Measurements, HW-32476. August 26, 1954 .

53. J. De Pangher. Neutron Energies Calculated for $\mathrm{Be}^{9}(\mathrm{~d}, \mathrm{n}) \mathrm{B}^{10}$ for Deuterons Up to $2 \mathrm{Mev}$, HW-47284. December 17, 1956.

54. J. De Pangher. Neutron Measurements 11. Operating Points for Obtaining Neutrons from the HAPO Positive Ion Accelerator, HW-55085. February 3, 1958.

55. J. De Pangher. Neutron Measurements 111. Calibration of Long Counter No, 2 with Radioactive Neutron Sources, HW-56199. May 15, 1958.

56. R. D. McCormick and J. D. McCormack. "Hydrogen and Carbon Target Preparation for a Positive Ion Accelerator, "Nucl. Instr. Methods, vol. 13, pp. 147-152. 1961.

57. R. D. McCormick and J.. D. McCormack. Hydrogen and Carbon Target Preparation for a Positive Ion Accelerator, HW-67797. October 26, 1960 .

58. B. I. Griffin and R. D. McCormick. An Improved Technique for the Preparation of Carbon Targets for a Positive Ion Accelerator, HW-71548. November 2, 1961.

59. J. De Pangher and G. E. Driver. "Time of Flight Facility for Measuring the Energy of Fast Neutrons, " Conference on Neutron Cross Sections by Time of Flight Methods, Los Alamos. June 1956.

60. H. W. Lefevre and J. T. Russel. The Vernier Chronotron, HW-49669. April 12, 1957.

61. J. De Pangher, L. L. Nichols, and R. A. R. Kent. Characteristics of a Large Neutron Moderator for Activiation Studies, HW-73913. August 1, 1962.

62. J. De Pangher. "Double Moderator Neutron Dosimeter, " Nucl. Inst. Methods, vol. 5, pp. 61-74. 1959.

63. J. De Pangher and W. C. Roesch. "A Neutron Dosimeter with Uniform Sensitivity from 0.1 to $5.1 \mathrm{Mev}, " \boldsymbol{A m}$. Phys. Soc., Los Angeles. December 1955.

64. J. De Pangher. "Double Moderator Neutron Dosimeter, "Physics Dept. Symposium, Washington State University, Pullman, Washington. May 1959.

65. J. De Pangher. Double Moderator Neutron Dosimeter, HW-57293. July 15, 1958. 
66. J. De Pangher. A Moderated Detector for Measuring Neutron Dose, HW-60758. February 24, 1959.

67. P. E. Bramson. Hanford Criticality Dosimeter, HW-7 1710. January 24, 1962.

68. R. A. R. Kent. "Dose Rate and Flux Density of Cosmic Ray Neutrons," Health Physics Society, New York, June 11-13, 1963.

69. J. De Pangher. "Energy Spectra for Several Radioactive Neutron Sources," Am. Phys. Soc.., Ottawa. May 1960.

70. D. M. Fleming and I. T. Myers. "Calorimetric Determination of the Half-Life of $\mathbf{S b}^{124}$," (submitted to Intern. J. of Appl. Radiation Isotopes)

71. Physical Aspects of Irradiation, ICRU Report 10b, NBS Handbook 85, 1962.

72. J. De Pangher. "A Reproducible Precision Polyethylene Long Counter for Measuring Fast Neutron Flux, "Am. Phys. Soc., Washington. April 1961.

73. J. S. Loomis. An Investigation of the Operational Characteristics of the Perlow Spectrometer, HW-69471. May 2, 1961.

74. F. D. Brooks. "A Scintillation Counter with Neutron and Gamma Ray Discriminators, " Nucl. Instr. Methods, vol. 4, p. 151. 1959.

75. W. C. Roesch. "Beta Ray Age-Diffusion Theory," Am. Phys. Soc., New York. January 1954.

76. W. C。Roesch. Age-Diffusion Theory for Beta Ray Problems, HW-32121. May 24, 1954.

77. W. C. Roesch. Surface Dose Rate from Thorium, HW-32534. July 23, 1954.

78. W. C. Roesch. "Surface Dose from Plutonium," Proceedings of the Second United Nations International Conference on the Peaceful Uses of Atomic Energy, vol. 23, pp. 339-345. United Nations, Geneva, 1958.

79. W. C. Roesch. "Surface Dose from Plutonium," Progress in Nuclear Energy, XII, Health Physics, Pergamon Press, New York, 1959, pp. 193-205.

80. W. C. Roesch. "Dosage from High Exposure Plutonium, "Plutonium Fuel Technology Symposium, Richland, Washington. April 1958.

81. W. C. Roesch. Surface-Dose from Plutonium, HW-51317. July 10, 1957.

82. W. C. Roesch. Penetration of Gamma Ray Secondaries, HW-46697. September 28, 1956.

83. W. C. Roesch. "Dose for Nonelectronic Equilibrium Conditions," Radiation Res. , vol. 9, pp. 399-410. 1958. 
84. W. C. Roesch, F. H. Attix, M. Berger, W. Gross, and G. N. Whyte. Stopping Powers for Use with Cavity Chambers, NBS Handbook 79. 1961.

85. W. C. Roesch. "Stopping Powers for Use with Cavity Chambers," Radiological Society of North America, Chicago. November 1959.

86. W. C. Roesch. "Cavity Chamber Theory, " Radiology, vol. 74, pp. 109-110. 1960.

87. W. C. Roesch. "Cavity Chamber Theory, "Radiological Society of North'America, Chicago. November 1959.

88. H. H. Rossi and W. C. Roesch. "Field Equations in Dosimetry," Radiation Res., voly 16, pp. 783-795. 1962.

89. Radiation Quantities and Units, ICRU Report 10a, NBS Handbook 84. 1962.

90. I. T. Myers. "Improved Method of Gamma Ray Calorimetry," Rev. Sci. Inst., vol. 29, pp. 758-761. 1958.

91. I. T. Myers. "Improved Method of Gamma Ray Calorimetry," Am. Phys. Soc., Eugene. June 1956.

92. I. T. Myers, W. H. LeBlanc, and D. M. Fleming. "Precision Adiabatic Gamma-Ray Calorimetry Using Thermistor Thermometry," Rev. Sci. Inst., vol. 32, pp. 1013-1015. 1961.

93. H. V. Larson, I. T. Myers, and W. H. LeBlanc. "A Method of Linearizing Thermistor Thermometry Data in Calorimetry, "I Sei. Inst., vol. 38, p. 400. 1961.

94. I. T. Myers, H. V. Larson, and W. H. LeBlanc. "A Method of Linearizing Thermistor Thermometry Data in Calorimetry,"

Calorimetry Conference, Ottawa. August 1961,

95. W. H. LeBlanc, I. T. Myers, and D. M. Fleming. An Intercomparison of Adiabatic Calorimetry and Coincidence Counting for the Activity Determination of a Cobalt-60 Source, HW-66262. July 29, 1960.

96. I. T, Myers, W. H. LeBlanc, D. M. Fleming, and H. O. Wyckoff. "An Adiabatic Calorimeter for High Precision Source Standardization and Determinatioe of Wair," Radiation Research Society, Washington. May 1961.

97. D. M. Fleming and I. T. Myers. "Calorimetric Determination of the Half Life of Antimony-124," Am. Phys. Soc., Washington. April 1962.

98. E. J. Wheelwright, D. M. Fleming, and F. P. Roberts. Calorimetric Determination of the Decay Energy of Promethium-147, HW-77344. April 30, 1964.

99. I. T. Myers and D. M. Fleming. "The Heat Amplifier--A New Technic in Calorimetry, "Radiology, vol. 78, p. 111. 1962. 
100. I. T. Myers and D. M. Fleming. "The Heat Amplifier--A New Technique in Calorimetry," Radiological Society of North America, Chicago. November 1961.

101. I. T. Myers and H. V. Larson. "A Calorimeter for Accelerator Voltage Calibration and Absorbed Dose Measurements, "Calorimetry Conference, Gatlinberg. September 1960.

102. H. V. Larson and I. T. Myers. "Precision Capacitor Divider Method for Measuring High Voltage," Rev. Sci. Inst. , vol. 30, pp. 1022-1024. 1959.

103. I. T. Myers and H. V. Larson. "Precision Capacitor-Divider Method for Measuring High Voltages," Am. Phys. Soc., Austin. March 1959.

104. I. T. Myers and G. T. Orton. A Precision Current Integrator, HW-65802. February 16, 1960.

105. I. T. Myers and H. V. Larson. "Precision Instrumentation for an Electron Accelerator," Nucl. Inst. Methods, vol. 10, pp. 281-288. 1961.

106. H. V. Larson, I., T. Myers, R. I. Elder, and W. J. Dittrich. An Adiabatic Calorimeter for Stopping Power Measurements in ThinFoils, HW-69203. April 1961.

107. H. V. Larson. Gamma Ray Calibration of Gold Shield Badges, HW-32696. August 6, 1954.

108. H. V. Larson, I. T. Myers, and W. C. Roesch. "Wide-Beam Fluorescent X-Ray Source," Nucleonics, vol. 11, pp. 100-102. 1955.

109. H. V. Larson. "The Fluorescent X-Ray Source, "Film Dosimetry Information Exchange, Richland, Washington. September 1960.

110. "H. V. Larson. Heavily Filtered X Rays, HW-31,883. June 26, 1954.

111. H. V. Larson. "An Investigation of the Bragg-Gray Principle with Fluorescent X Rays," Radiation Res. vol. 5, pp. 558-568. 1956.

112. H. V. Larson. "Investigation of the Bragg-Gray Principle with Fluorescent X Rays," Am. Phys. Soc., Eugene. June 1956.

113. W. C. Roesch. Radiation Dosimetry, HW-68636. December 23, 1958.

114. G. L. Helgeson. Surface Dosimetry and Effective Energy Calculations, HW-41439. September 8, 1956.

115. I. T. Myers. An Ionization Chamber Method for Absolution Gamma Ray Dose Measurements, HW-29732. October 14, 1953.

116. I. T. Myers and E. C. Watson. The Response of Hanford Portable Gamma Instruments to Radiation from Pile Effluent Water, HW-28728. July 15, 1953. (Secret) 
117. I.' T. Myers. "Measurement of Wair for Tritium Beta Particles and Co60 Gamma Rays, " Radiation Research Society, Rochester. May 1957,

118. I. T. Myers. "A Differential Method for the Measurement of the Energy Required to Produce an Ion Pair in a Gas, ". Am. Phys. Soc., Ithaca. June 1958.

119. H. V. Larson. "Energy Loss Per Ion Pair for Protons in Various Gases," Phys, Rev., vol. 112, pp. 1927-1928. 1958.

120. H. V. Larson, "AnInvestigation of the Energy Loss Per Ion Pair for Protons in Various Gases," Am. Phys. Soc., Washington. May 1958.

121. H. V. Larson. Gamma Dose Measurements with Hanford Film Badges, HW-32516. July 21, 1954,

122. R. C. McCall. A Semiportable High Sensitivity Scintillation Counter, HW-54676. January 24, 1958.

123. W. C. Roesch, R. C. McCall; and F. L. Rising. "A Pulse Reading Method for Condenser Ion Chambers, "Health Physics, vol. 1, pp. 340-344. 1958.

124. W. C. Roesch, R. C. McCall, and F. L. Rising. "A Pulse Reading Method for Condenser Ion Chambers, "Health Physics Society, Berkeley. June 1958.

125. H. V. Larson. "A Sensitive Pocket Dosimeter Reader, " Health Physics, vol. 4, pp. 233-235. 1961.

126. H. V. Larson. "A Sensitive Pocket Dosimeter Reader, "Conference on Ionization Chamber Measurements of Radioactivity and Radiation, San Francisco. November 1959.

127. G. H. Whipple and H. E. Leap. Extrapolation Chamber Measurements of the Beta Ray Surface Dose from Uranium, HW-11379. October 28, 1948.

128. W. C. Roesch and E. E. Donaldson. "Portable Instruments for Beta Ray Dosimetry, "Proceedings of the International Conference on the Peaceful Uses of Atomic Energy, vol. 14, pp. 172-175. 1956.

129. E. E. Donaldson. An Improved Beta Dose Reading Chamber, HW-32720. August 26, 1954.

130. E. D. Falk and W. C. Roesch. Beta and Gamma Ray Dosimetry with Thin Scintillators, HW-33505. September 9, 1954.

131. R. Loevinger, E. M. Japha, and G. L. Brownell. "Discrete Radioisotope Sources, “ Radiation Dosimetry, edited by $\boldsymbol{G}$. J. Hine and G. L. Brownell, Academic Press, New York, 1956.

132. W. C, Roesch. Beta Ray Dose Calculations: Cylindrical Geometry, HW-51318 REV. October 8, 1957. 
133. H. G. Rieck, I. T. Myers, and R. F. Palmer. "A Tritiated Water Standard," Radiation Res., vol. 4, pp. 451-466. 1956.

134. I. T. Myers. An Ionization Chamber Method for the Standardization of Tritiated Water Samples, HW-29282. July 23, 1953.

135. J. S. Reddie. Determination of Film Exposure by Neutron Activation of Reduced Silver, HW-30606. January 14, 1954.

136. I. T. Myers, H. V. Larson, and J. S. Loomis. "Resistivity Changes in Electron Irradiated Graphite, "Fifth Carbon Conference, Pennsylvania State University. June 1961.

137. I. T. Myers. Radiation Damage in Graphite by High Energy Electrons. HW-75428. October 29, 1962.

138. J. S. Loomis, I. T. Myers, H. V. Larson, and D. E. Wisehart. "Ozone Hazards Incurred by Electron Van de Graaff Operation," Nucl. Inst. Methods, vol. 15, pp. 243-248. 1962.

139. W. D. Norwood, J. W. Healy, E. E. Donaldson, W. C. Roesch, and C. W. Kirklin. "The Gonadal Radiation Dose Received by the People of a Small American City Due to the Diagnostic Use of Roentgen Rays, " Am. J. Radiol.,. vol. 82, pp. 1081-1097. 1959. 
INTERNAL DISTRIBUTION

$\begin{array}{rlrl}\frac{\text { copy }}{1} & \text { F. W. Albaugh } & & \\ 2 & \text { W. J. Bair } & 25 . & \text { L. L. Nichols } \\ 3 & \text { C. A. Bennett } & 26 & \text { J. M. Nielson } \\ 4 & \text { L. A. Braby } & 27 & \text { W. D. Norwood } \\ 5 & \text { S. H. Bush } & 28 & \text { H. E. Palmer } \\ 6 & \text { L. K. Bustad } & 29 & \text { R. F. Palmer } \\ 7 & \text { E. D. Clayton } & 30 & \text { H. M. Parker } \\ 8 & \text { F. G. Dawson, Jr. } & 31 & \text { R. S. Paul } \\ 9 & \text { D. M. Fleming } & 32 & \text { W. D. Richmond, Jr. } \\ 10 & \text { R. F. Foster } & 33-182 & \text { W. C. Roesch } \\ 11 & \text { P. A. Fuqua } & 183 & \text { D. N. Samsky } \\ 12 & \text { J. J. Fuquay } & 184 & \text { W. G. Spear } \\ 13 & \text { W. A. Glass } & 185 & \text { A. J. Stevens } \\ 14 & \text { B. I. Griffin } & 186 & \text { K. L. Swinth } \\ 15 & \text { O. F. Hill } & 187 & \text { R. C. Thompson, Jr. } \\ 16 & \text { F. P. Hungate } & 188 & \text { C. M. Unruh } \\ 17 & \text { R. L. Junkins } & 189 & \text { M. T. Walling } \\ 18 & \text { A. R. Keene } & 190 & \text { E. C. Watson } \\ 19 & \text { H. A. Kornberg } & 192-193 & \text { D. C. Worlton } \\ 20 & \text { H. V. Larson, } & 194 & \text { Recogy Library } \\ 21 & \text { B. R. Leonard, Jr. } & 195 & 300 \text { File } \\ 22 & \text { R. E. Nakatani } & 196 & \text { Technical Publications } \\ 23 & \text { I. C.. Nelson } & 197-200 & \text { Extra } \\ 24 & \text { C. E. Newton } & & \end{array}$

EXTERNAL DISTRIBUTION (Special)

No. of Copies

1 Atomic Energy Commission, Washington

Military Liaison Committee

Attn: Captain D. E. McCoy, Staff Assistant to the Chairman

2 General Electric Technical Data Center, Schenectady

1 RLOO Technical Information Library 
UC-48

BIOLOGY AND MEDICINE

$$
\text { Pt }
$$

Standard Distribution

AQERDEEN PROYING GROUND

AEROJET-GENERAL CORPORATION

AERONAUTICAL SYSTEMSDIVISION

AIR FORCE INSTITUTE OF TECHNOLOGY

AIRFORCESURGEONGENERAL

AIR FORCEWEAPONS LABORATORY

ARGONNE CANCER RESEARCH HOSPITAL

ARGONNE NATIONAL LABORATORY

ARMED FORCES INSTITUTE OF PATHOLOGY

ARMED FORCES RADIOBIOLOGY RESEARCH INSTITUTE

ARMY CHEMICAL RESEARCHAND DEVELOPMENT LABORATORIES

ARMY ELECTRONICS RESEARCH AND DEVELOPMENT LABORATORIES
ARMY ENVIRONMENTALHYGIENE AGENCY

ARMY MEDICAL RESEARCH LABORATORY

ARMY HATICK LABORATORIES

ARMY NUCLEAR DEFENSE LABORATORY

ARMY SURGEONGENERAL

ATOMIC BOMB CASUALTY COMMISSION

ATOMIC ENERGY COMMISSION, BETHESDA

AEC SCIENTIFIC REPRESENTATIVE, FRANCE

AEC SCIENTIFIC REPRESENTATIVE, JAPAN

ATOMIC ENERGY COMMISSION, WASHINGTON

ATOMIC ENERGY OF CANADA LIMITED

ATOMIC ENERGY OF CANADA LIMITED, WHITESHELL

ATOMICS INTERNATIONAL

BATTELLE MEMORIAL INSTITUTE

bIOSEARCH COMPANY

BROOKE ARHY MEOICAL CENTER

BRWKHAVEN NATIONAL LABORATORY

BUREAUOF SHIPS (CODE 1500)

BUREAUOF YARDS AND DOCKS

CHICAGO PATENT GROUP

COLORADO STATE UNIVERSITY

COLUMBIA UNIVERSITY(ROSSI)
Ptd.

1

3

1

2

1

1

1

1

2

2

1

TID-4500

34th Ed.

Standard Distribution

COMMITTEE ON THE EFFECTS OF ATOMIC RADIATION

DEFENCERESEARCHMEMBER

DEFENSE ATOMIC SUPPORT AGENCY, WASHINGTON

DU PONT COMPANY, AIKEN

DU PONT COMPANY, WILHUGGON

EDGERTON, GERMESHAUSEN AND GRIER, INC, GOLETA

EDGERTON, GERMESHAUSEN AND GRIER, INC., LAS VEGM

EOGEWOOD ARSENAL

GENERAL DYNAYICS/FORT WORTH

GENERAL ELECTRIC COMPANY, CINCINNATI

GENERAL ELECTRIC COMPANY, PLEASANTON

HAZL ETOK NUCLEAR SCIENCE CORPORATION

HUGHES AIRCRAFT COMPANY

IOWA STATE UNIVERSITY

KNOLLS ATOMIC POWER LABORATORY

LOS ALAMOS SCIENTIFIC LABORATORY

LOVELACE FOUNDATION

HARTINHARIETTA CORPORATION

MASSACHUSETTSINSTITUTEOF TECHNOLOGY

MOUNDLABORATORY

NASAMANNEOSPACECRAFTCENTER

NASA SCIENTIFIC AND TECHNICAL INFORHATION FACILITY

NATIONAL BUREAUOF STANDARDS

NATIONAL CANCER INSTITUTE

NATIONAL LEAD COMPANY OF OHIO

NATIONAL LIBRARY OF MEDICINE

NAVAL MEDICAL RESEARCH INSTITUTE

NAVALORDNANCE LABORATORY

NAVAL POSTGRADUATESCHOOL

NAVAL RADIOLOGICAL DEFENSE LABORATORY 
Standard Distribution

NEWJERSEYSTATEDEPARTMENTOFHEUTH

NEW YORK OPERATIONSOFFICE

NEW YORK UNIVERSITY (EISENBUD)

NRA, INC

NUCLEAR UTILITY SERVICES, INC.

OFFICE OF ASSISTAHT GENERAL COUNSEL FOR PATENTS (AEC)

OFFICE OF RAVAL RESEARCH

OFFICE OF NAVAL RESEARCH(CODE 128)

OFFICE OF THE CHIEF OF RESEARCH AND DEVELOPMENT

OHIO STATE UNIVERSITY

PHILLIPS PETROLEUMCOMPANY (NRTS)

PRATT AND WHITNEY AIRCRAFT DIVISION

PUBLIC HEALTH SERVICE

PUBLIC HEALTH SERVICE, LAS VEGAS

PUBLIC HEALTH SERVICE (LEE)

PUBLIC HEALTH SERVICE, MONTGOMERY

RAND CORPORATION ,

RESEARCHANALYSIS CORPORATION

REYNOLDS ELECTRICAL AND ENGINEERING COMPANY, INC.

\section{ROCKY HOUNTAIN ARSENAL}

SANDIA CORPORATION, ALBUQUERQUE SOHOOL OF AEROSPACE HEDANE

SECOND AIR FORCE (SAC)

SOLON (LEONARD)

STRATEGIC AIR COMMAND

TULANE UNIVERSITY

UNION CARBIDE CORPORATION (ORGDP)

UNION CARBIDE CORPORATION (ORNL)
Ptd.

BIOLOGY AND MEDICINE

Standard Distribution

UNITED NUCLEAR CORPORATION(NDA)

U. S GEOLOGICAL SURVEY (BAL)

U. S. GEOLOGICAL SURVEY, DENVER

U. S. GEOLOGICAL SURVEY, HENLO PARK

U. S GEOLOGICALSURVEY, WASHINGTON

U. S. WEATHER BUREAU, LAS VEGAS

U. S. WEATHER BUREAU, WASHINGTON

UNIVERSITY OF CALIFORNIA, BERKELEY

UNIVERSITY OF CALIFORNIA, DAVIS

UNIVERSITY OF CALIFORNIA, LIVERMORE

UNIVERSITY OF CALIFORNIA, LIVERMORE (BHL)

UNIVERSITY OF CALIFORNIA, LOS ANGELES

UNIVERSITY OF CALIFORNIA, SAM FRANCISCO

UNIVERSITY OF CHICAGO, USAF RADIATION LABORATORY

UNIVERSITY OF HAWAII

UNIVERSITYOF PUERTORICO

UNIVERSITY OF ROCHESTER

UNIVERSITY OF TENNESSEE (UTA)

UNIVERSITYOF UTAH

UNIVERSITY OF WASHINGTON

WALTERREEDARMYMEDICALCENTER

WAYNE STATE UNIVERSITY

WESTERN RESERVE UNIVERSITY

YESTINGHOUSE ELECTRIC CORPORATION (MASA)

325

DIVISIONOF TECHNICAL INFORMATION EXTENSION

CLEARINGHOUSEFOR FEDERAL SCIENTIFIC AND TECHNICAL INFORMATION 